\title{
Internal Valve Design and Response Analysis for a Circulation Control Augmented Vertical Axis Wind Turbine
}

Andrew J. Nawrocki

West Virginia University

Follow this and additional works at: https://researchrepository.wvu.edu/etd

\section{Recommended Citation}

Nawrocki, Andrew J., "Internal Valve Design and Response Analysis for a Circulation Control Augmented Vertical Axis Wind Turbine" (2009). Graduate Theses, Dissertations, and Problem Reports. 2274. https://researchrepository.wvu.edu/etd/2274

This Thesis is protected by copyright and/or related rights. It has been brought to you by the The Research Repository @ WVU with permission from the rights-holder(s). You are free to use this Thesis in any way that is permitted by the copyright and related rights legislation that applies to your use. For other uses you must obtain permission from the rights-holder(s) directly, unless additional rights are indicated by a Creative Commons license in the record and/ or on the work itself. This Thesis has been accepted for inclusion in WVU Graduate Theses, Dissertations, and Problem Reports collection by an authorized administrator of The Research Repository @ WVU. For more information, please contact researchrepository@mail.wvu.edu. 


\title{
Internal Valve Design and Response Analysis for a Circulation Control Augmented Vertical Axis Wind Turbine
}

\author{
Andrew J. Nawrocki, BSME
}

\author{
Thesis Submitted to the \\ College of Engineering and Mineral Resources \\ At West Virginia University \\ In Partial Fulfillment of the Requirements \\ For the Degree of \\ Master of Science \\ in \\ Mechanical Engineering
}

James E. Smith, Ph.D., Committee Chair

Kenneth H. Means, Ph.D.

Andrew C. Nix, Ph.D.

Department of Mechanical and Aerospace Engineering

Morgantown, WV

2009

Keywords: Circulation Control, Valve, Wind Turbine

Copyright 2009 Andrew J. Nawrocki 
Abstract

Internal Valve Design and Response Analysis for a Circulation

Control Augmented Vertical Axis Wind Turbine

\section{Andrew J. Nawrocki}

Circulation control is an established method for increasing lift on an airfoil-shaped body. Previous research has focused on the application of circulation control to fixed-wing aircraft as well as rotorcraft; ongoing research at the Center for Industrial Research Applications (CIRA) involves the application of circulation control to vertical-axis wind turbines (VAWT). Due to size and response time constraints, one of the key technical hurdles of this application that must be overcome is the valve mechanism for controlling the airflow out of the blowing slots. A valve design consisting of a slotted, sliding gate mated to a slotted, fixed surface within the wind turbine blade is presented. The sliding gate is actuated via a solenoid, forcing the slots into alignment and allowing air to flow freely; the gate is returned via spring, forcing the slots out of alignment and preventing the flow of air. The design was modeled with CAD software and the dynamics of the system were modeled with Simulink. An experimental apparatus was fabricated to test this design, and the valve met all of the design specifications with the exception of the leakage rate. Recommendations are made in order to remedy this problem. 


\section{Contents}

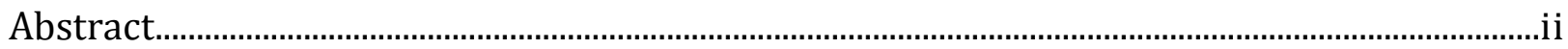

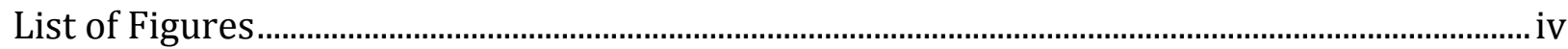

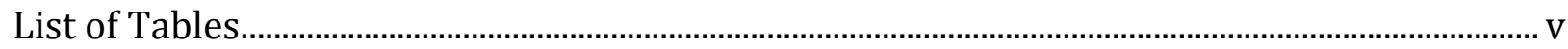

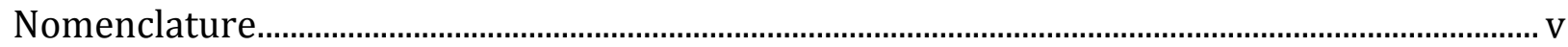

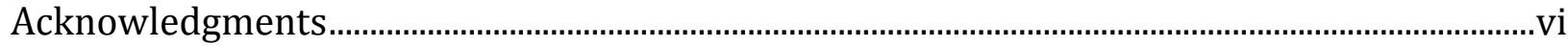

1. Introduction

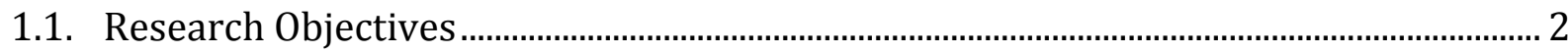

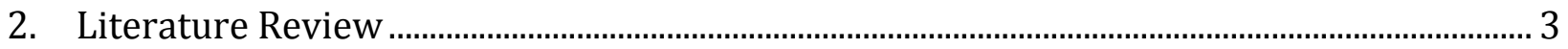

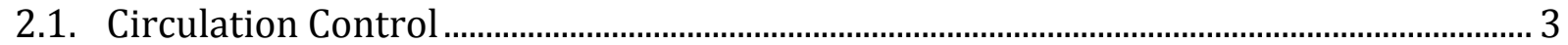

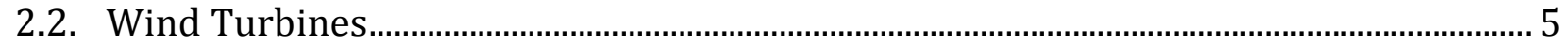

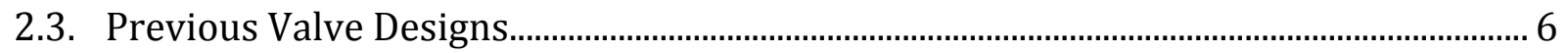

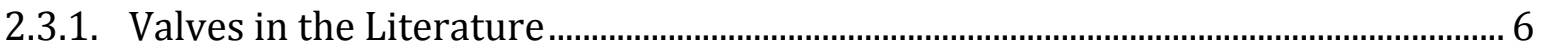

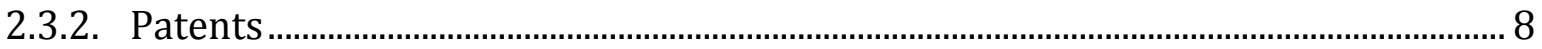

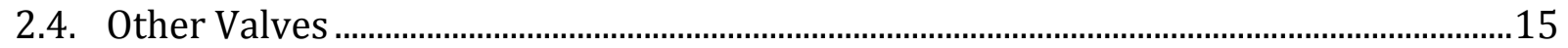

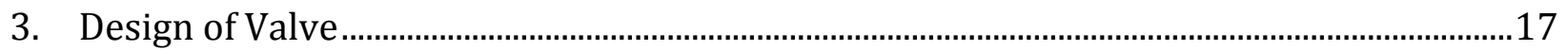

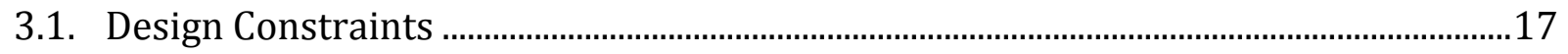

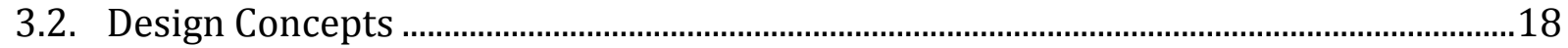

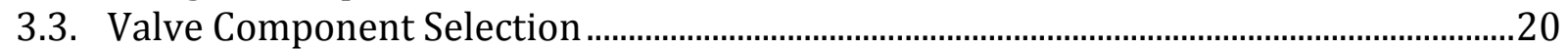

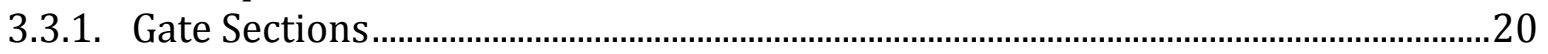

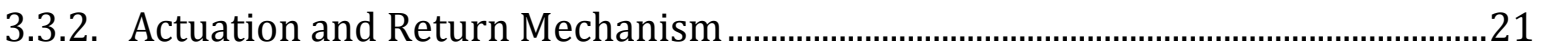

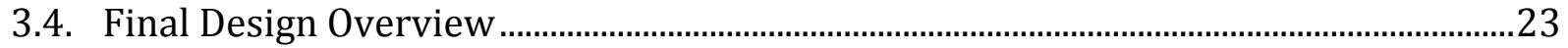

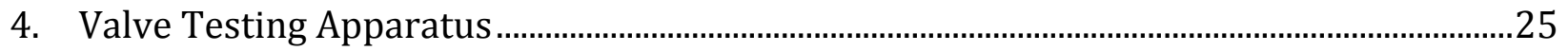

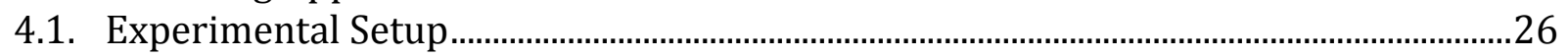

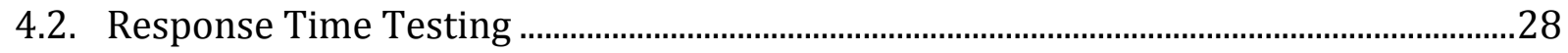

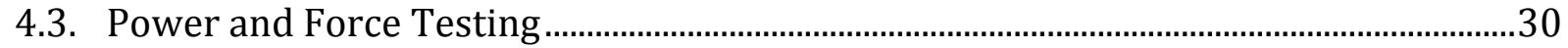

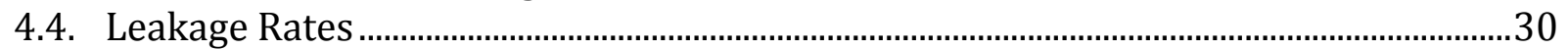

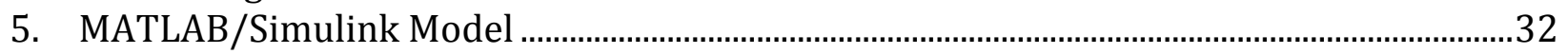

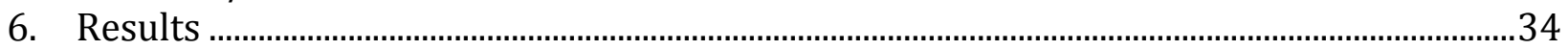

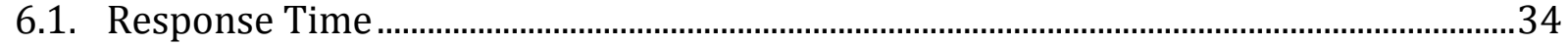

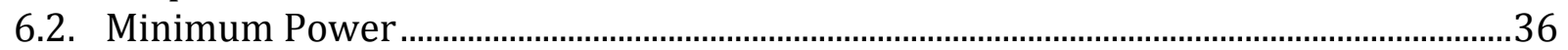

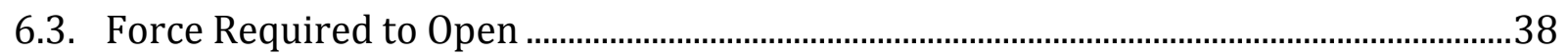

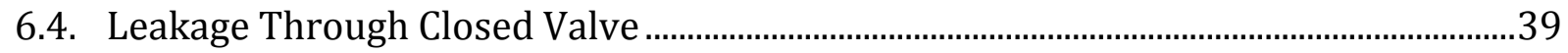

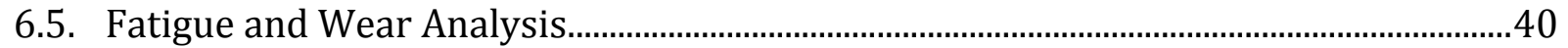

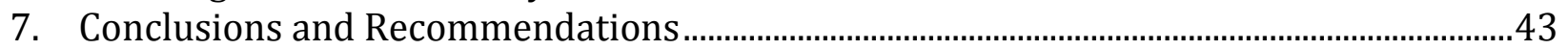

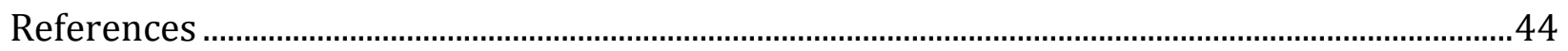

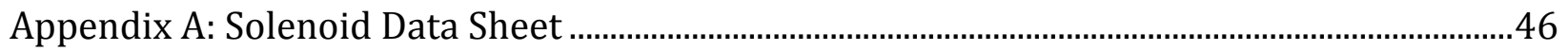

Appendix B: Component List for Testing Apparatus and Equipment ............................................49

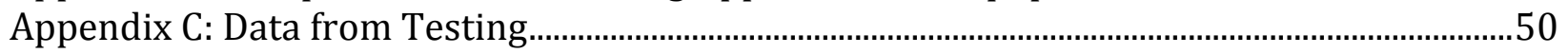




\section{List of Figures}

Figure 1: Jet Flow Around Rounded Trailing Edge (Newman, 1961).............................................. 3

Figure 2: HAWT (Left) and H-Darrieus VAWT (Right). Wikimedia Commons............................... 5

Figure 3: Rotating Trailing Edge as a Valve (Angle II, 2008)...........................................................

Figure 4: High Speed Valve and Diffuser (Cagle \& Jones, 2002) ………………………………... 8

Figure 5: Complete Model with Actuators and Diffusers (Cagle \& Jones, 2002) .......................... 8

Figure 6: Hub-Mounted Valve (Flint \& George, 1968) ...................................................................... 9

Figure 7: Hub-Mounted Teacup Valve (Eilerson, 1975)................................................................ 10

Figure 8: Hub-Mounted Butterfly Valve (Danielson, 1976) ......................................................... 11

Figure 9: Internal Rotating Cam Valve (Spargo, 1976) .............................................................. 12

Figure 10: Deformable Trailing Edge (Schmidt, 1978).............................................................. 12

Figure 11: Internal Rotating Cam Valve (Amelio \& Fischer, 1990) ……………………………... 13

Figure 12: Internal Sliding Cam (Amelio \& Fischer, 1990) ........................................................... 13

Figure 13: Piezoelectric Internal Valve (Hall \& Spangler Jr., 1993) ............................................ 14

Figure 14: Electronically Deformable Actuator (Humpherson, 1996) ........................................ 14

Figure 15: Smart Material Internal Valve (Dancila \& Armanios, 1998) ...................................... 15

Figure 16: Piezoelectric Actuator at Blowing Slot (Smith, Loth, Craven, \& Bond, 2002)....... 15

Figure 17: Knife Gate (Rovalves, distributed by Tyco Flow Control) .......................................... 16

Figure 18: Preliminary Sketch of Design....................................................................................... 19

Figure 19: Close-up of Sliding Gates............................................................................................. 20

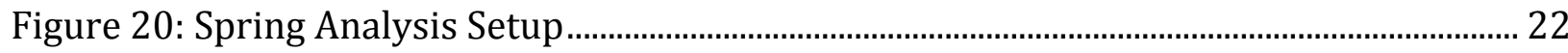

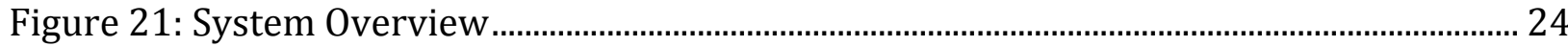

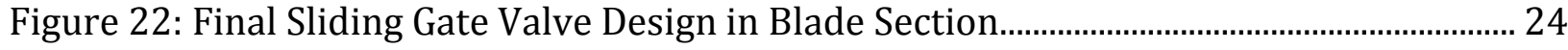

Figure 23- Testing Apparatus ....................................................................................................... 25

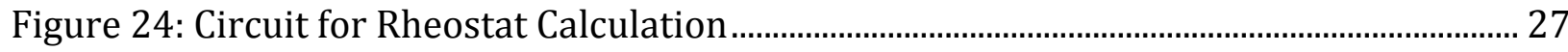

Figure 25: Circuit for Extra Resistor Calculation............................................................................ 28

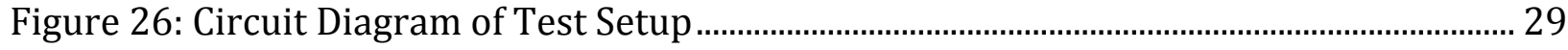

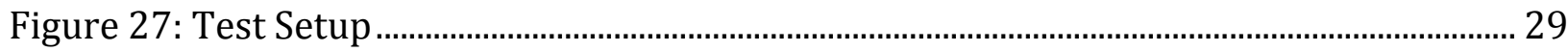

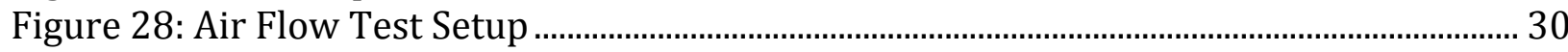

Figure 29: Complete Test Setup ……………………………………………………………. 31

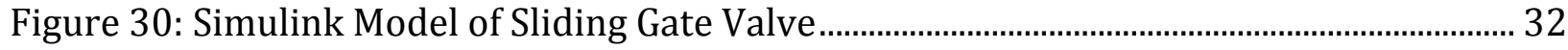

Figure 31: Experimental Response Time at Varying Pressures.................................................... 34

Figure 32: Experimental vs Simulink Response Time Data for 0-20 Psi...................................... 35

Figure 33: Relative Error of Experimental vs Simulation Data ..................................................... 36

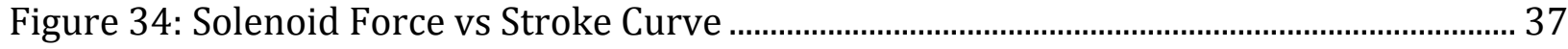

Figure 35: Minimum Actuation Power at Varying Pressures........................................................... 37

Figure 36: Interpolated Force vs Power at 0.215" Stroke ............................................................ 38

Figure 37: Actuation Force Required at Varying Pressures …………………………………….... 39

Figure 38: Leakage at Varying Pressures....................................................................................... 40

Figure 39: Von Mises Stress Distribution ....................................................................................... 41

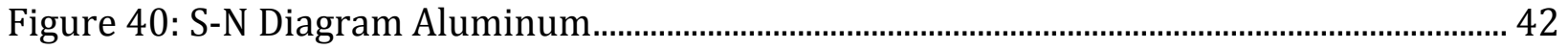




\section{List of Tables}

Table 1: Design Constraints ................................................................................................................ 18

Table 2: Forces for Solenoid Selection at 20 Psig ............................................................................ 23

Table 3: Solenoid Forces at 0.22" Stroke and 10\% Duty Cycle........................................................ 23

Table 4: Simulink Component Glossary …………………………………………………………... 33

Table 5: Predicted vs Measured Minimum Forces at 20 Psig........................................................... 39

Table 6: Estimated Solenoid Lifetime................................................................................................ 42

\section{Nomenclature}

\begin{tabular}{|c|c|c|}
\hline Symbol & Description & Units \\
\hline CC & Circulation Control & \\
\hline CIRA & Center for Industrial Research Application & \\
\hline HAWT & Horizontal Axis Wind Turbine & \\
\hline STOL & Vertical Take-off and Landing & \\
\hline VAWT & Vertical Axis Wind Turbine & $\mathrm{lb}_{\mathrm{f}}$ \\
\hline VTOL & Vertical Take-off and Landing & Ampere \\
\hline F & Force & lb $\mathrm{f} /$ in \\
\hline I & Current & psi \\
\hline $\mathrm{k}$ & Spring Constant & Ohms \\
\hline P & Pressure & V \\
\hline R & Resistance & Ohm \\
\hline V & Volts & \\
\hline$\Omega$ & Resistance & \\
\hline$\mu$ & Friction Coefficient & \\
\hline
\end{tabular}




\section{Acknowledgments}

I would first like to take the opportunity to thank my defense committee members for their direction and assistance, especially my research advisor Dr. James E. Smith for his steadfast guidance. In addition thank you to all the members of CIRA, including Dr. Franz Pertl, Dr. Gerald Angle II, Mrs. Emily Pertl, Mr. Jay Wilhelm, Mr. Kenny Williams, Mr. Chad Panther, Mr. John Kweder, Mr. Pat Wildfire, Mr. Steve Hard, Ms. Christina Yarborough, Mr. Erik Pietrowski and Mr. Justin Smith. I would also like to thank everyone else from the College of Engineering \& Mineral Resources at West Virginia University who has helped me in my studies over the years.

Many thanks also go out to all of my family and friends, who have continued to support me in so many ways. Without your unwavering support over the years I would not be where I am today. 


\section{Introduction}

Circulation control (CC) has been proposed as a means to enhance the lift characteristics of an aircraft wing in lieu of a traditional flap. Circulation control involves the use of a high-speed air jet ejected at the trailing edge of an airfoil-shaped body, which "circulates" air around the trailing edge via the Coandă effect. The airflow around this body is thus altered, resulting in increased lift without the typical increase in drag that a flap causes, as well as an alteration of the stall angle. This approach shows a myriad of benefits for high-lift aircraft. Engineers can increase payload while decreasing take-off and landing distances and shortening wing size overall, which in turn decreases drag at cruising speeds. This technology is to be applied in the future to rotorcraft, with CC benefiting in much the same way as it benefits fixed-wing aircraft.

Ongoing research at the Center for Industrial Research Applications (CIRA) at West Virginia University (WVU) in Morgantown, West Virginia involves the application of circulation control to vertical-axis wind turbines (VAWT). This project seeks to utilize the lift enhancement of CC to increase the power output of the VAWT, which could potentially lead to more efficient wind turbines as well as the increased adoption of wind power as an alternative energy solution.

One of the most critical components of any CC system is the valve that controls the high-pressure air that must be delivered to the blowing slot at the trailing edge of the airfoil-shaped body. With fixed-wing aircraft it is allowable, although not necessary, to place a valve far away from the blowing slots, i.e. at the fuselage, because valve on-off response time is far less important than the steady-state response. The same is true for any steady-state wind tunnel test of CC wings (or rotors or blades). The valve component for these scenarios can be simple, as even a manually operated valve would be acceptable for testing purposes.

Rotorcraft usage introduces a new set of design constraints for the valve components because the blowing must be meticulously controlled. This is because during forward flight, the rotor experiences differing relative air velocities that must be matched with specific blowing amounts in order to yield the desired flight characteristics. There are 
numerous valves that accomplish this feat, including elaborate hub-mounted designs, surface-mounted designs and designs located anywhere in between.

The valve system for a CC-VAWT shares some of the same design criteria as those for rotorcraft, including weight, size and a low response time. The valve system is further complicated because a blade for a VAWT requires both an upper and a lower blowing slot rather than a single blowing slot. In conjunction with the aforementioned research project by CIRA at WVU, a valve system is necessary that allows testing of a technology demonstrator VAWT. This thesis presents a realized concept of a valve design (the "SlidingGate" design) that fits within the blade of the wind turbine near the blowing slot, as well as testing and analysis of an experimental valve prototype.

\subsection{Research Objectives}

The primary research objectives of this project is to design, fabricate and test a valve system that fits within the blade(s) of a small (8 inch chord) CC-VAWT. The response time, power requirements, force requirements and leakage rates are tested in the prototype model. Upon completion of a functional test model, it is envisioned that this design (or an adaptation thereof) will be employed in a technology demonstrator and further tested and refined. 


\section{Literature Review}

This chapter summarizes relevant background information and history related to circulation control valve systems. Topics include circulation control, vertical axis wind turbines, existing and envisioned valve designs, other valve technologies that share similarities with this design and actuators. With an understanding of these fundamental topics, the unique requirements of this design began to take shape.

\subsection{Circulation Control}

Although the proposed use of blown air to augment airfoil lift dates back to 1928, the concept was primarily applied in the form of blown flaps or jet flaps (Loth, 2006). Circulation control is a progression of these early devices, with one key difference: a curved trailing edge that utilizes the Coandă effect. At low blowing rates, the jet entrains the boundary layer to prevent flow separation. At higher blowing rates, the static pressure, viscous shear stress and centrifugal force combine to separate the jet, forming a new stagnation point and streamline on the lower surface. The large flow entrainment of this jet, combined with the large deflection of the stagnation streamline produces a pneumatic camber, as shown in Figure 1. In this figure, the jet exits the blowing slot at the bottom of the trailing edge and bends upward and around. If the flow of the jet is controlled the lift and drag can be predicted pneumatically (Englar, 2006).

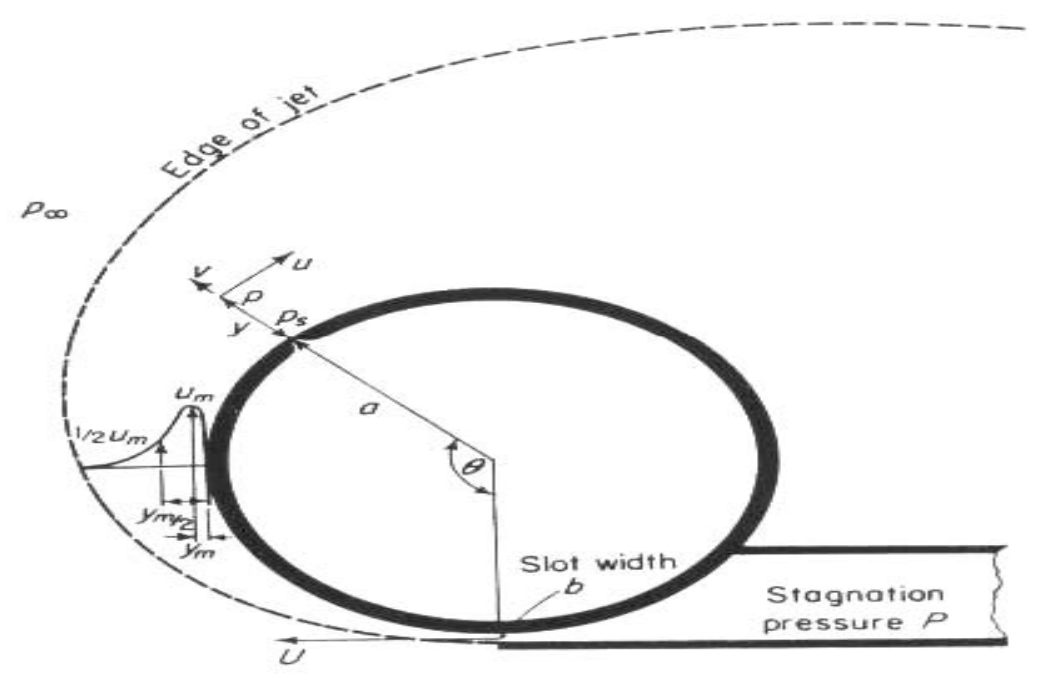

Figure 1: Jet Flow around Rounded Trailing Edge (Newman, 1961) 
During the last 50 years, the primary research applications of CC have been aircraft, most notably short take-off and landing (STOL) and vertical take-off and landing (VTOL) vehicles, where the additional lift generated through the use of CC lends itself to such applications. Typically, air is supplied from high-pressure bleed ports on a turbojet engine and ported to the wing, where the blown air exits out of the blowing slot, where the reduced thrust of the engine due to bleeding is often more than made up with significant increases in lift. For a fixed-wing aircraft, once the aircraft has achieved stable flight the bleed ports can be closed and normal flight ensues (Englar, 2006).

Circulation control is not limited to fixed-wing aircraft, however. Rotorcraft may also utilize the boundary layer control and lift/drag advantages that CC brings. In 1979, a CC Rotor demonstrator based on a Kaman H-2 helicopter was developed (Wilkerson, Barnes, \& Bill, 1979) (Mayfield, 1980), but perhaps the most notable rotorcraft to utilize CC was the X-Wing VTOL research vehicle, which utilized a rotor for VTOL capability as well as fixed wings for steady flight. After takeoff, the craft's rigid rotors could be stopped midflight to act as X-shaped wings during forward flight. A concept X-Wing was flown at the NASA Ames wind tunnel facility, and successfully transitioned from hover to a fixed-wing state using pneumatics (Williams, Leitner, \& Rogers, 1976).

$\mathrm{CC}$ is also not limited to flight vehicles, however. It can be useful in many applications that deal with drag, and even with fluids other than air. Non-flight research applications of CC include boats, submarines, fans and wind turbines, cars and even longhaul trucks. The US Navy is currently investigating the use of CC on submarines, which could use water jets instead of dive planes and rudders; wind turbines may use CC to effectively alter blade pitch non-mechanically; Formula 1 racecars can increase downward force for high speed cornering while reducing drag or entraining flow for cooling across a radiator; passenger cars and long haul trucks can increase fuel economy through reduced drag, or increase drag for braking, as well as lateral control during side winds (Englar, 2006)(Wright, 2007). 


\subsection{Wind Turbines}

Wind power has positioned itself as a mainstream energy source in recent years. As of 2008, over $74 \mathrm{GW}$ of wind power are installed globally, and current estimates indicate that by 2030 wind energy could supply up to $29 \%$ of world's electricity demands (Paraschivoiu, Trifu, \& Saeed, 2009).

Within the industry there are two technologies that have seen active development: the Horizontal Axis Wind Turbine (HAWT) and the Darrieus-type (lift-based) Vertical Axis Wind Turbine (VAWT), as shown in Figure 2.
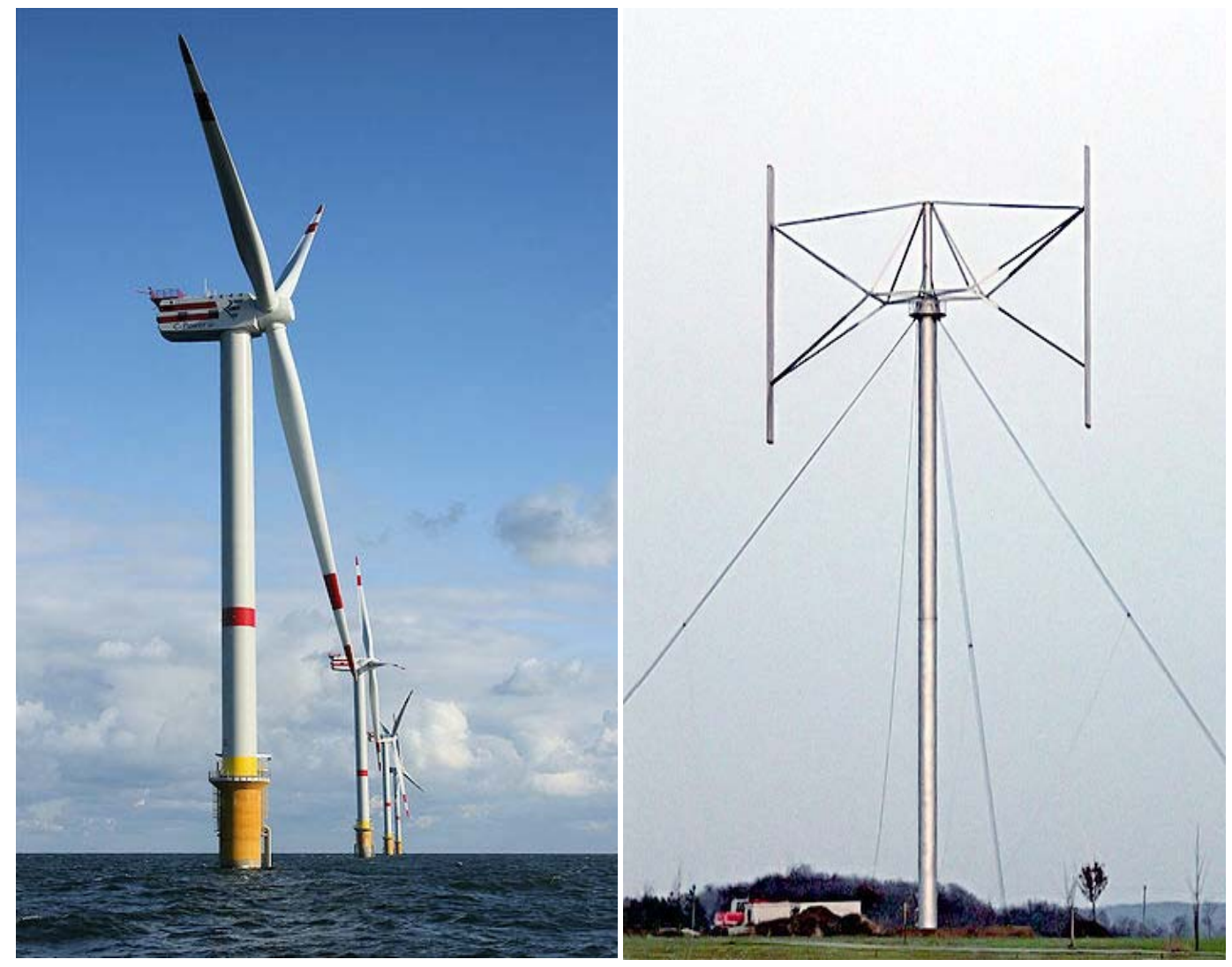

Figure 2: HAWT (Left) and H-Darrieus VAWT (Right). Wikimedia Commons

The fundamental goal of these devices is the same: extract energy from wind through a rotating shaft. The differences are in the placement of the axis of rotation, which affects the angle of attack and lift generation throughout rotation. The HAWT captures axially flowing wind with perpendicularly rotating blades, which allows a constant angle of attack through rotation. The VAWT captures flow through the assembly of rotating blades, 
which creates a varying angle of attack as the blades rotate. The lift and drag on each blade vary throughout rotation based on this angle of attack, but the VAWT achieves a net power output similar to that of a HAWT over an entire rotation. Both the HAWT and VAWT are lift-based devices, and have achieved a very high level of aerodynamic efficiency in recent years (Shikha, Bhatt, \& Kothari, 2003).

The HAWT has become the dominant design type, especially in the large and very large scale wind turbines, due to the inherent drawbacks of the conventional VAWT design: slightly less overall efficiency, not self-starting, lower power output due to proximity with the ground and greater vibrations. The VAWT design strength, however, lies in its simplicity. By locating the gearbox and generator at the bottom of the structure, a significantly smaller foundation is needed. The structure does not need to face the wind like the nacelle and blades of a HAWT in order to harness wind energy as well. Furthermore, VAWTs are expected to be cheaper to produce than a similarly sized HAWT, and in the "small wind" domain they are expected to become a major player (Paraschivoiu, Trifu, \& Saeed, 2009).

It is believed that the ongoing research at CIRA on a CC-VAWT prototype will allow the vertical-axis type to become increasingly more competitive, reducing or eliminating the previously mentioned problems.

\subsection{Previous Valve Designs}

This section discusses previous methods of controlling flow for circulation control wings, rotors and blades. An emphasis is placed on valve systems used in previous research on circulation control as well as relevant patents for valves.

\subsubsection{Valves in the Literature}

As stated previously, the majority of valves used to test experimental CC airfoils are external to the airfoil-shaped body itself. Several airfoils were constructed at WVU in the 1970's with external valves (Harness, 1970)(Myer, 1972), as well as an external valve designed for pulsed flow (Holt, 1972). This rotary valve had a brass core that rotated inside of a steel pipe by way of an electric motor; a hole was drilled through the brass core with 
fittings attached to the steel pipe so that when the hole was in line with the fitting, air was permitted to flow through the valve.

In order to test the aerodynamic response time of a $\mathrm{CC}$ airfoil, Angle built a wing with the valve directly at the trailing edge (Angle II, 2008). This wing employed a rotating, cambered trailing edge as the valve itself, actuated externally by a large solenoid, as shown in Figure 3. This design represents a very low-profile design that could potentially be used on a CC-VAWT.

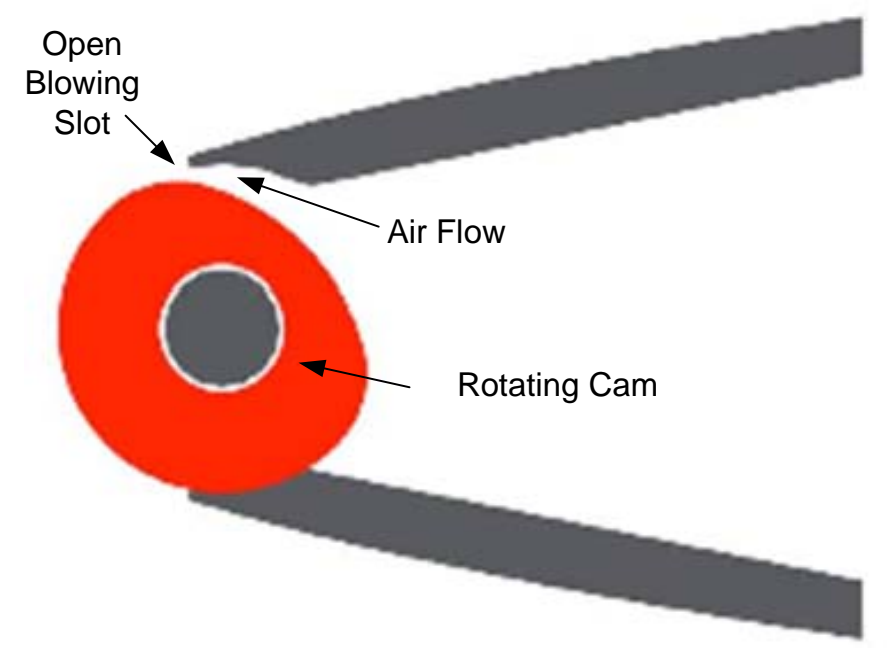

Figure 3: Rotating Trailing Edge as a Valve (Angle II, 2008)

A 2002 NASA study about pulsed flow circulation control utilized a completely internal valve system composed of many miniature solenoid valves with diffusers (Figure 4) located right next to each other within the wing section (Cagle \& Jones, 2002). This test model had a 9.4 inch chord and was 28 inches long, and the maximum flow rate was in excess of 100 SCFM for the model at 200 psig at the valve inlet. The entire wing model is shown in Figure 5. This model, however, only controls one blowing slot rather than the upper and lower blowing slots that a VAWT requires, in addition to requiring a prohibitively high intake air pressure (200 psig) required to get an adequate flow rate. Diffusers were also necessary to achieve uniform flow out of the blowing slots, and much of this study details the design of these diffusers. This design represents a practical solution to the problem of controlling the air flow in a pulsed-blowing CC application. 


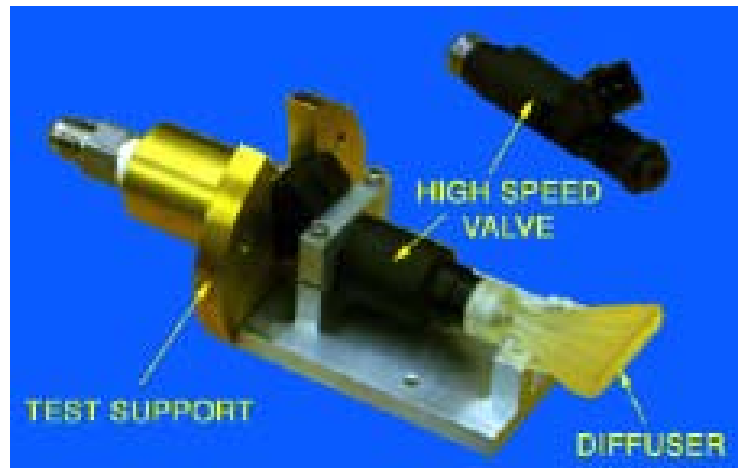

Figure 4: High Speed Valve and Diffuser (Cagle \& Jones, 2002)

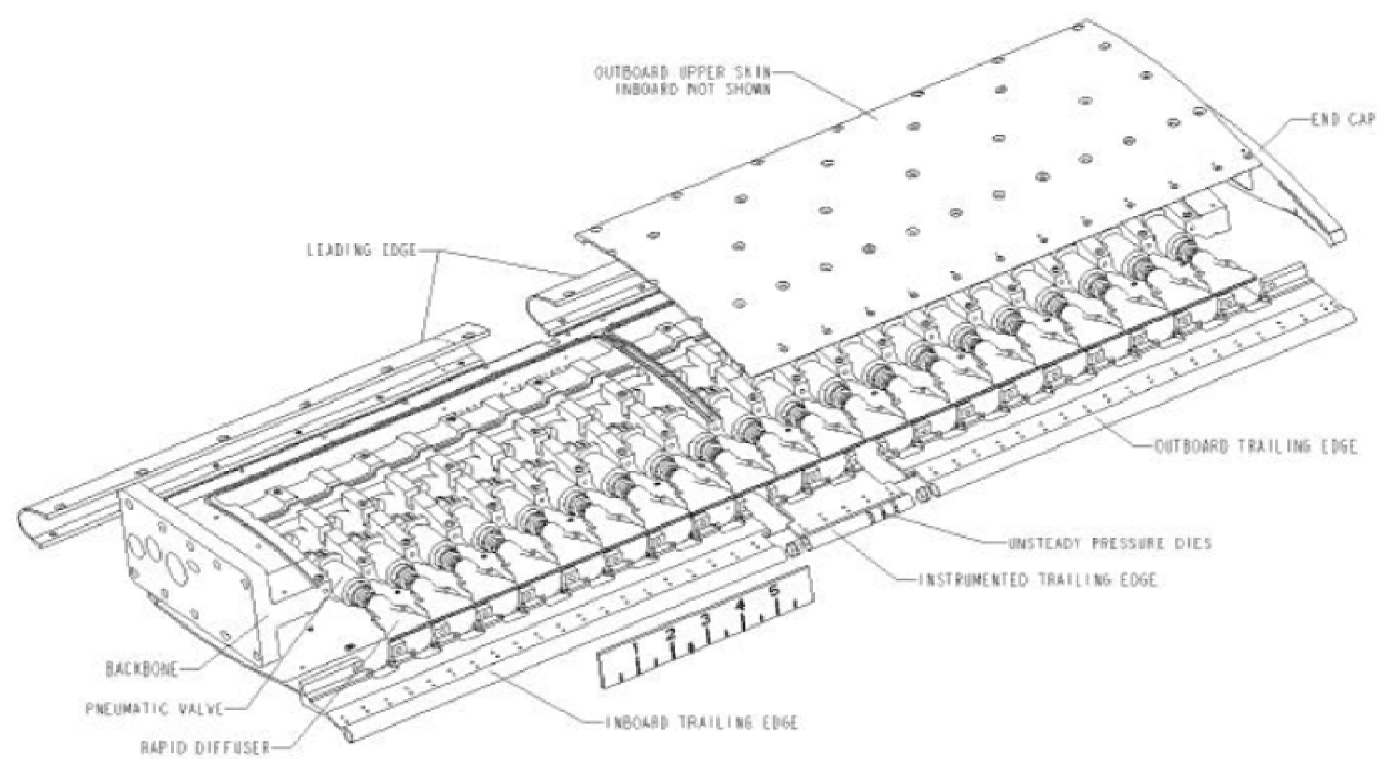

Figure 5: Complete Model with Actuators and Diffusers (Cagle \& Jones, 2002)

A 1993 study on a miniature oscillatory valve for use in a hydrofoil employed a solenoid actuated rocker valve within the trailing edge to control two blowing slots (Imber, Rogers, \& Abramson). The purpose of this study was to reduce unsteady wing load via an oscillating valve that switched the flow rapidly between the upper and lower blowing slots. This configuration required one of the blowing slots to remain open at all times, however.

\subsubsection{Patents}

The valve systems described in the previous section detail some of the experimental work that has been done. There are many more envisioned designs that have never been 
realized, although many have been patented. A patent search yielded many designs from the simple to the intricate. This section describes some of the more relevant US patents.

Many inventions relate to rotorcraft applications of CC, dating all the way back to 1937 (and perhaps earlier). Edward Stalker in 1937 described a rotary wing aircraft with "boundary layer means of suppressing lateral dissymmetry in lift arising from differences in relative air velocities" (Stalker, Aircraft, 1937). This patent is vague with respect to the valve system involved, but it is assumed to be hub-mounted and consisting of pushrods actuated by rotating cam faces. A plethora of elaborate embodiments to this general idea followed. Some of the more descriptive inventions are detailed, while others are simply cited.

Flint and George patented a hub-mounted sliding valve operated by pushrods from a swash-plate, as shown in Figure 6 (Flint \& George, 1968). The pushrod (61) is actuated by the swash plate (63). The valve seal is located at (49) in the figure.

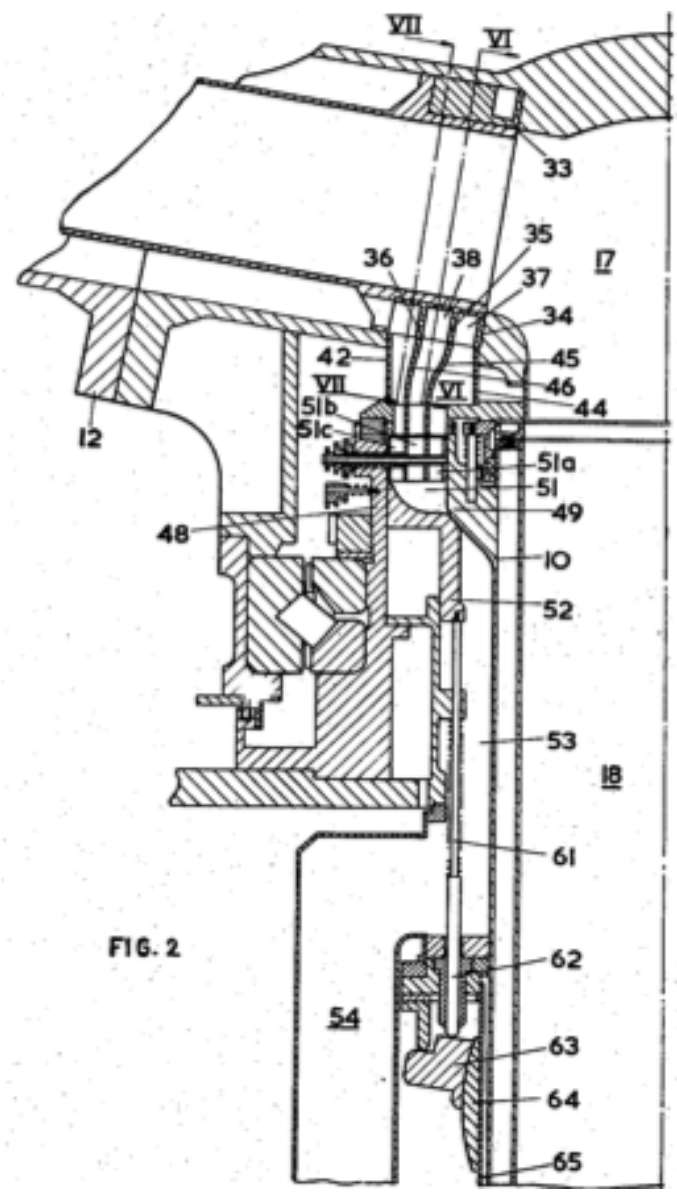

Figure 6: Hub-Mounted Valve (Flint \& George, 1968) 
Eilertson patented a rather simple mechanism in 1975 that describes a CC rotor hub with pushrod valves and an axial mounted cam surface that actuated the pushrods once per revolution, as shown in Figure 7. The fixed cam (15) forces the plunger (24) to open and close against the base of the wing (Eilerson, 1975).

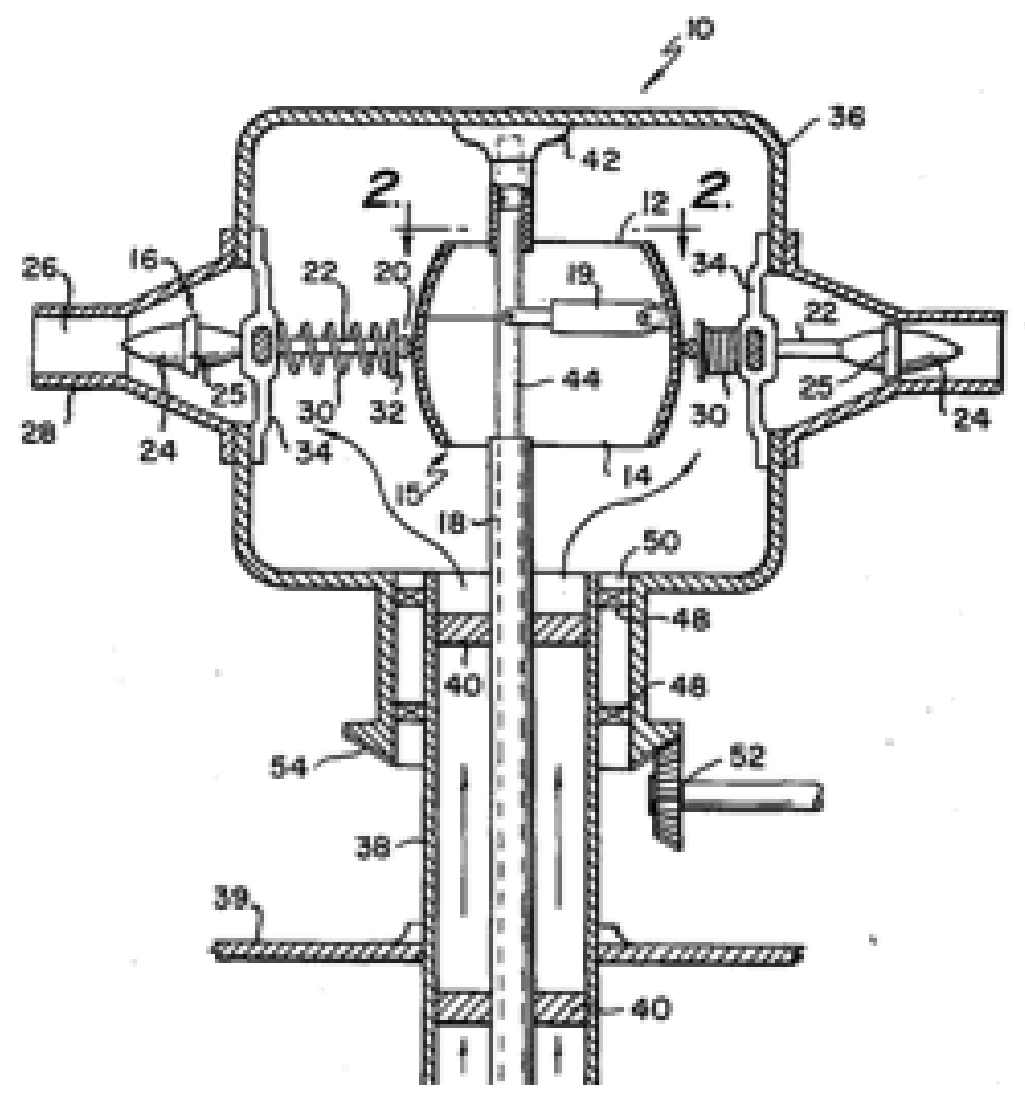

Figure 7: Hub-Mounted Teacup Valve (Eilerson, 1975)

Danielson patented a similar design in 1976, except with hub-mounted butterfly valves actuated by pushrods (68) parallel to the rotating shaft (Danielson, 1976). 


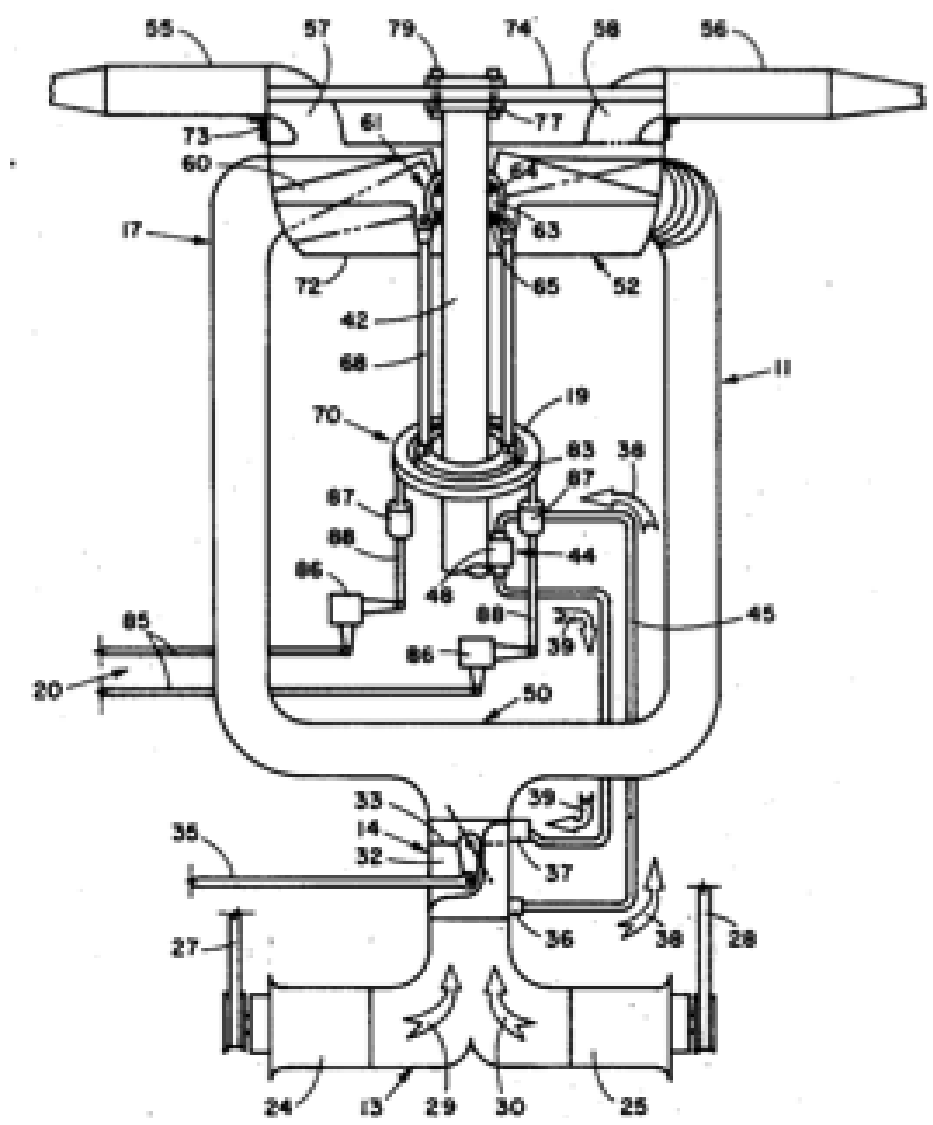

Figure 8: Hub-Mounted Butterfly Valve (Danielson, 1976)

There are many other patents relating to similar hub-mounted valve systems operated by pushrods and cams, including, but not limited to: 2457936 (Stalker, 1949), 2493041 (Stalker, 1950), 2925129 (Yuan \& Von Karman, 1960) 3139936 (Davidson \& Islip, 1964), 3524711 (Cheeseman, George, \& Lawrence, 1970) and 4507050 (Jeffrey \& Lawrence, 1985).

Spargo in 1976 patented an airflow control valve consisting of an internal rotatable cam(20) that opens a u-shaped member (18) around a port (32) to the trailing edge, and is returned via spring, as shown in Figure 9 (Spargo, 1976). Although the method for actuating the cam is not specified, this was an attempt at placing the valve within the body of the blade. 


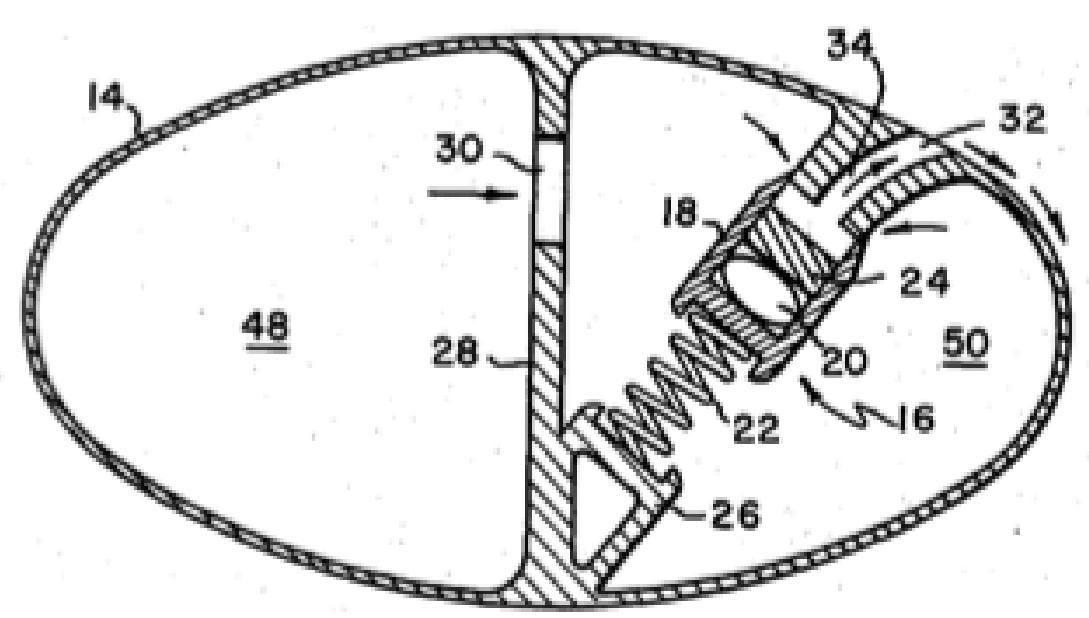

Figure 9: Internal Rotating Cam Valve (Spargo, 1976)

Schmidt in 1978 patented a deformable trailing edge structure as shown in Figure 10 consisting of a rigid edge lip (42) and a deformable tube (44) acting as a trailing edge. This allows precise setting of the slot height as well as potential to close the slot altogether directly at the trailing edge. Future technologies may allow an actively deformable trailing edge (either the trailing edge itself or the lip) as a fluid control method (Schmidt, 1978).

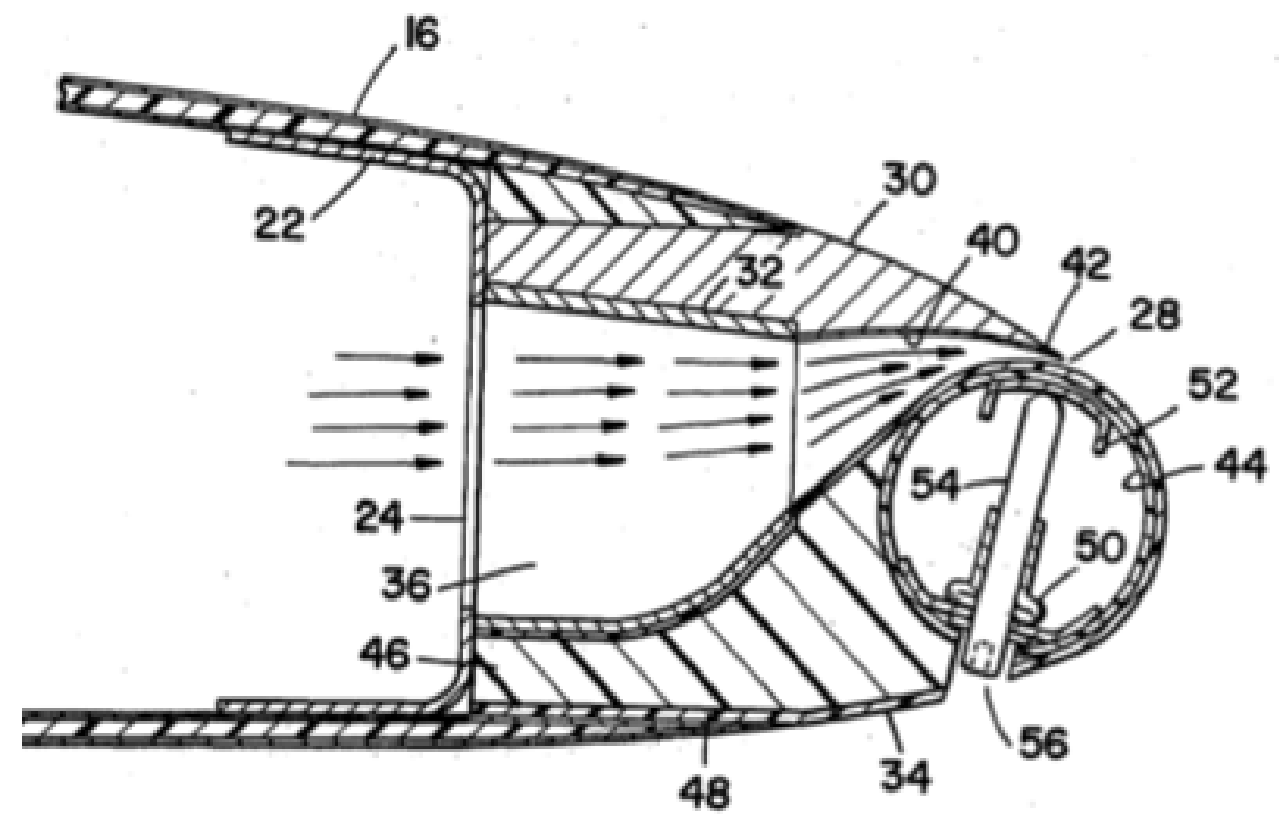

Figure 10: Deformable Trailing Edge (Schmidt, 1978)

Amelio and Fischer Jr. in 1990 patented several embodiments of a mechanically deformable skin at the blowing slot. Figure 11 uses a rotating cam (108) to deform the skin 
(112), opening and closing the blowing slot. Figure 12 uses a transversely mounted linear actuator (126) to force a slider (132) up a ramp (134), effectively accomplishing the same task (Amelio \& Fischer, 1990).

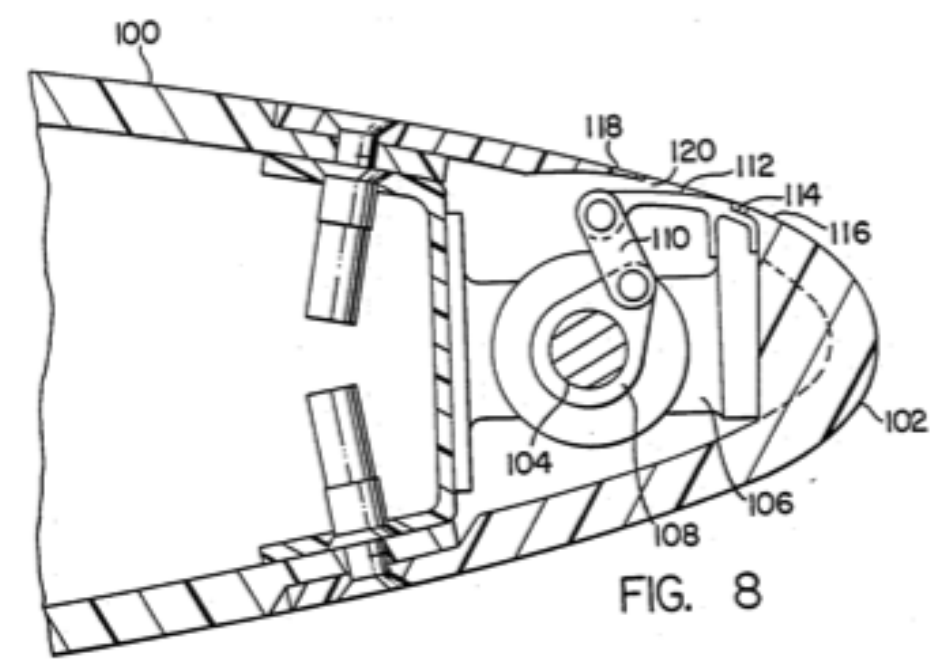

Figure 11: Internal Rotating Cam Valve (Amelio \& Fischer, 1990)

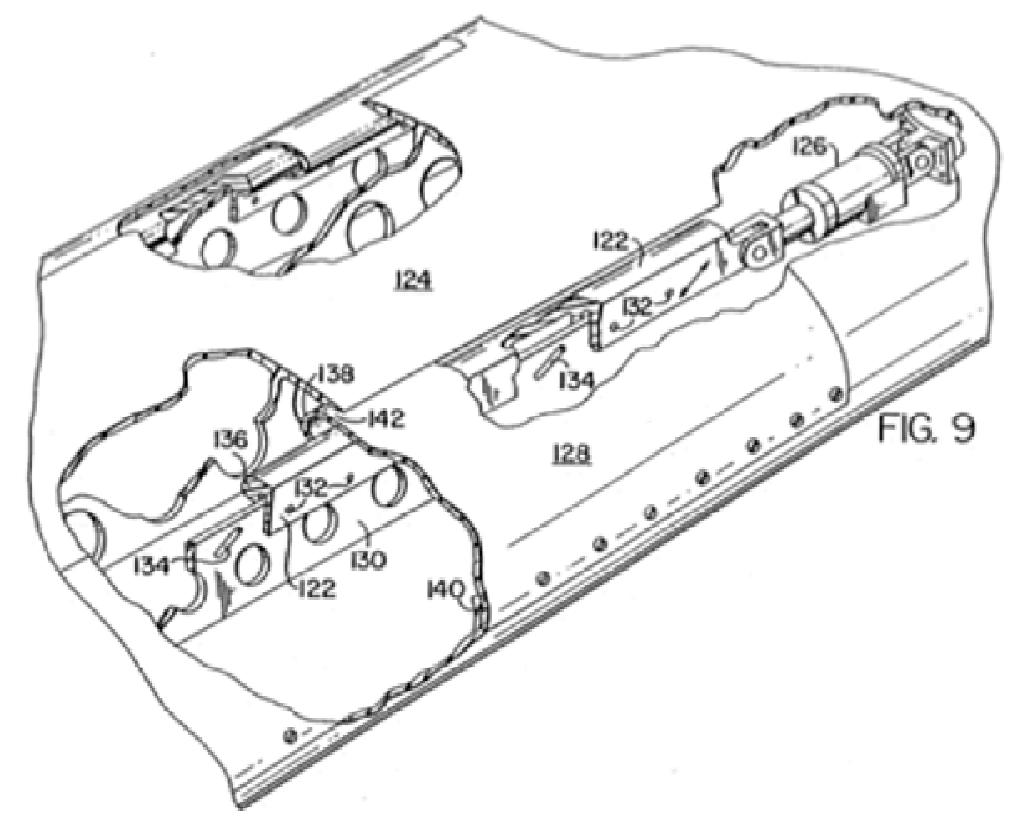

Figure 12: Internal Sliding Cam (Amelio \& Fischer, 1990)

In the 1990's, inventors began to realize the potential for shape-changing materials (e.g. piezoelectric materials and shape-memory alloys) to create novel valve systems. Hall and Spangler in 1993 patented a piezoelectric actuator (20 and 22) that caused an internal 
beam (22) to move up and down, opening and closing a blowing slot, as shown in Figure 13 (Hall \& Spangler Jr., 1993).

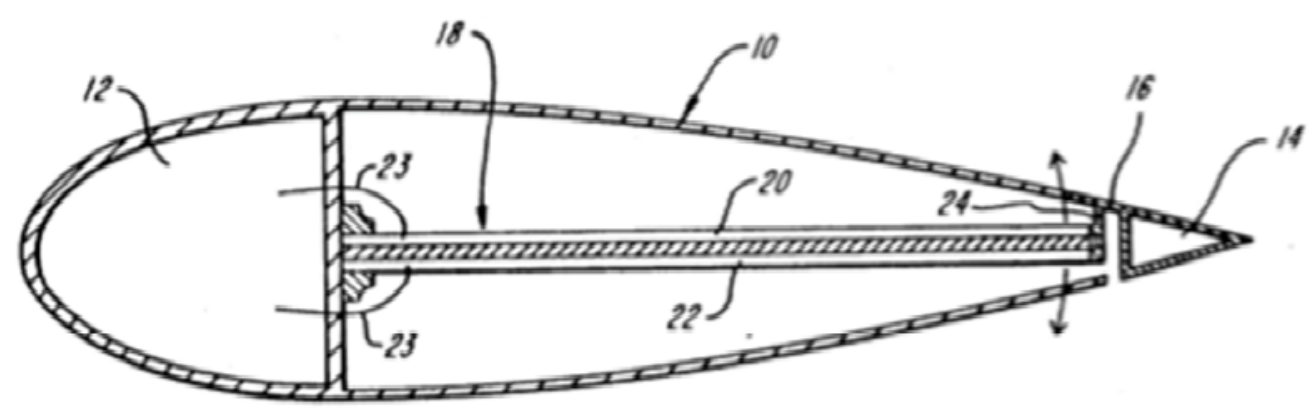

Figure 13: Piezoelectric Internal Valve (Hall \& Spangler Jr., 1993)

Humpherson in 1996 patented a CC airfoil whose trailing edge consisted of an exhaust slot that could change size via actuators of "electrically deformable material (19)," as shown in Figure 14 (Humpherson, 1996).

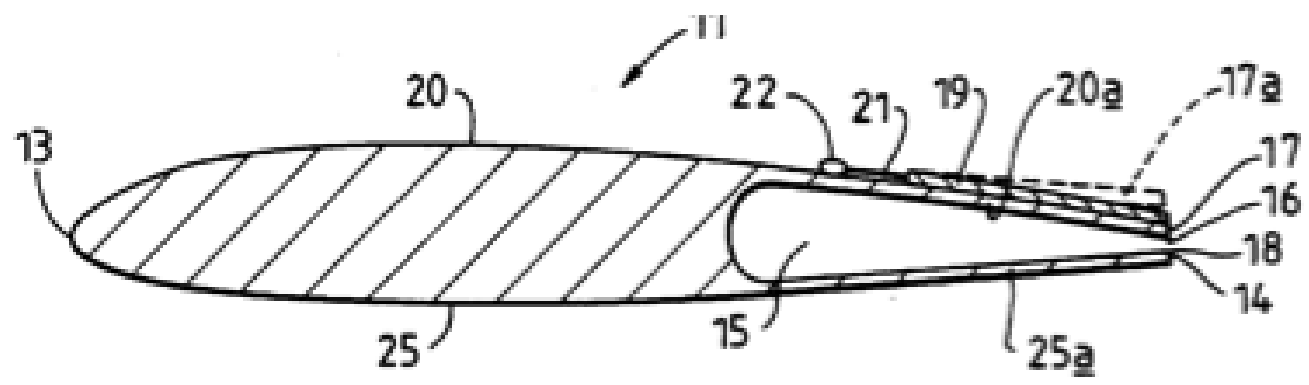

Figure 14: Electronically Deformable Actuator (Humpherson, 1996)

Dancila and Armanios in 1998 patented a very similar design to Humpherson, except that the smart material actuator (29) operated a gate (32), as shown in Figure 15 (Dancila \& Armanios, 1998). 


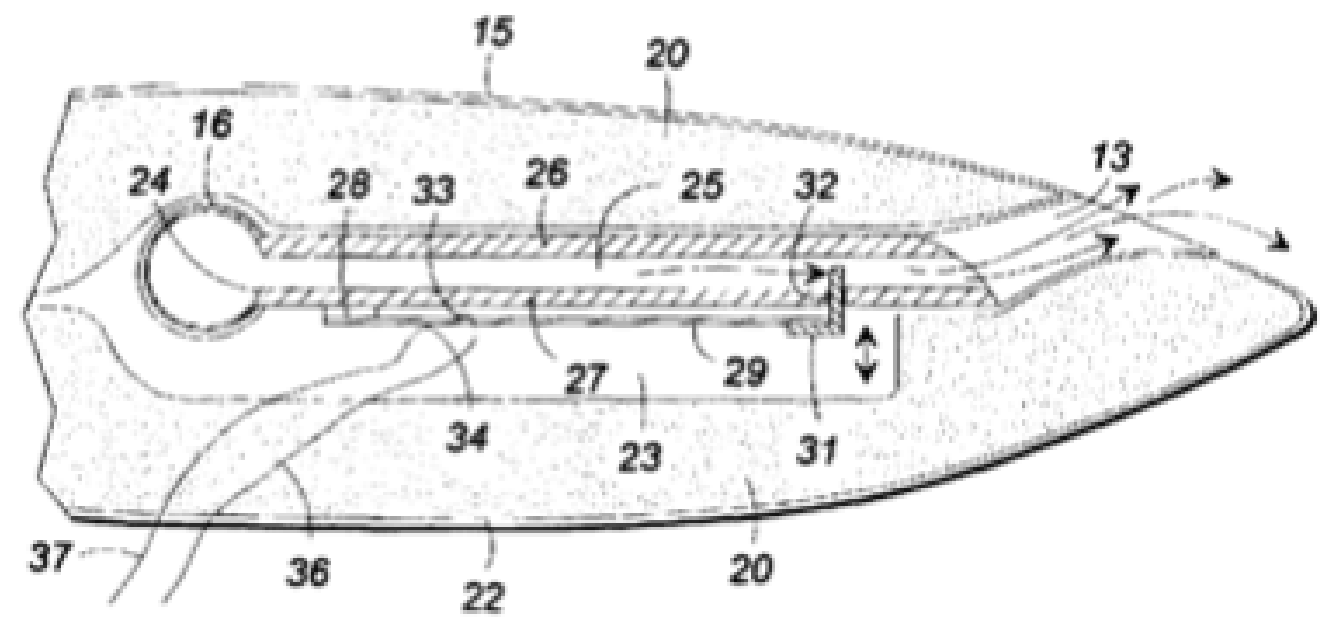

Figure 15: Smart Material Internal Valve (Dancila \& Armanios, 1998)

Smith et al. in 2002 patented a novel piezoelectric actuator (116) directly at the blowing surface (114), mounted on the internal plenum (112), as shown in Figure 16 (Smith, Loth, Craven, \& Bond, 2002).

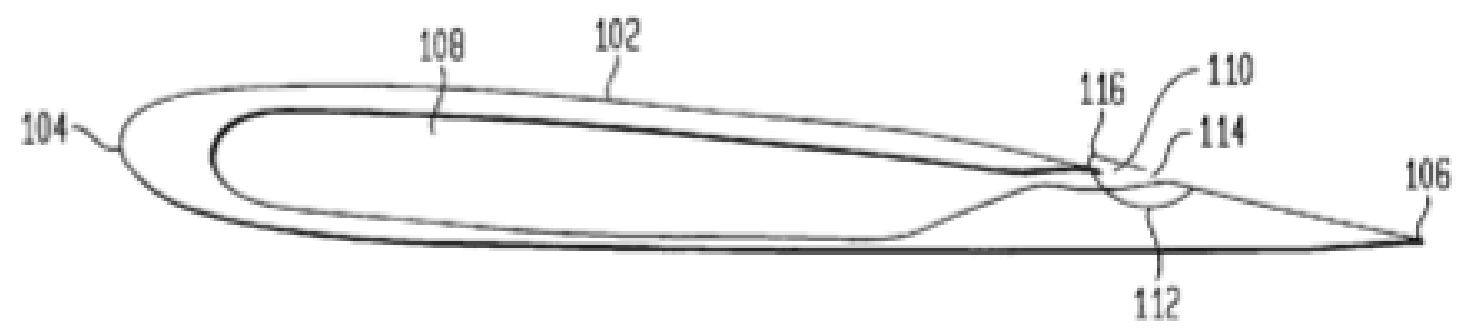

Figure 16: Piezoelectric Actuator at Blowing Slot (Smith, Loth, Craven, \& Bond, 2002)

\subsection{Other Valves}

In addition to the aforementioned CC valve designs, several other industrial valves share much in common with systems that could potentially function as a CC valve. Solenoid valves are commonly available components, but the key limiting factors are size and flow rate. Off-the-shelf solenoid valves that are small enough to fit within a test prototype (approximately 8 inch chord), such as those described by Cagle and Jones, require very high input pressures to achieve necessary flow rates. These valves are very similar to direct-injection fuel valves used in modern engines, which typically deal with very high pressures and relatively low flow rates. Solenoid valves offer several distinct advantages, however, including reliability, speed, and availability. 
Another valve design that shares a lot in common with the proposed sliding-gate design is the sluice gate (or knife gate), as shown in Figure 17. This simple design is primarily used to control flow rates in rivers and canals, but also in industrial processes such as wastewater treatment. In the figure, an actuator (knob driven by hand) forces a metal sheet that obstructs an opening, thereby restricting flow.

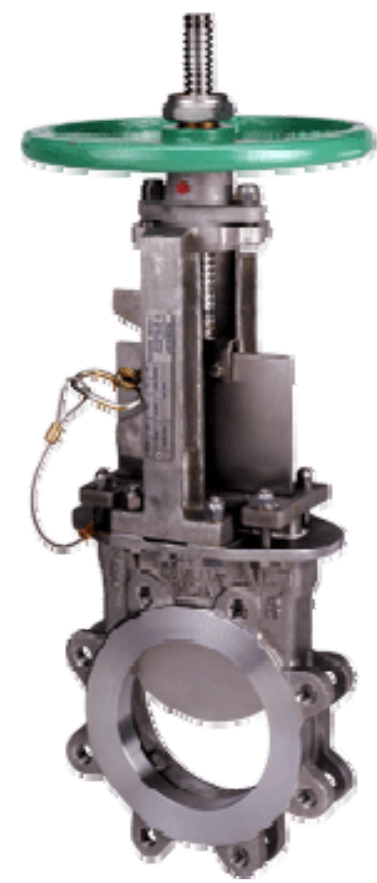

Figure 17: Knife Gate (Rovalves, distributed by Tyco Flow Control) 


\section{Design of Valve}

Several different designs were envisioned prior to the fabrication and testing of the sliding-gate design, including previous CC valve systems, off-the-shelf valves and several original embodiments. This chapter describes the design constraints for a CC-VAWT valve, designs and actuators considered and a methodology for choosing individual components.

\subsection{Design Constraints}

Perhaps the most important constraint is physical size; the valve must fit completely within the blade and still allow room for plumbing, wiring and structural components. Given that the blades for the proposed technology demonstrator VAWT (as well as models intended for wind tunnel testing) are to be of the NACA0018 shape with an 8" chord, this leaves approximately 1.25 " from top to bottom at the widest point. In order to lower the aerodynamic response time, it is important to place the valve as close to the trailing edge as possible. For structural reasons, ribs are to be placed approximately every 8" along the span of the blade; these provide a natural partition of the valve as well, with each section representing an individual valve system that can be controlled independent of the other partitions. Given that there are both upper and lower blowing slots, two valve systems must effectively exist within each of the blade partitions in order to control each of the respective blowing slots.

Another important consideration is airflow, which includes the plumbing used to direct the air to the blowing slot as well as the valve components. The main consideration is to avoid choked flow so that the prescribed flow rate can be attainted. The upper limit for volumetric flow is also set at 35 SCFM per 8" blade section, based on a model of the same size and shape that is currently under testing in conjunction with this research project. As long as the orifice area is larger than that of the blowing slot area, this condition is avoided. The air supply system (inlet side) was not studied for this thesis. It is also important that any leakage through the closed valve be kept to a minimum; a guideline was set at $5 \%$ of the airflow of the fully open condition at a given pressure. The pressures present within the plenum should range between 0 and 20 psig. 
The actuation (as well as subsequent return) times should be lower than $50 \mathrm{~ms}$ each, which is based on a control model developed in conjunction with this research project. The faster (and thus more controllable) the system can react, the better. Another factor that is usually related to response time is the power required. Most electricalmechanical actuators (such as a solenoid) can function under a variety of input voltages, and a higher voltage will increase the speed of actuation at the expense of extra energy usage and wear and tear on the solenoid itself. This is counter-productive to an extent; the valve must function within specifications, but not be overdesigned so that the power requirements detract from the performance gains of the CC-VAWT.

Other design constraints include weight and cost. The system must not be prohibitively heavy so that it complicates or adds to the structural design. For the proposed technology demonstrator, this leaves approximately $25 \mathrm{lb}$ of valve for a 10' section, or about $1.5 \mathrm{lb}$ per 8" section, which is based on a structural design model developed in conjunction with this research project. Any weight added to the blade also affects the rotational inertia of the VAWT; this effect is not considered in this thesis, however. The total cost (and availability of components) must also be considered. A summary of the design constraints is presented in Table 1.

Table 1: Design Constraints

\begin{tabular}{|l|l|}
\hline \multicolumn{1}{|c|}{ Constraint } & \multicolumn{1}{c|}{ Description } \\
\hline Physical Size & Fit within airfoil \\
\hline Flow Requirements & No choked flow, variable along length \\
\hline Flow Rate & Up to 35 SCFM per 8" section \\
\hline Leakage Rate & Less that 5\% of total flow \\
\hline Plenum Pressure & $0-20$ psig \\
\hline Actuation Time & Under 50 ms \\
\hline Power Requirements & Low as possible \\
\hline Weight & Less than 1.5 lb \\
\hline Cost & Not prohibitively expensive \\
\hline
\end{tabular}

\subsection{Design Concepts}

Several concepts were considered before choosing the sliding-gate design. The placement of the valve can be either directly at the trailing edge or back from the edge, 
creating a secondary air plenum. The former design can be achieved via a movable skin or a movable trailing edge while the latter can be achieved via an off-the shelf valve placed within the blade or a knife gate, on which this valve design is based.

After much consideration, a preliminary design began to take shape, as shown in Figure 18. The valve was positioned between span-wise spaced rib sections (F) of the turbine blade, dividing the length of the turbine blade into multiple blowing slots between rib elements. The valve contains a fixed gate section (C) that creates a plenum between itself and the blowing slot. This section may be integrated as part of the structure for the turbine blade. This fixed section supports a sliding gate (B) (shown in greater detail in Figure 19) that has the ability to slide in the span-wise direction. These two plates have slots milled out of them that are aligned in a manner that allows for full-flow and no-flow conditions by sliding the plate linearly in the span-wise direction. A partial-flow condition can be achieved by having some sections on and some sections off altogether, as defined by the control strategy. The design has two separate sliding plates; one for the upper and another for the lower blown jet, as required. There is a secondary plate (D) that separates the upper and lower blowing areas, which is attached to the trailing edge (E).

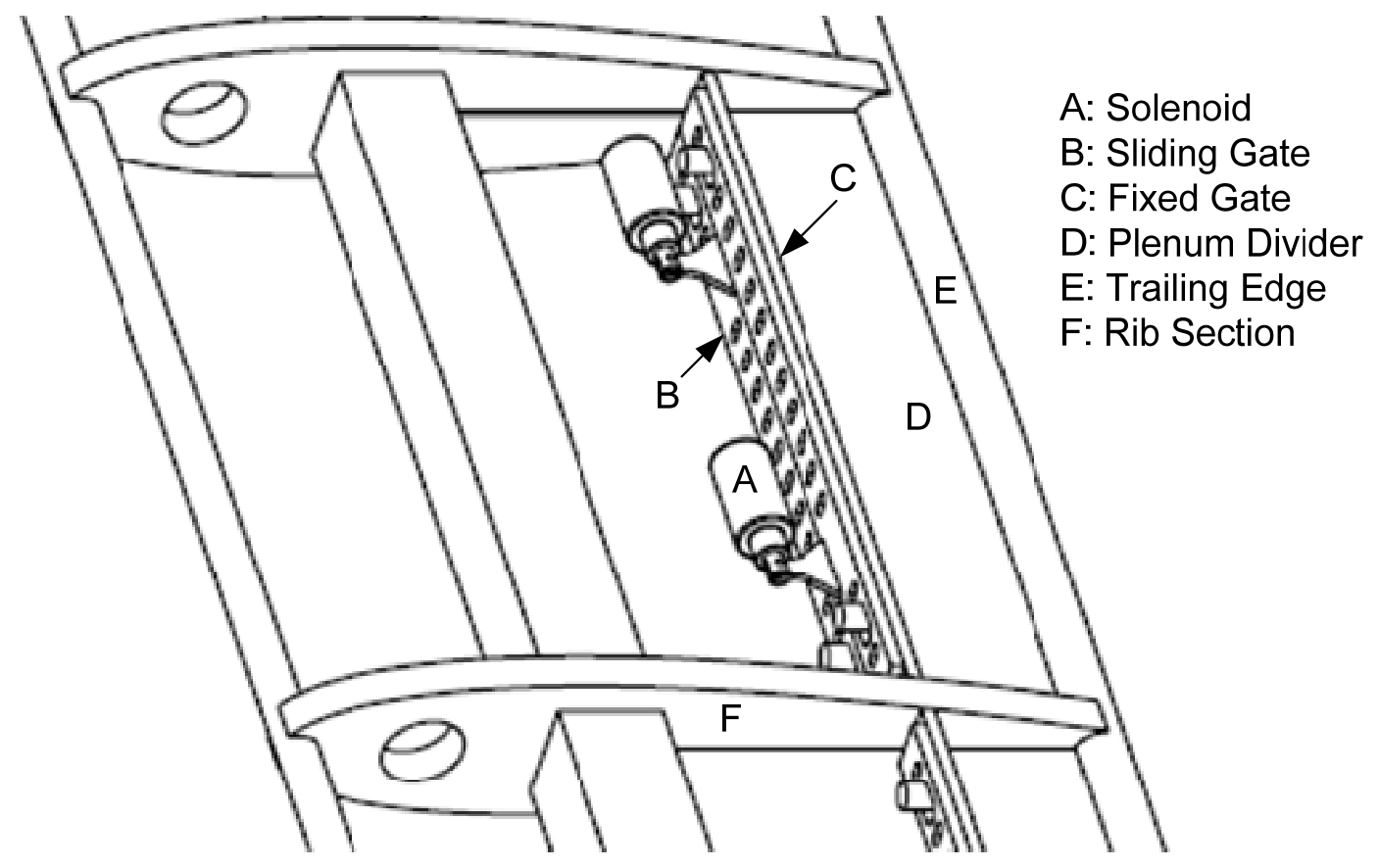

Figure 18: Preliminary Sketch of Design 
The sliding mechanism can be actuated by a number of devices including solenoids, linear servo motors, shape memory alloys (SMA), piezoelectric actuators or rotary motors. A close-up of the gate sections is shown in Figure 19. The upper and lower gates are clearly attached to the fixed gate at the rear via 4 cap screws, and a solenoid is shown as the preferred actuator attached to the upper sliding gate. In this figure the upper gate is open (actuated), allowing air to flow from the top of the trailing edge while the lower gate is closed, blocking air flow to the bottom of the trailing edge.

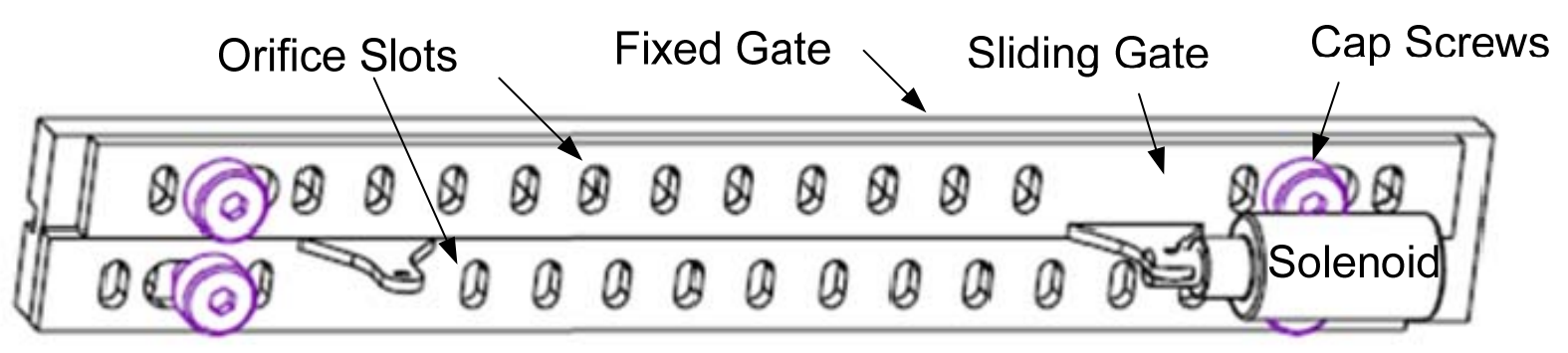

Figure 19: Close-up of Sliding Gates

\subsection{Valve Component Selection}

Once the preliminary design was envisioned, the final components were chosen and the design took shape. The important components are the sliding gate, actuators and return mechanism, along with mounting brackets and sealing materials.

\subsubsection{Gate Sections}

The gate sections consist of a fixed gate and a sliding gate. There are 14 orifice slots that each measure $1 / 8$ inch by $1 / 4$ inch, with a spacing of 0.43 inches. These slots were sized so that their total area was much greater than the area of the blowing slot in order to prevent choked flow at the slots, while also being relatively easy to machine. The area of each slot is $0.028 \mathrm{in}^{2}$, giving a total slot area of $0.39 \mathrm{in}^{2}$. This is large in comparison to the blowing slot area of $0.08 \mathrm{in}^{2}$ and thus eliminates the possibility of choked flow at the blowing slot.

The gate must travel 0.215 inches laterally in order to open completely, with the default position fully closed. The height of each sliding gate is $1 / 2$ inch, which gives a total 
height of 1 inch for the fixed gate. The fixed gate was positioned as near the trailing edge that allowed a 1 inch section to fit within the skin surfaces without interference.

\subsubsection{Actuation and Return Mechanism}

The size and spacing of the slots was chosen for two reasons: ease of machining and consideration of an actuator. Among the actuator choices (solenoids, linear servo motors, shape memory alloys, piezoelectric actuators or rotary motors), the solenoid stood out as not having any serious flaws: the linear servo motors available have too slow a response time, shape memory actuators are not strong or fast enough, currently available piezoelectric actuators do not travel enough to actuate the gate and rotary motors would require an added linkage or gear to create linear motion.

Once the solenoid was chosen as the preferred actuator, a specific model could be selected. As a starting point, an estimate for the force required by the solenoid was calculated based on a friction coefficient of 0.4 (Collins, 2003) and the predicted normal force of the sliding gate on the fixed gate due to pressure in the plenum. From Equation 1 and Equation 2, with a plenum pressure of 20 psig and a gate area of $2.88 \mathrm{in}^{2}$, the predicted force due only to pressure acting on the gate was estimated at $2.3 \mathrm{lb}$.

$$
\begin{array}{ll}
F_{\text {normal }}=P \times A & \text { Equation 1 } \\
F=F_{\text {normal }} \times \mu_{\text {friction }} & \text { Equation 2 } \\
F=20 p s i \times 2.88 \text { in }^{2} \times 0.04=2.3 \mathrm{lb} &
\end{array}
$$

Because solenoids only provide force in one direction, a mechanism to return the gate to its original position is necessary. For simplicity, a spring was chosen that would connect the sliding gate to a mounting surface. The spring effectively acts as an actuator of sorts, and must be strong enough to return the gate on its own. Because of the added resistance due to the spring, the solenoid must have enough force to overcome the friction force on the gate due to pressure as well as the resistive force of the spring. Therefore, the spring was specified based on the initial force requirements, as shown in Figure 20. It must be stressed that this was meant only to provide a rough estimate of the required forces in 
order to specify a spring. Once a spring was specified, it could be tested in the valve testing apparatus (see chapter 5). It is also important to note that the preload could be adjusted as necessary to increase or decrease the force produced by the spring.

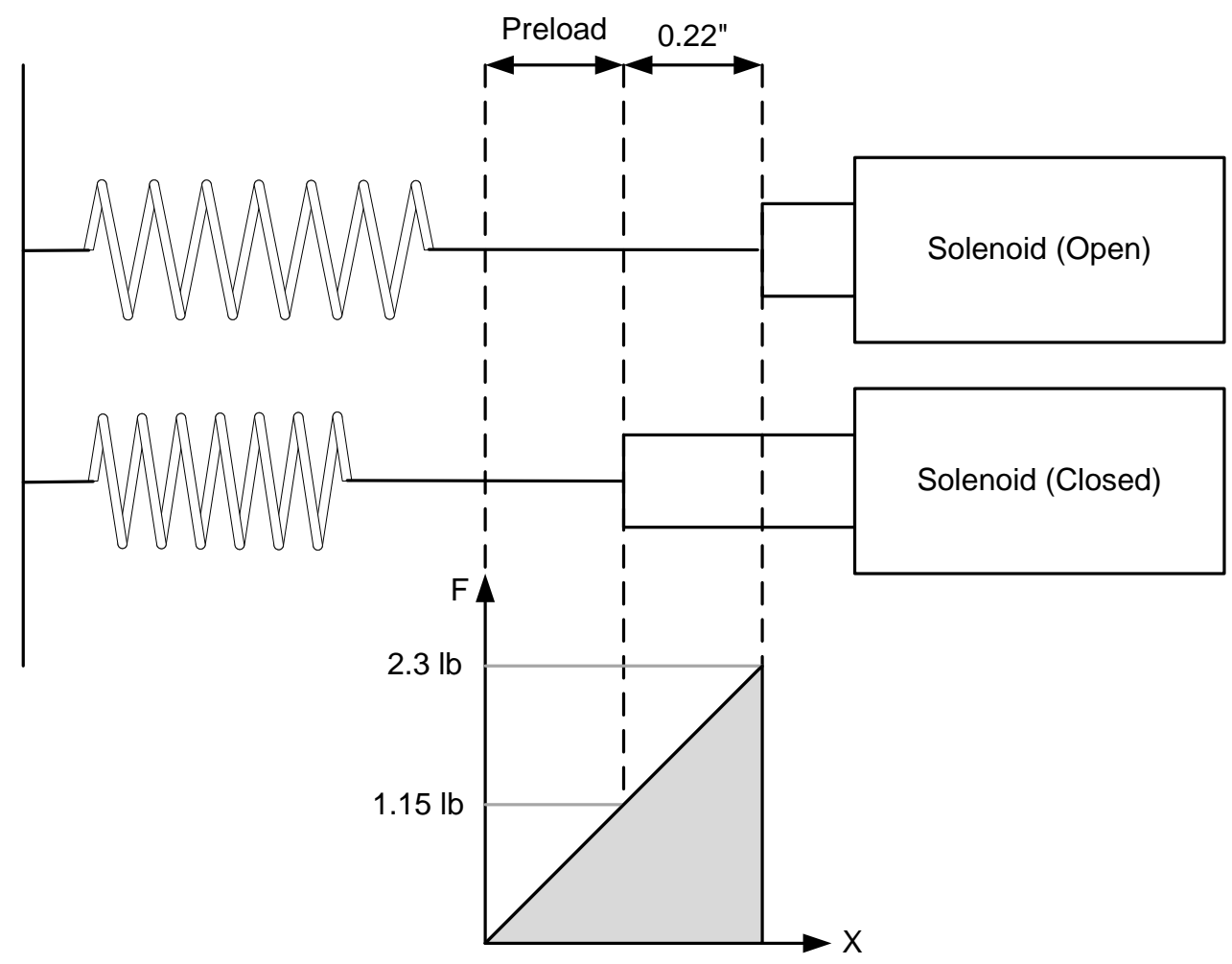

Figure 20: Spring Analysis Setup

As a starting point, $2.3 \mathrm{lb}$ was chosen as the force required to set the gate in motion, with half of that force $(1.15 \mathrm{lb})$ at the fully closed position and the preload set equal to the distance between fully open and fully closed. Again, the ability to tweak the preload as necessary allows the use of many different springs, so this decision was somewhat arbitrary. According to Equation 3, this yields a spring constant of $5.4 \mathrm{lb} / \mathrm{in}$.

$$
\begin{aligned}
& F=k x \\
& (2.3-1.15) l b=k(0.215 i n) \\
& k=5.4 l b / \text { in }
\end{aligned}
$$

Now that the forces due to the pressure acting on the sliding gate and the return mechanism have been approximated, a suitable solenoid can be specified. By totaling the 
forces at the fully closed position, this yields $3.45 \mathrm{lb}$. The force requirements are summarized in Table 2.

Table 2: Forces for Solenoid Selection at 20 Psig

\begin{tabular}{|l|l|}
\hline \multicolumn{1}{|c|}{ Component } & \multicolumn{1}{c|}{ Force (lbf) } \\
\hline Force due to pressure & 2.3 \\
\hline Return Force & 1.15 \\
\hline Total & 3.45 \\
\hline
\end{tabular}

Several tubular solenoid models from Ledex ${ }^{\circledR}$ in the 0.5 to 1 inch diameter range were examined, and from the data sheets, the 1 inch diameter solenoid was chosen for its superior force rating at 0.215 inch stroke, based on data shown in Table 3 . These values were taken from the force-stroke diagrams at $10 \%$ duty cycle, which is the maximum that data was supplied for.

Table 3: Solenoid Forces at 0.22" Stroke and 10\% Duty Cycle

\begin{tabular}{|l|l|}
\hline \multicolumn{1}{|c|}{ Solenoid Size } & \multicolumn{1}{c|}{ Force $(\mathbf{l b f})$} \\
\hline 1 " diameter & 6 \\
\hline 0.75 " diameter & 2.5 \\
\hline 0.5 " diameter & 0.5 \\
\hline
\end{tabular}

A lower duty cycle (corresponding to a higher instantaneous power input) would increase the force further, but at the risk of burning up the solenoid. Because the 1 inch diameter model was able to fit inside the prototype blade, this model was chosen as the actuator. The data sheet for this solenoid can be found in Appendix A.

\subsection{Final Design Overview}

Based on the preliminary calculations and the simulation, a final design has taken shape. This design is known as the sliding gate valve, and consists of two gate sections that form a seal based on their relative positions, which in turn is determined by the actuation of a solenoid and a corresponding spring as a return mechanism. This valve is fully integrated within the blade section so that the upper and lower skin surfaces of the blade itself act as body of the valve. The air inlet is to be piped through the VAWT shaft and 
support members, eventually reaching the valve and the blowing slot, as described in Figure 21. Given the large orifice size compared to that of the blowing slots $\left(0.39 \mathrm{in}^{2} \mathrm{vs}\right.$. $0.08 \mathrm{in}^{2}$ ), maximum flow rate calculations were not performed because the $\mathrm{CC}$ is defined by the plenum pressure and the slot area; this valve was designed to function as if the system is entirely open when actuated.

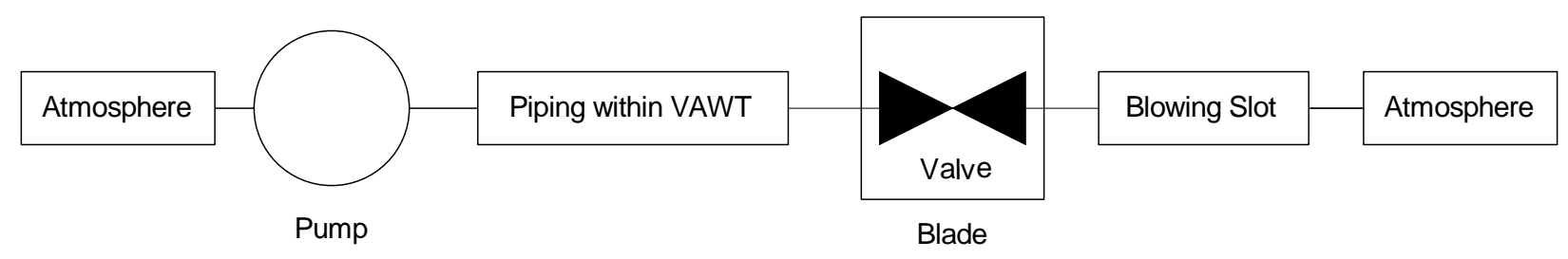

Figure 21: System Overview

A Pro/E rendition of the complete design within a blade section is shown as Figure 22. The air is supplied via the square span-wise support member, with the skin of the blade completing the valve body.

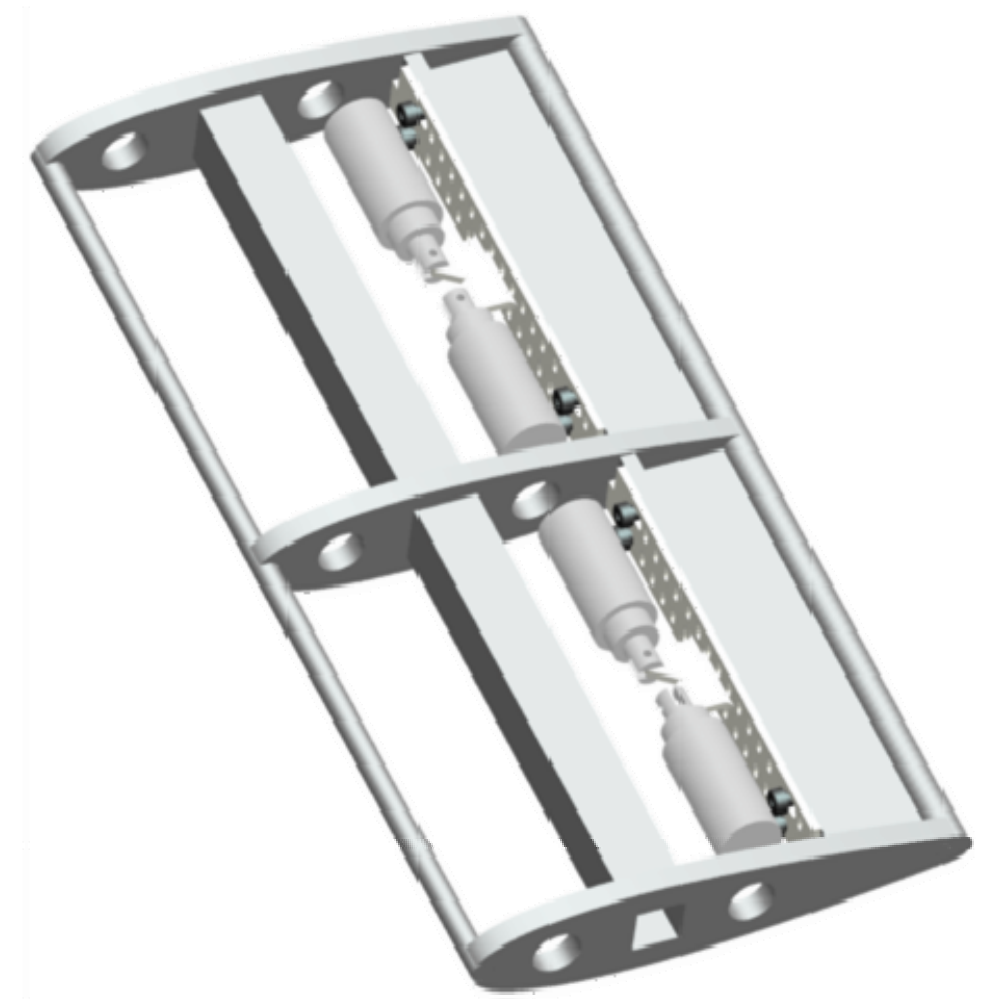

Figure 22: Final Sliding Gate Valve Design in Blade Section 


\section{Valve Testing Apparatus}

The sliding-gate valve design testing apparatus was built so that this valve design could be tested. This apparatus represents the first iteration of the sliding gate valve mechanism, and is intended as a "proof of concept" to see if the gate can indeed be actuated by the solenoid and returned via the spring under operating pressure (up to $20 \mathrm{psig}$ ), and to test the sealing of the PTFE (also known as Teflon ${ }^{\circledR}$ ) on aluminum gate sections. This apparatus was designed to be easy to fabricate and resemble the internals of the blade section as closely as possible, while readily allowing for any necessary valve modifications therein. The fully assembled testing apparatus is shown in Figure 23.

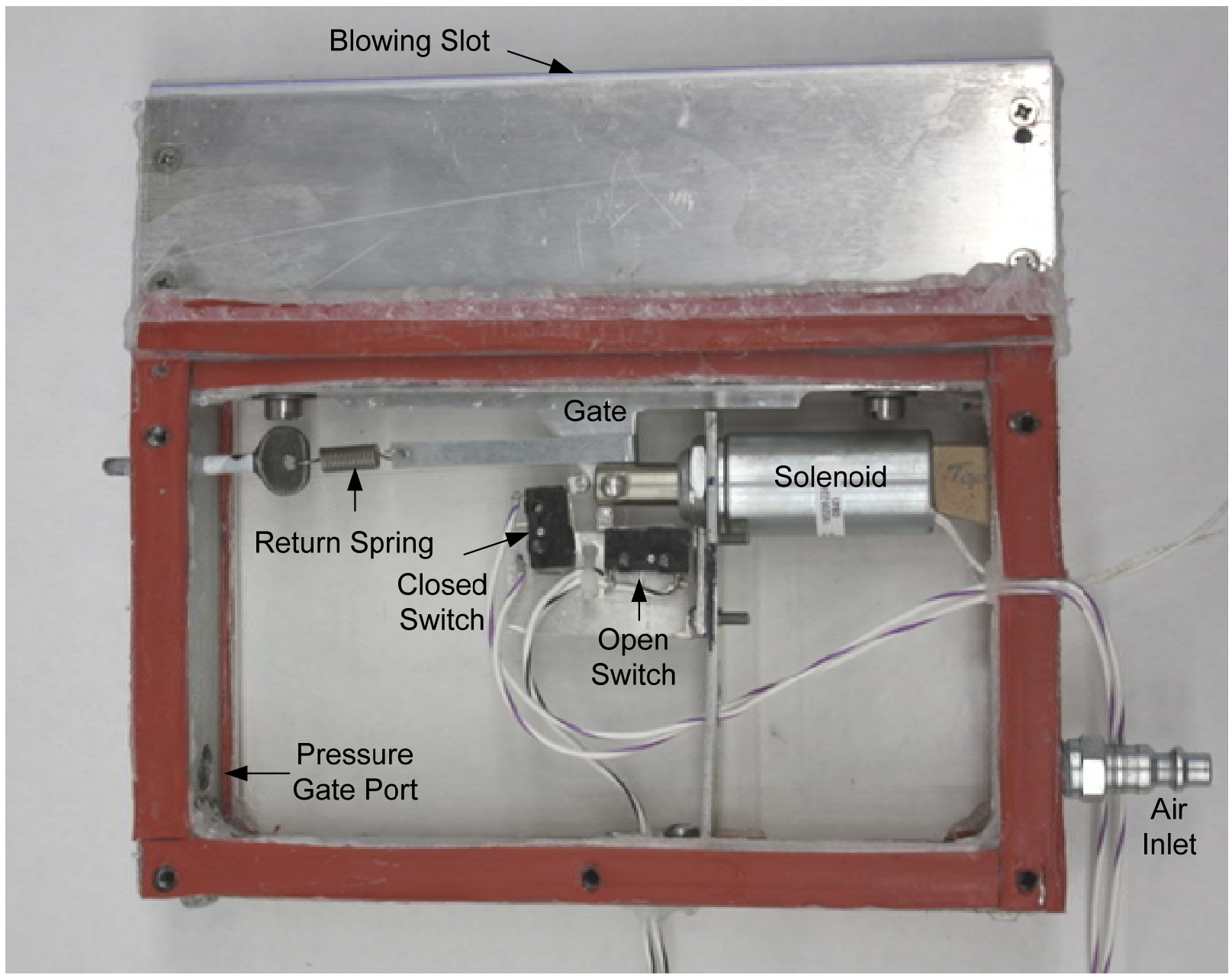

Figure 23: Testing Apparatus 
Aluminum was chosen as the primary material for ease of machining and likeness to the proposed final wind turbine blade. Only the upper blowing slot and valve were constructed because both the upper and lower valves are identical. The ribs and back plate was made from $1 / 2$ inch aluminum plate, welded together along with the $1 / 2$ inch diameter trailing edge to form the main structure. The fixed gate was made from $1 / 4$ inch aluminum and the slots were machined on a CNC mill. Next, 1/32 inch PTFE sheet was glued onto the fixed gate at the interface to reduce friction and provide a better seal. The sliding gate was made from 1/16 inch thick aluminum angle iron, also milled on a CNC mill. The sliding gate surface at the interface with the PTFE was also polished to reduce friction as much as possible.

The solenoid was mounted to the back plate via 3/32 inch sheet aluminum bent to form an L-bracket. The spring was mounted via a screw threaded into the rib section attached to the spring by way of a small piece of sheet metal. This end of this component was bent to form a hook that fit over the sliding gate section itself.

Plexiglas was used as the top and bottom covers so that the valve mechanism was visible during testing. This was to visually ensure that the design was functioning properly. These covers were attached via screws threaded into the body of the testing apparatus. A silicone rubber sealant was applied at this interface to prevent leakage. Finally, two 1/4 inch holes were drilled and threaded into the rib sections: one for a pressure gauge; one for compressed air intake line.

The components used for the testing apparatus are described in Appendix B, and all machining was done in-house by the WVU Mechanical \& Aerospace Machine Shop.

\subsection{Experimental Setup}

In order to test the valve, an experimental test setup was devised. This includes position sensors within the apparatus as well as a power supply, digital oscilloscope, flow meter and all respective connections and electrical circuits. For testing the position of the gate during actuation and release, roller switches were fitted that engage when the gate is both fully open and fully closed. The solenoid was connected via a manual switch to a $28 \mathrm{~V}$ power supply in line with a rheostat and resistor, which allows the voltage to be varied 
between approximately $5 \mathrm{~V}$ and $28 \mathrm{~V}$. The circuit used for sizing the rheostat is shown in Figure 24

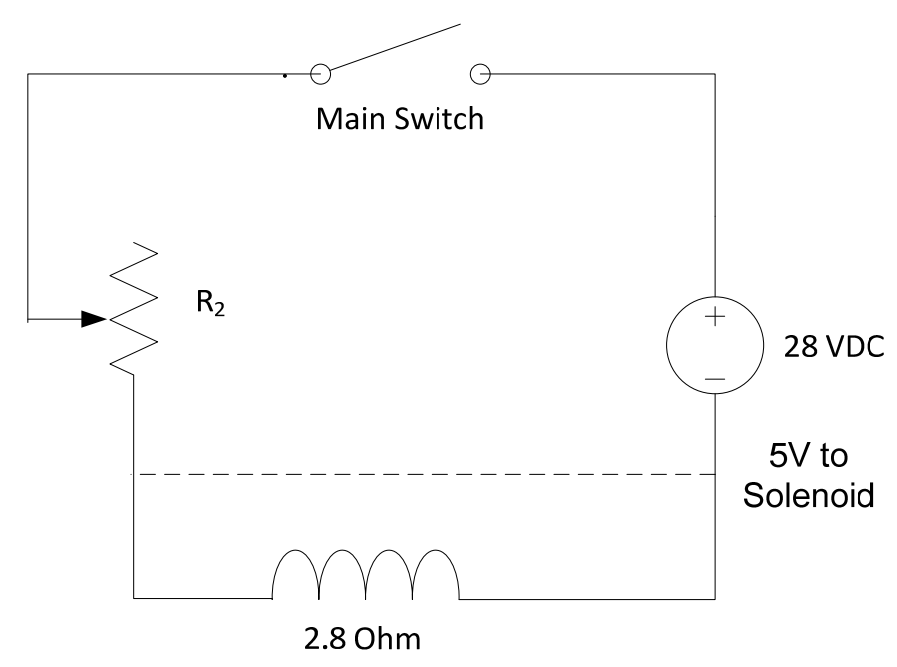

Figure 24: Circuit for Rheostat Calculation

Based on this circuit, Ohm's Law was used to calculate a rheostat resistance, as shown in Equation 4. This yields a resistance of $12.4 \mathrm{Ohms}$ for the rheostat.

$$
\begin{aligned}
& \frac{V_{0}}{R_{1}+R_{2}}=\frac{V_{\text {in }}}{R_{2}} \\
& \frac{27.2}{2.8+R_{2}}=\frac{22.2}{R_{2}} \\
& R_{2}=12.4 \Omega
\end{aligned}
$$

Equation 4

At the time of purchase no rheostat fit this specification, so an extra resistor was put in parallel (see Figure 25) in order to increase the total resistance to $35 \mathrm{Ohms.}$ 


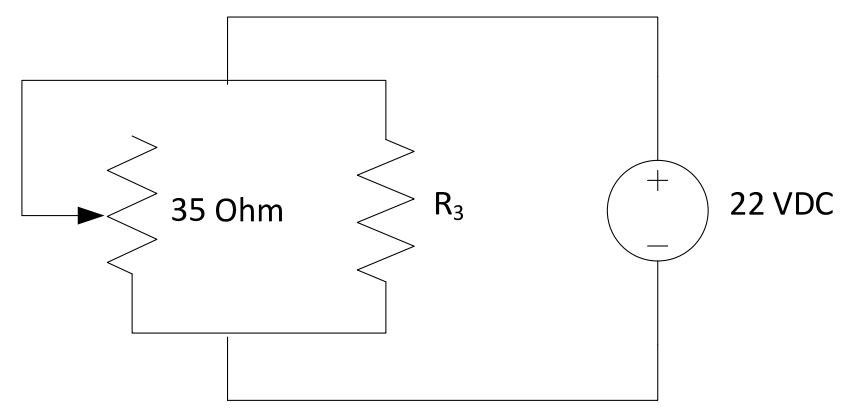

Figure 25: Circuit for Extra Resistor Calculation

From Ohm's Law, a $20 \mathrm{Ohm}$ resistor with a power rating of 25 Watts met the specification. These components make up the electrical testing circuit that allows the voltage to the solenoid to vary incrementally.

\subsection{Response Time Testing}

A digital oscilloscope was set up to monitor 4 channels: the VALVE OPEN switch (1), the VALVE CLOSED switch (2), the voltage across the solenoid and the shunt resistor (3), and the voltage across the shunt resistor (4). From the digital oscilloscope, the time delay between the solenoid receiving power and the time until the VALVE OPEN switch was triggered represents the response time of the valve while opening. The time delay between the solenoid receiving zero power and the time until the VALVE CLOSE switch was triggered represents the response time while closing. Subtracting the voltage readings between channels (3) and (4) gives the voltage drop across the solenoid, and through Ohm's Law the current through the solenoid can be calculated from the voltage readings of channel (4). A schematic of the testing circuit is shown in Figure 26. Figure 27 shows a picture of the testing apparatus with the electrical test setup. With this setup, the response times at varying voltages and pressures can be measured. 


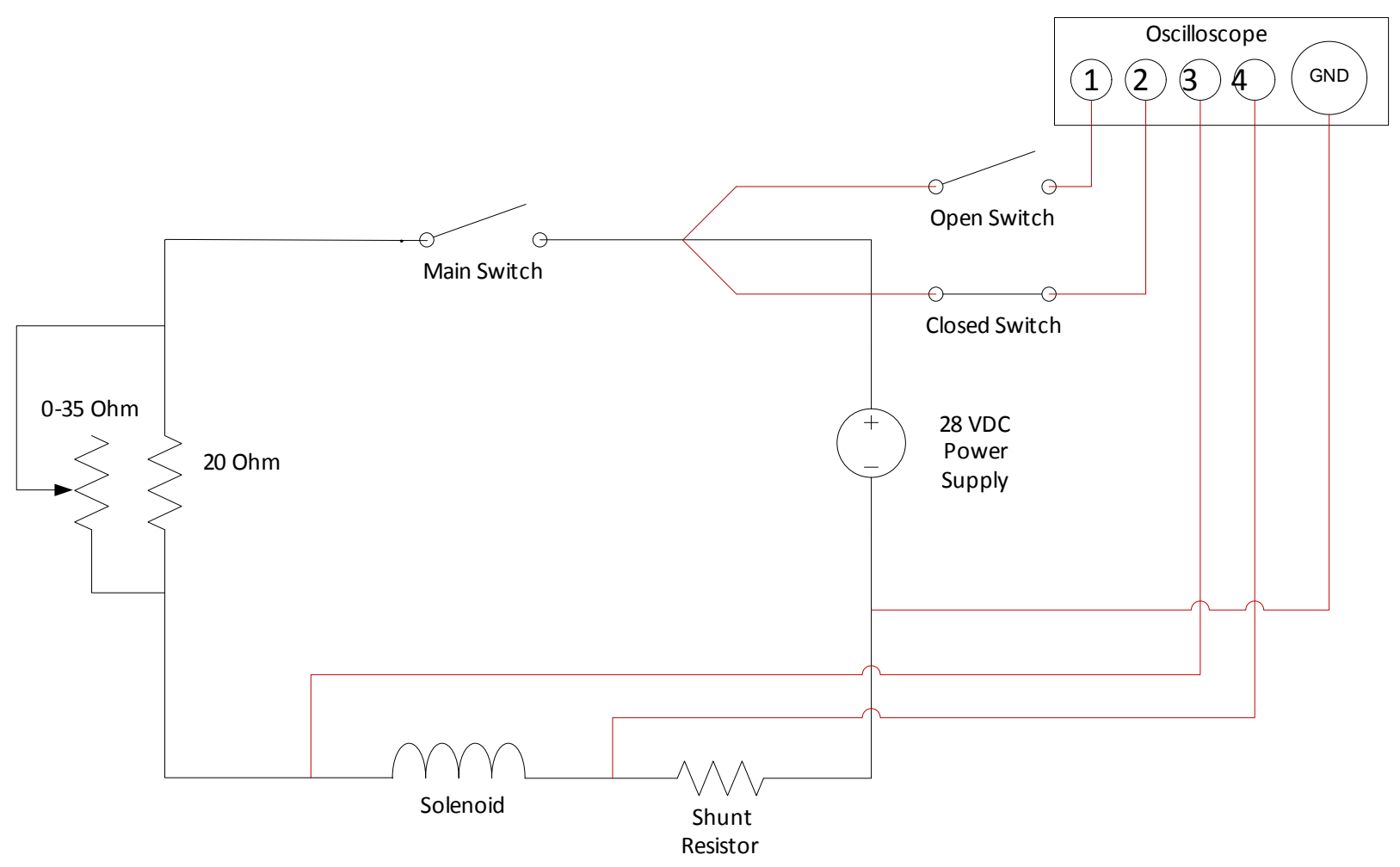

Figure 26: Circuit Diagram of Test Setup

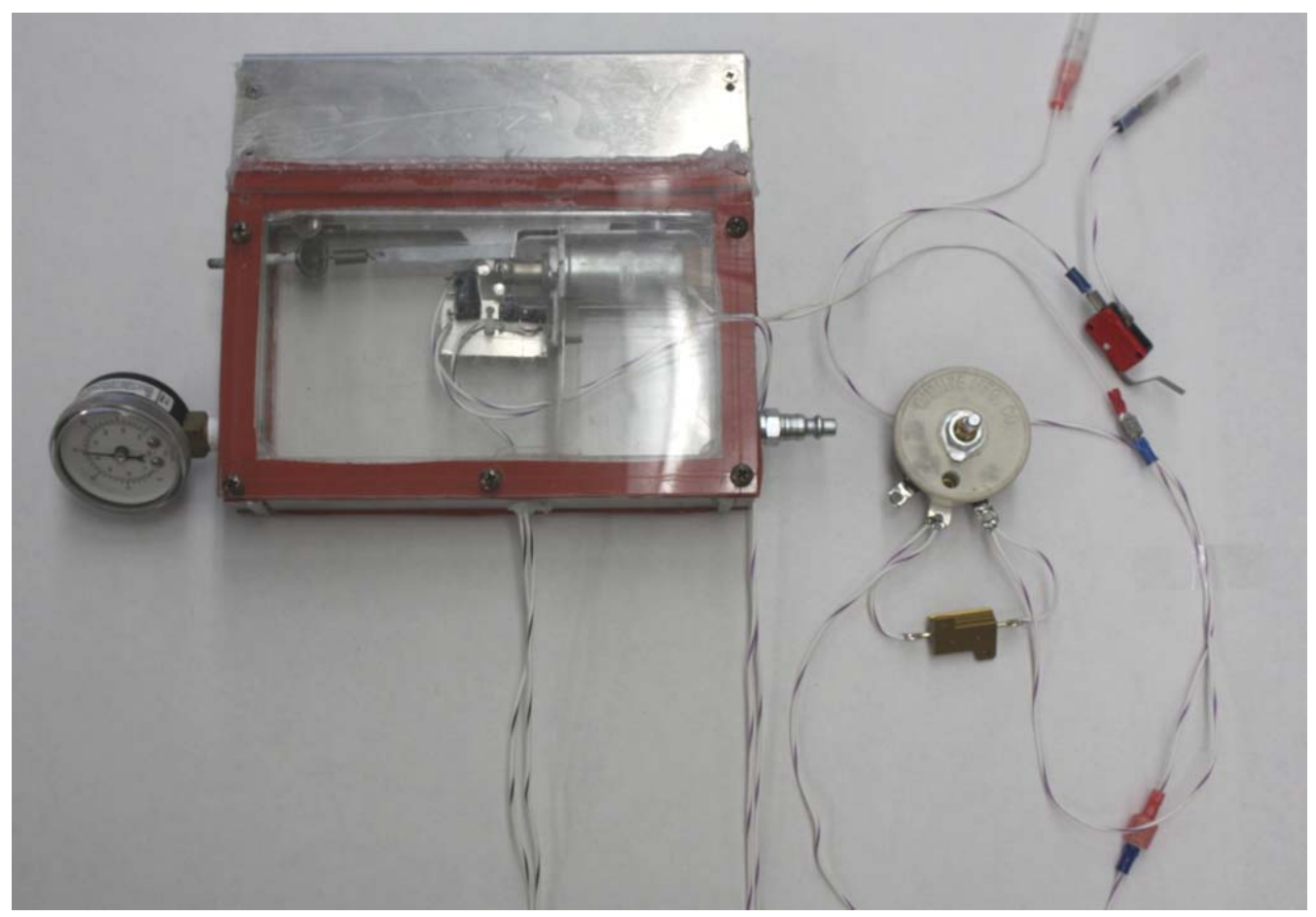

Figure 27: Test Setup 


\subsection{Power and Force Testing}

For varying plenum pressures (0-20 psig), the minimum power required to actuate the valve was recorded. Because the voltage and the current through the solenoid were measured, the power draw of the solenoid can be calculated. This experiment allows the minimum power to be calculated, as well as any other voltage that may be required to achieve an acceptable response time.

From the power requirements at varying voltages and plenum pressures, the actual forces required to open the sliding gate can be extrapolated. This is done using the manufacturer supplied curves that plot force versus stroke at various duty cycles.

\subsection{Leakage Rates}

The air input line was outfitted with an inline flow meter so that the leakage through the closed valve could be measured. The line was fitted with a regulator, a flow meter, an on/off valve and a 1/4 inch NPT quick connect that attaches to the testing apparatus itself. The complete setup is shown in Figure 28. Under various plenum pressures, the pressures on the intake of the flow meter and the flow rate (SCFM) were noted. This represents the leakage through the closed valve. The complete test setup is shown in Figure 29.

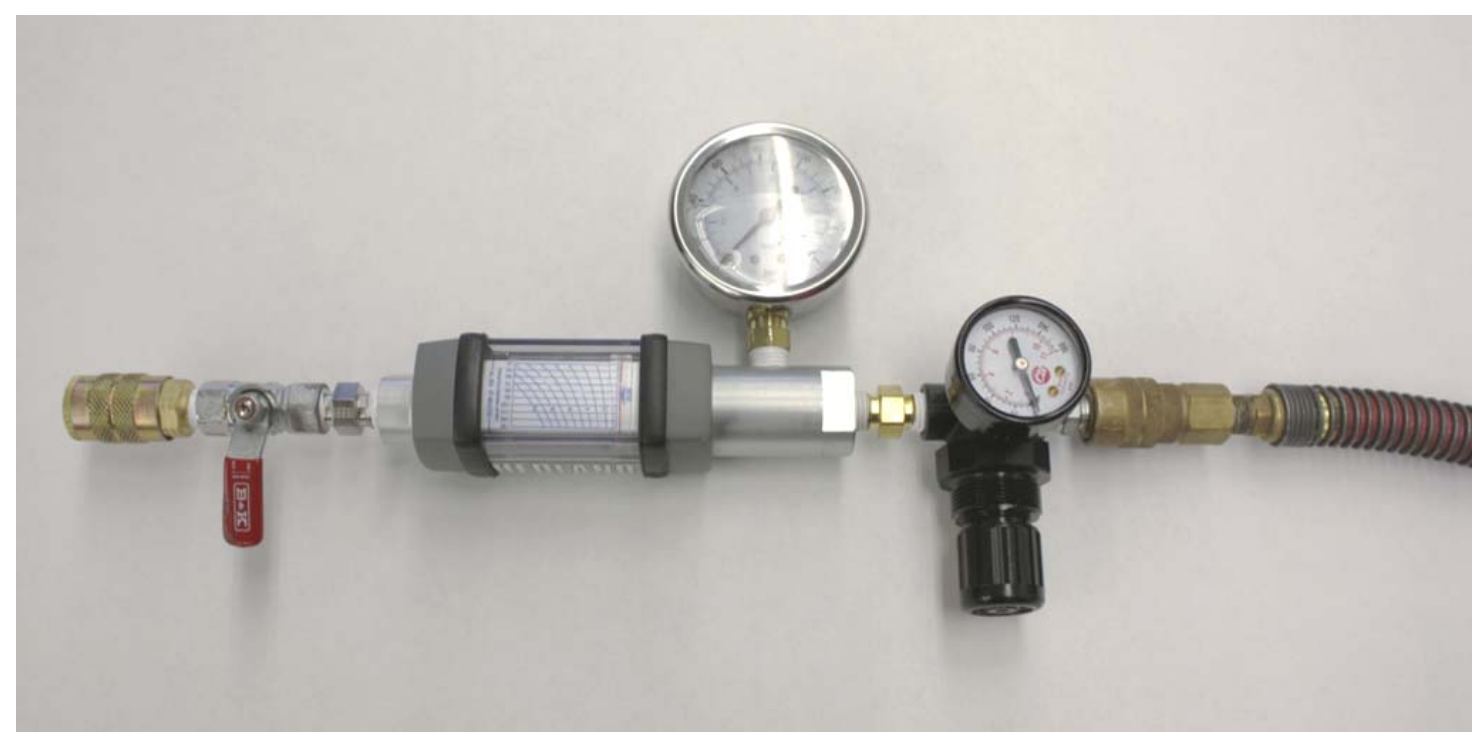

Figure 28: Air Flow Test Setup 


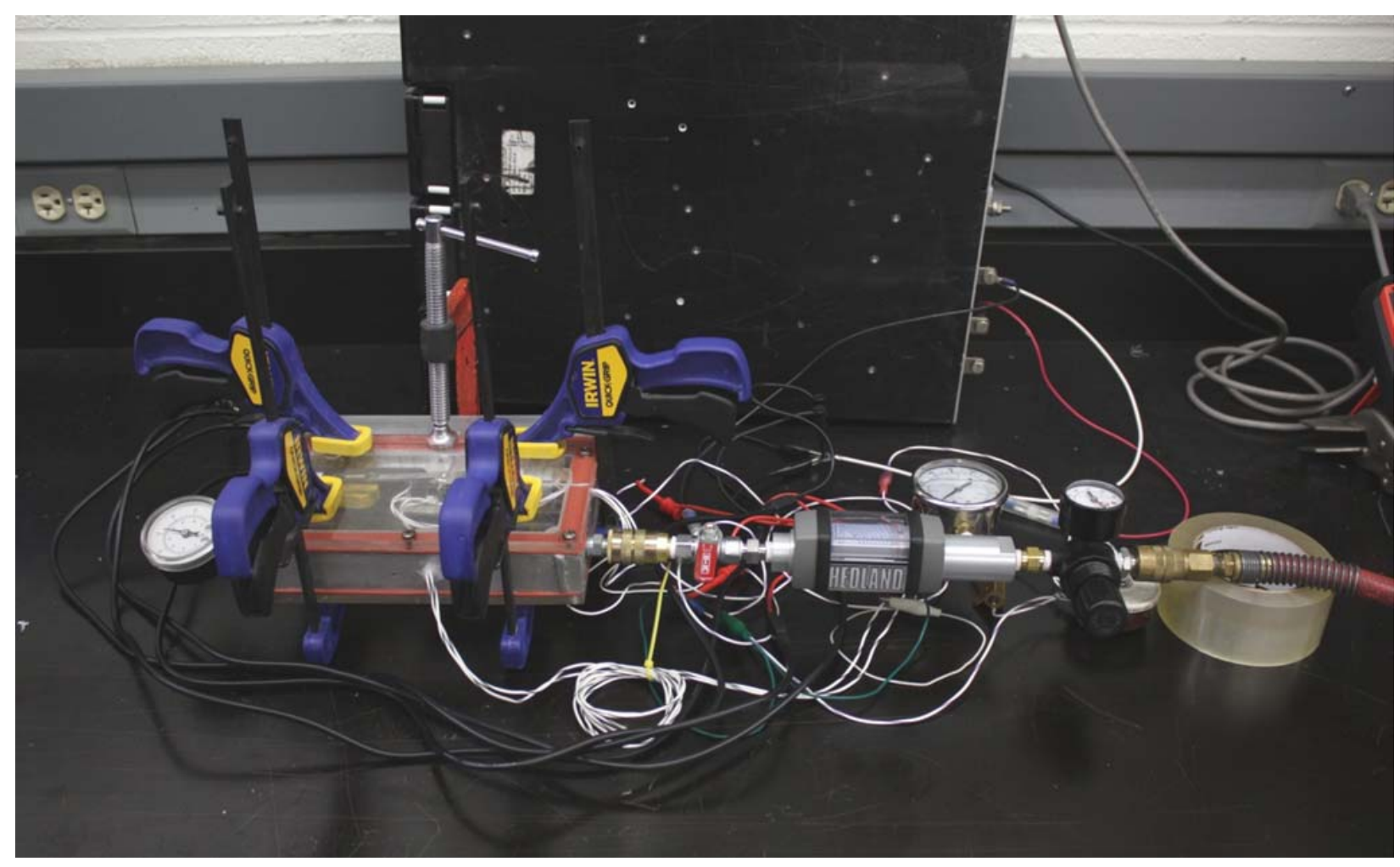

Figure 29: Complete Test Setup 


\section{MATLAB/Simulink Model}

Using the specified valve components, a computer model was created using the Simulink modeling package with MATLAB. All of the necessary blocks to model the sliding gate valve were included in the Simscape toolkit, which allows detailed modeling of a broad range of electromechanical systems. A model was created in order to test the response time and forces as the valve opened and closed, as shown in Figure 30. This model was intended to verify the response time and force data obtained from the testing apparatus as well as provide a way to simulate different components (actuators, springs, power supplies, etc.) quickly and without having to build a full model.

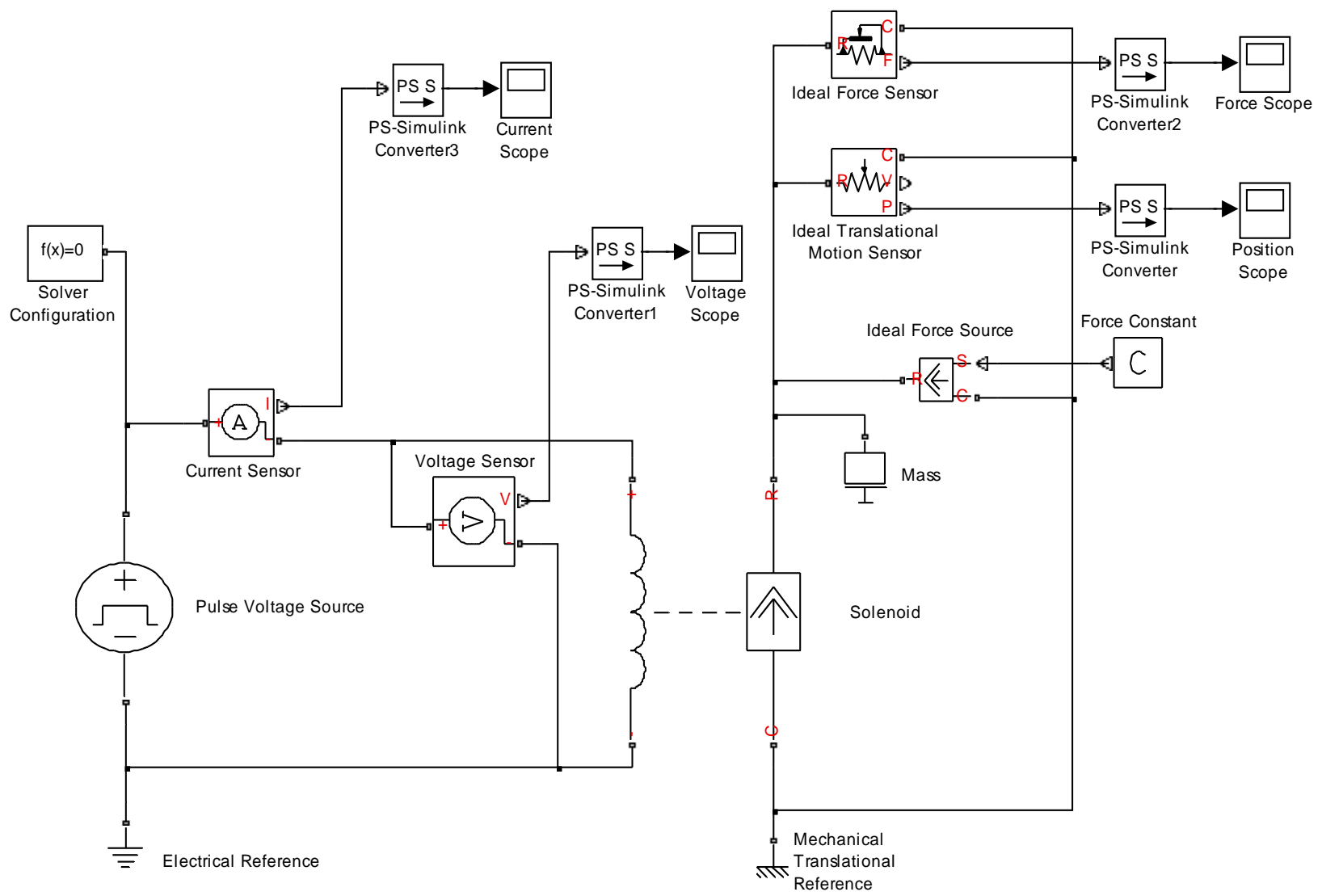

Figure 30: Simulink Model of Sliding Gate Valve

In this model, the circuit on the left represents the electronic circuit supplying power to the solenoid. A pulse voltage source was used to generate an ideal voltage for a specified amount of time and then turned off, which represents the on/off action of the solenoid. Current and voltage sensors were also added in order to monitor these 
characteristics. The circuit on the right represents the mechanical circuit, with a solenoid and spring (whose parameters are in the solenoid block), a mass block and an ideal force block, which represent the weight of the gate and the force due to pressure acting on the gate, respectively. The individual block components are summarized in Table 4.

Table 4: Simulink Component Glossary

\begin{tabular}{|l|l|}
\hline \multicolumn{1}{|c|}{ Simulink Component } & \multicolumn{1}{c|}{ Description } \\
\hline Current Sensor & Measures current \\
\hline Electrical Reference & Electrical ground for circuit \\
\hline Force Constant & Sets value for Ideal Force Source \\
\hline Ideal Force Sensor & Measures force \\
\hline Ideal Force Source & Simulates force due to pressure on gate \\
\hline Ideal Translational Motion Sensor & Measures linear motion \\
\hline Mass & Inertial mass of gate and connection pin \\
\hline Mechanical Translation Reference & Reference for linear motion \\
\hline PS-Simulink Converter & Converts physical signal to output signal \\
\hline Pulse Voltage Source & Power supply for solenoid \\
\hline Scopes & Show output signal \\
\hline Solenoid & Electromechanical actuator \\
\hline Solver Configuration & Parameters for simulation solver \\
\hline Voltage Sensor & Measures voltage \\
\hline
\end{tabular}

Next, all of the necessary parameters (solenoid data, mass, force, voltage etc.) were inputted in each of their respective Simulink blocks. A single test consists of setting the desired voltage and force (representing pressure) and noting the output of the scopes. Each of the parameters can be varied to represent different operating conditions. The results of the simulations are presented in the following chapter and compared to the experimental testing results. 


\section{Results}

With the test setup in place, the response times at varying voltages and pressures were measured, along with the voltages and currents to the solenoid. These values were compared with data produced by the Simulink model for a broad range of conditions. By looking at the minimum power that would still open the solenoid, the forces required to open the valve could be inferred and compared to the initial calculations and the predicted forces from the Simulink Model.. The leakage rates for the closed valve were also tested, as outlined in the previous section. The results of the testing are shown in this chapter, and the full data set is given as Appendix C.

\subsection{Response Time}

The response time to open the valve varies as a function of pressure and voltage. At higher pressures, the response is slower for a constant voltage, and at constant pressure, response is faster for a higher voltage. The response times to open the valve are shown in Figure 31 at a few different pressures. Note that the response times decrease rapidly as the voltage increases after the minimum actuation voltage, but then levels off.

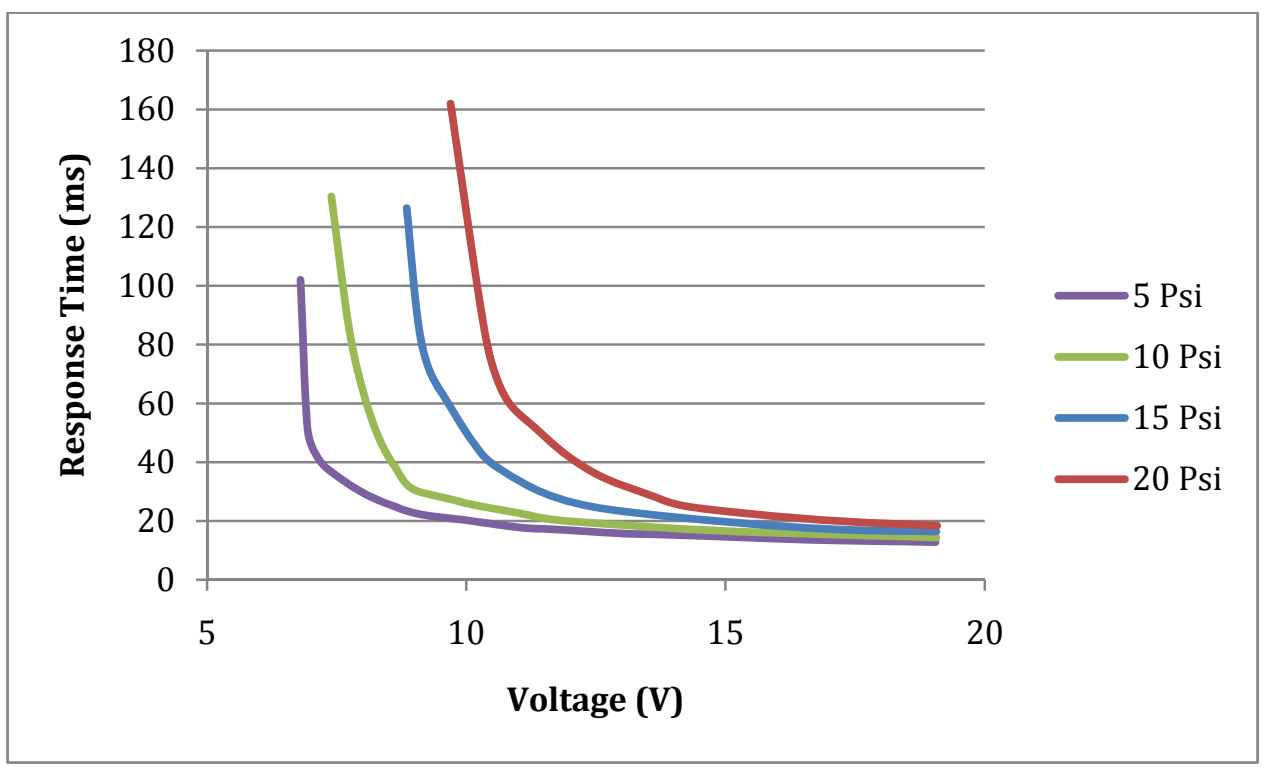

Figure 31: Experimental Response Time at Varying Pressures 
Next, the experimental response time data was compared to the Simulink simulation data for pressures $0,5,10,15$ and 20 psi. The results are shown in Figure 32.
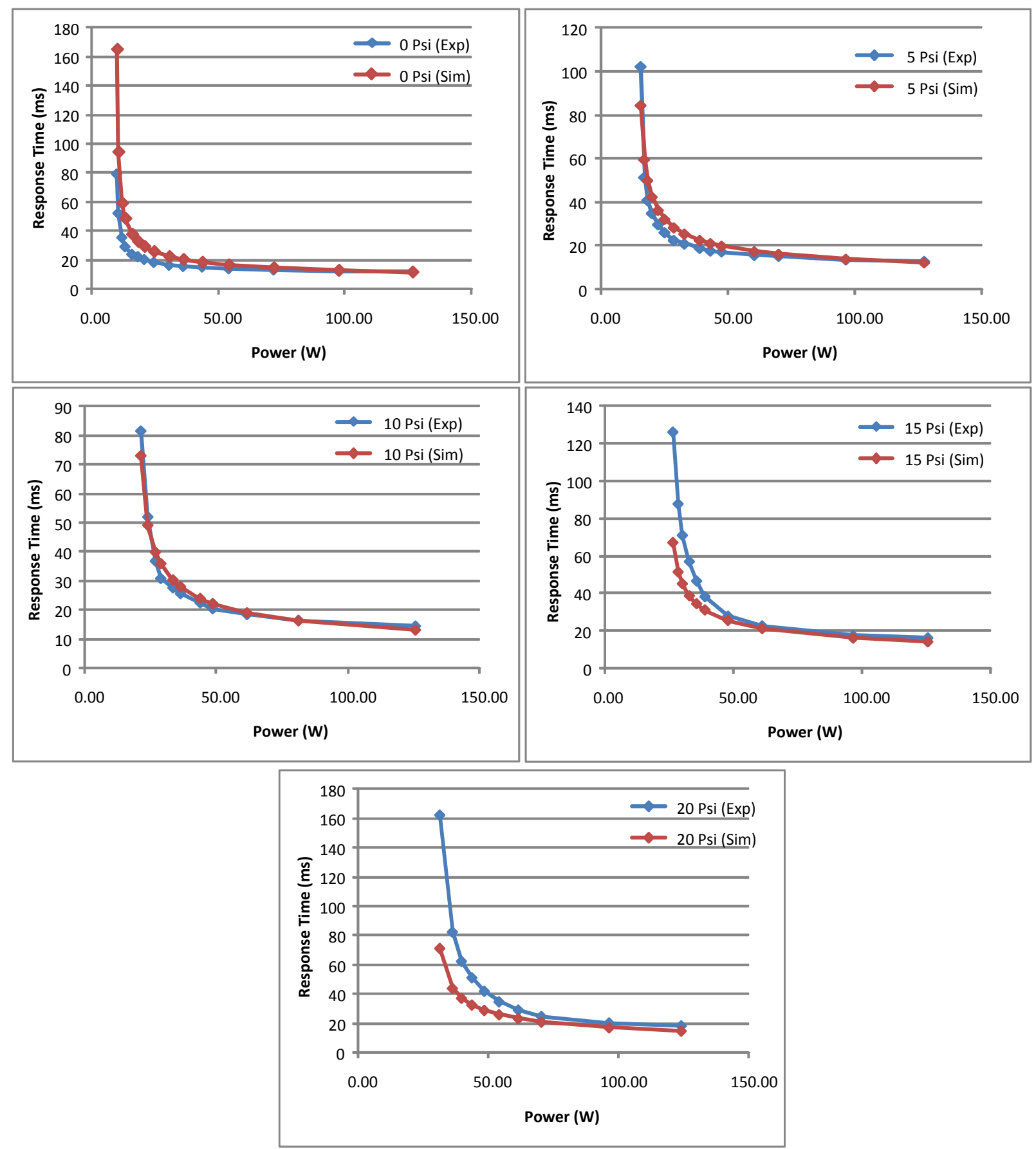

Figure 32: Experimental vs. Simulink Response Time Data for 0-20 Psi

From these curves, the Simulink model follows the similar trends as the experimental data. The relative percent error between the two data sets is shown in Figure 
33. The 5 psi and 10 psi data sets were the closest in agreement, while the other data sets showed less agreement, especially at low power. This is consistent with the system as a whole because small changes in power at low power cause large variation in response time. The solenoid will not typically operate at such low power conditions in order for the response time requirement to be met (less than $50 \mathrm{~ms}$ to open). At higher power levels the relative error is reduced.

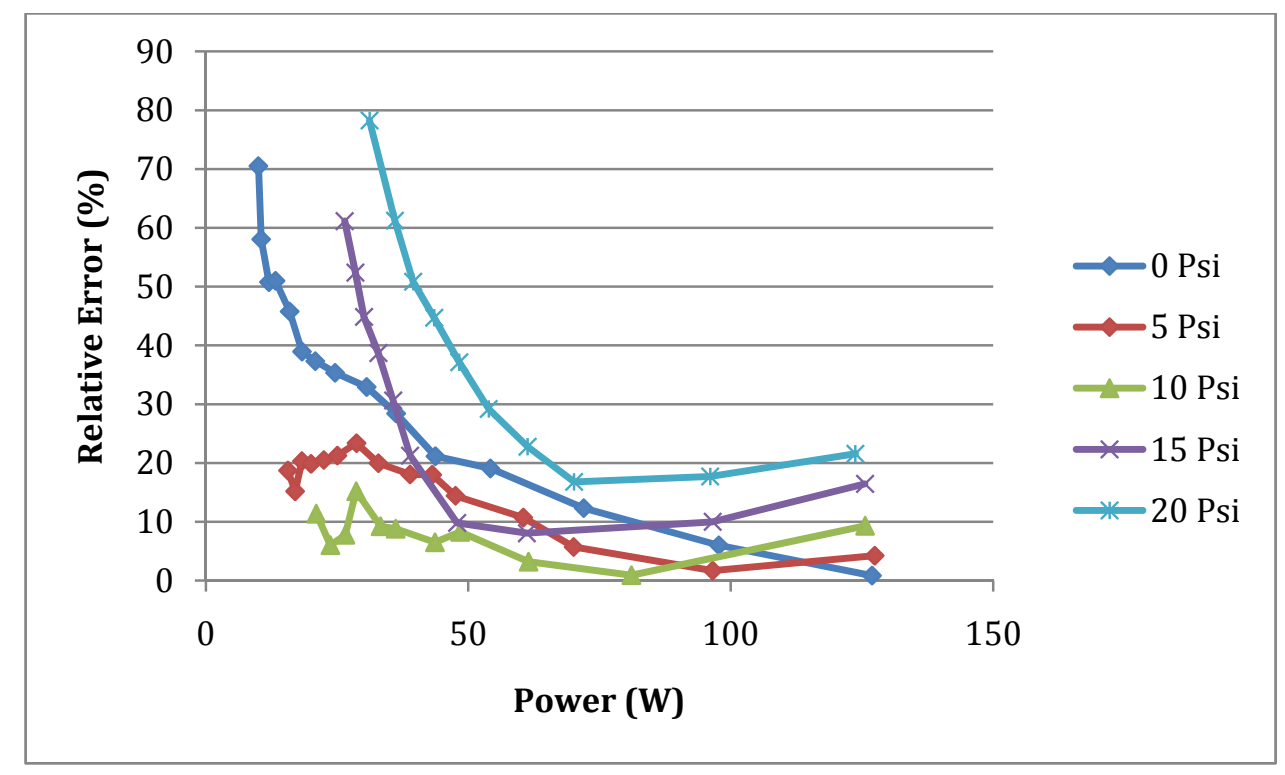

Figure 33: Relative Error of Experimental vs. Simulation Data

The response times to close the valve were consistent across all pressures and input voltages, and were always in the 11-15 ms range, with an average of $13.4 \mathrm{~ms}$ for all tests. For higher pressures and higher voltages, the return time was closer to $15 \mathrm{~ms}$, which is logical because the increased resistance due to pressure in the plenum when the valve is attempting to close (which is always lower than the set point for the closed valve). Also, the more power given to the solenoid the stronger the magnetic field, which in turn takes slightly longer to dissipate before the return mechanism takes over.

\subsection{Minimum Power}

From the response time data, the power required can be inferred from the solenoid data sheet. This plot has been recreated and is shown as Figure 34, with the black vertical line representing a stroke of 0.215 inches. 


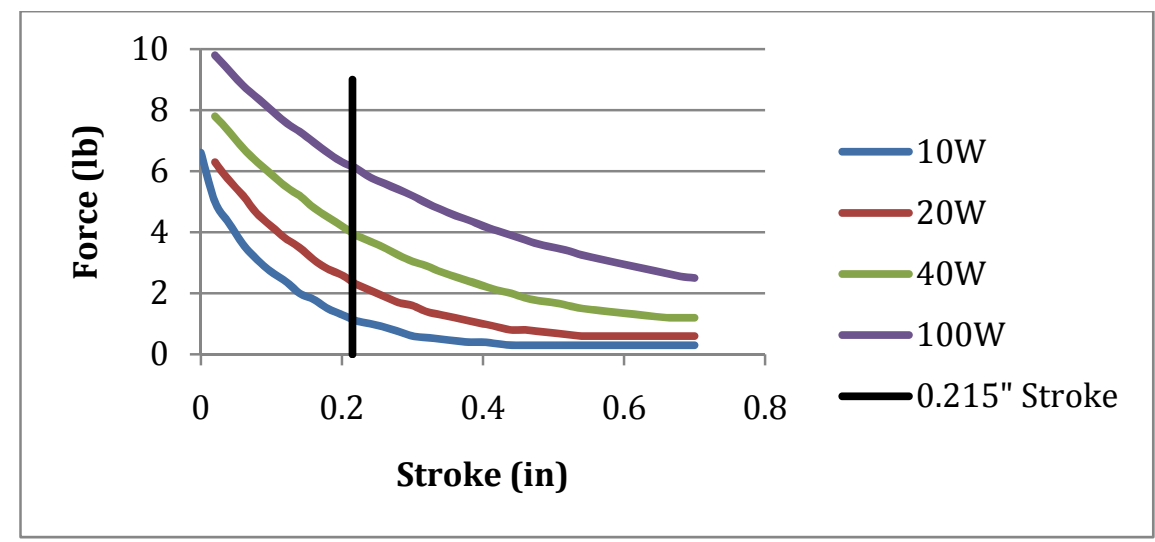

Figure 34: Solenoid Force vs. Stroke Curve

Next, the minimum power required to actuate the valve at each pressure was plotted along with the Simulink data for the minimum opening power as shown in Figure 35. The deviation from a true linear fit is due to experimental testing error, most likely from the difficulty in finding the true minimum power that would actuate the valve. This error was quantified for the minimum opening conditions by calculating the percent relative error between the first two collected data points. This represents the minimum achievable change in power that could be controlled by the rheostat. This error amounted to $3.96 \%$. Note that pressures 1-4 psig were not included because the valve would not seal as these pressures.

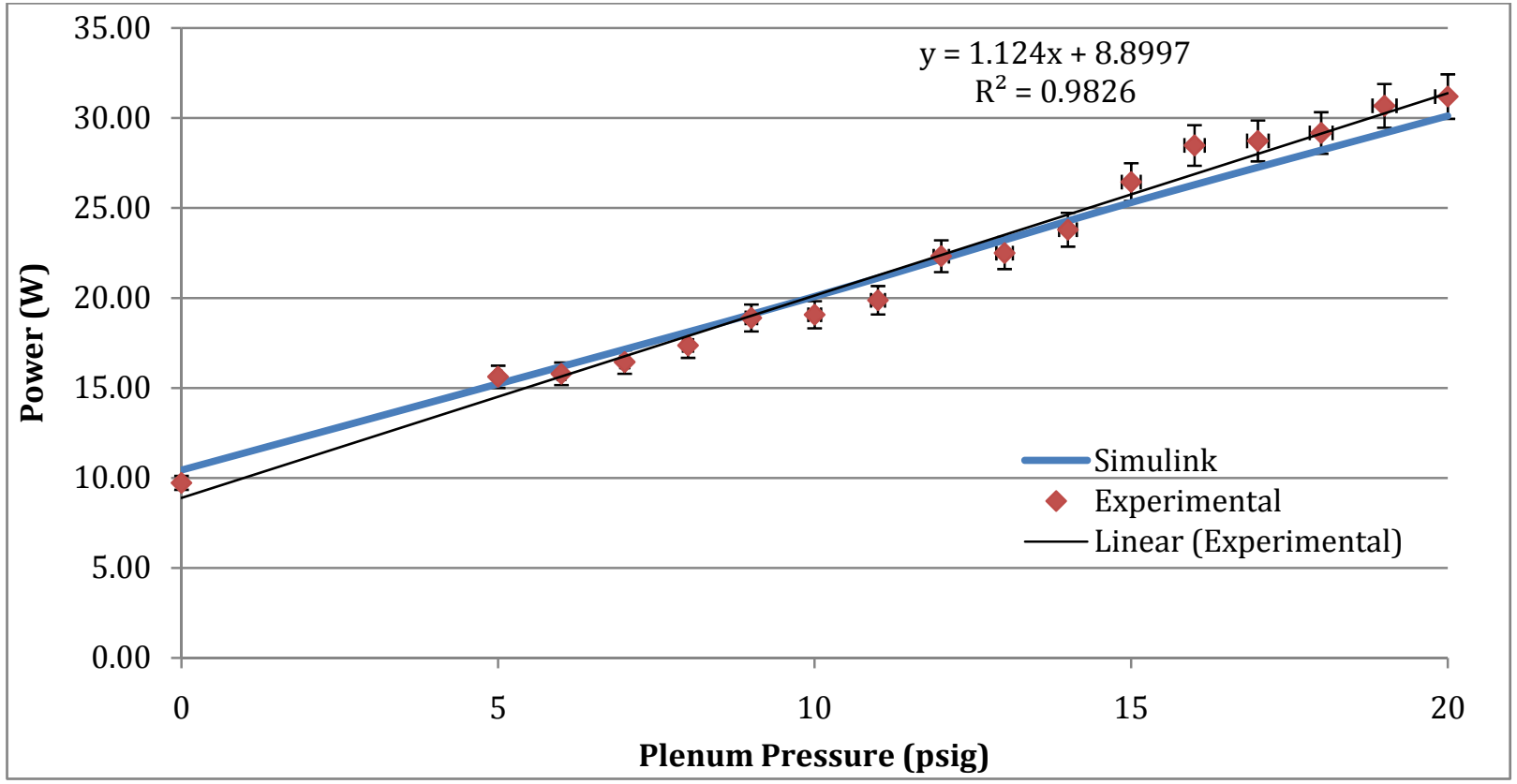

Figure 35: Minimum Actuation Power at Varying Pressures 


\subsection{Force Required to Open}

From Figure 34 (manufacturer's force-stroke curve), a best-fit line was applied to the four intersecting points that represent four power-force points at 0.215 inch stroke. From this, the forces at varying voltages could be interpolated, as shown in Figure 36.

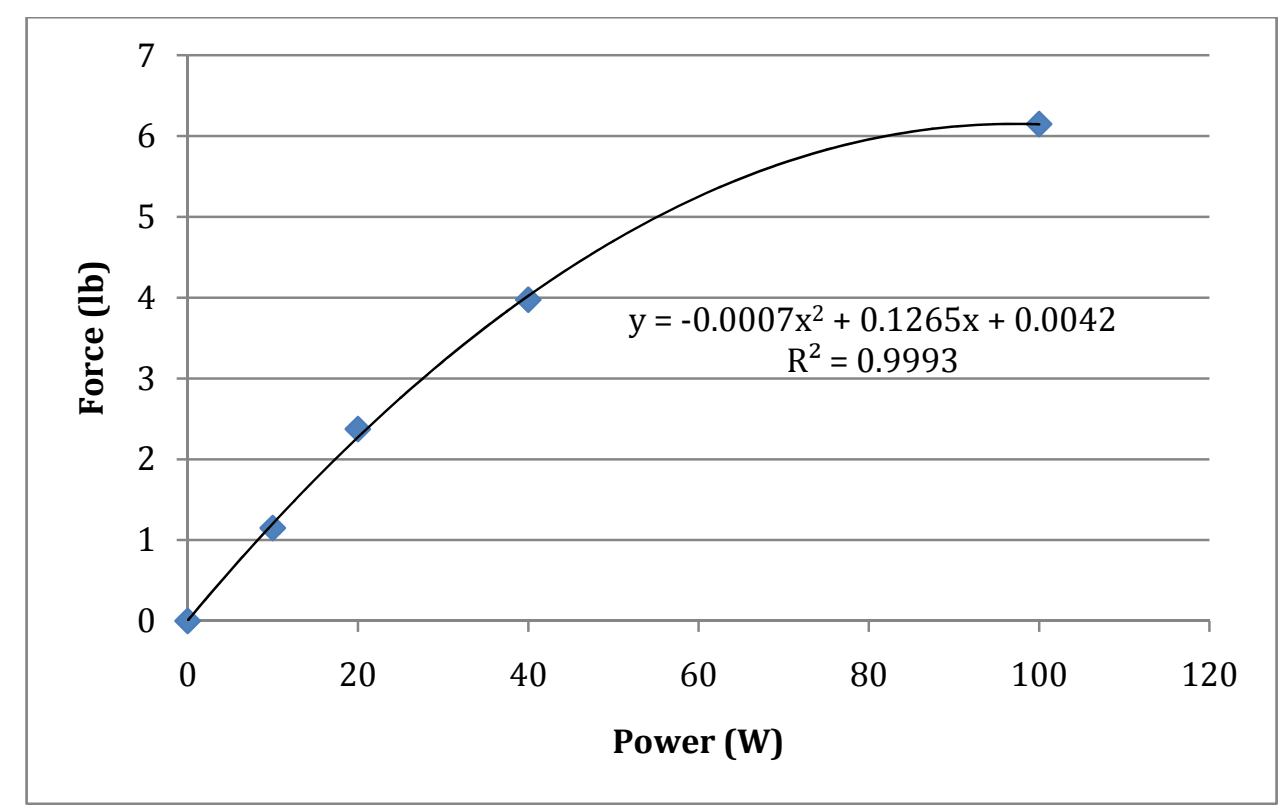

Figure 36: Interpolated Force vs. Power at 0.215" Stroke

Once the forces produced at each power level could be interpolated, the actual forces produced by the solenoid in the valve were inferred. Figure 37 shows the total force that must be overcome to open the valve, which includes the spring, an inertial load due to mass and frictional forces due to pressure. Also included in this plot are the minimum forces as predicted by the Simulink model for each of the pressures. The relative error is the same as for the minimum actuation power at 3.96\%. 


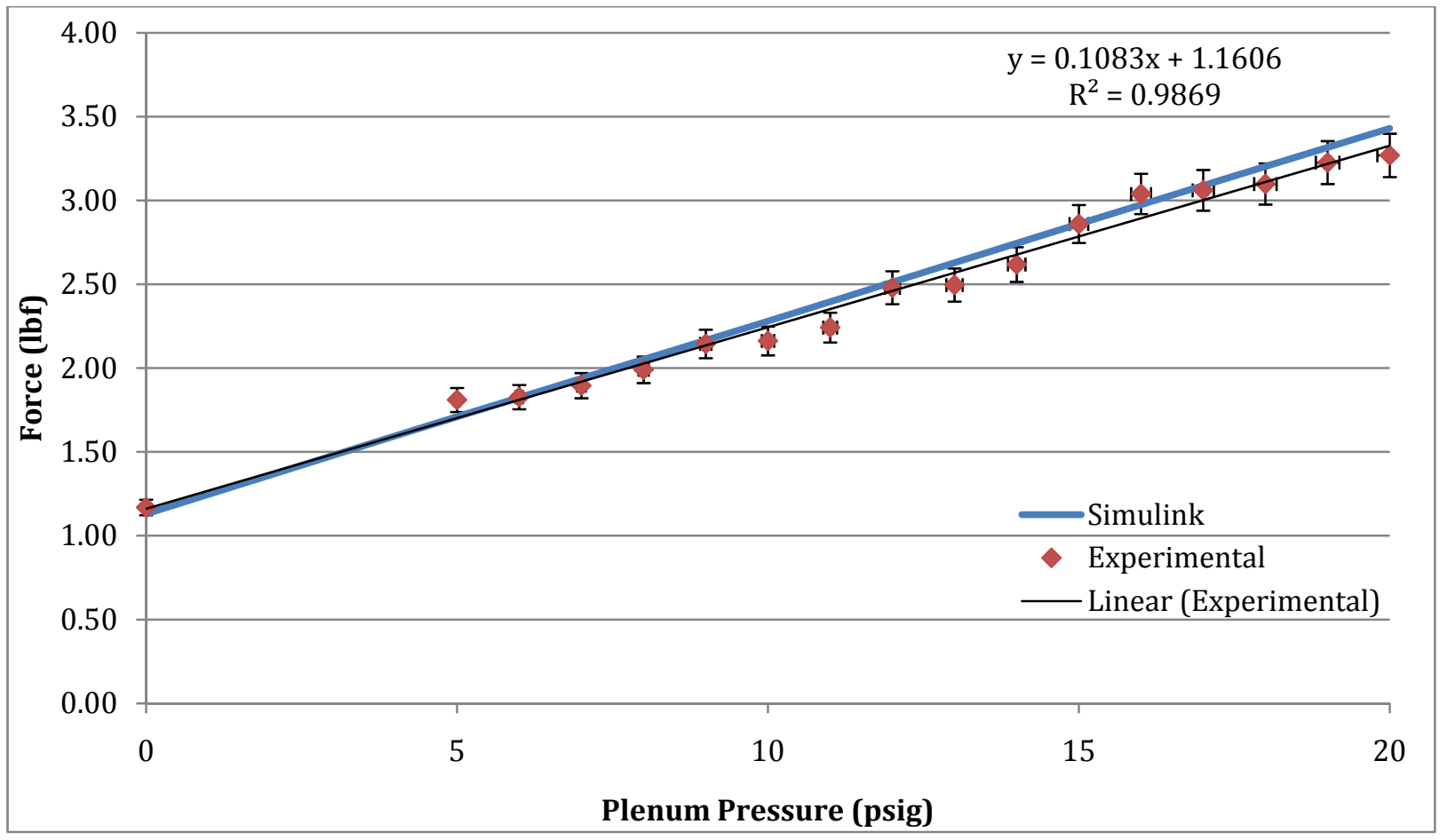

Figure 37: Actuation Force Required at Varying Pressures

The predicted force from the Simulink model at the minimum power that would actuate the valve was also calculated, and the results of all of the force measurements are shown in Table 5.

Table 5: Predicted vs. Measured Minimum Forces at 20 Psig

\begin{tabular}{|l|l|}
\hline Force (Predicted) & $3.45 \mathrm{lb}$ \\
\hline Force (Inferred from power data) & $3.27 \mathrm{lb}$ \\
\hline Force (Simulink Model) & $3.43 \mathrm{lb}$ \\
\hline
\end{tabular}

Once the forces required at each pressure were know, a friction coefficient between the sliding gate and the fixed gate (PFTE and aluminum interface) was calculated. The average friction coefficient for pressures $0-20$ psig was 0.037 . This value agrees closely with the initial assumption of 0.040 from the literature.

\subsection{Leakage Through Closed Valve}

The leakage through the closed valve was plotted at various pressures, and shown in Figure 38. The data starts at $2 \mathrm{psig}$, and decreases up to about 4 psig before increasing 
again. This verifies the previous statement that the valve did not seal properly before about 5 psig. At 15 psig, the leakage was around 4 CFM, which is approximately $11 \%$ of the full value at this pressure (assumed to be $35 \mathrm{CFM}$, as previously stated). This is beyond the specified amount, and the seal should be further refined before use in a prototype wind turbine. The error in this experiment is $3 \%$ based on the errors of the flow meter and the gauges used.

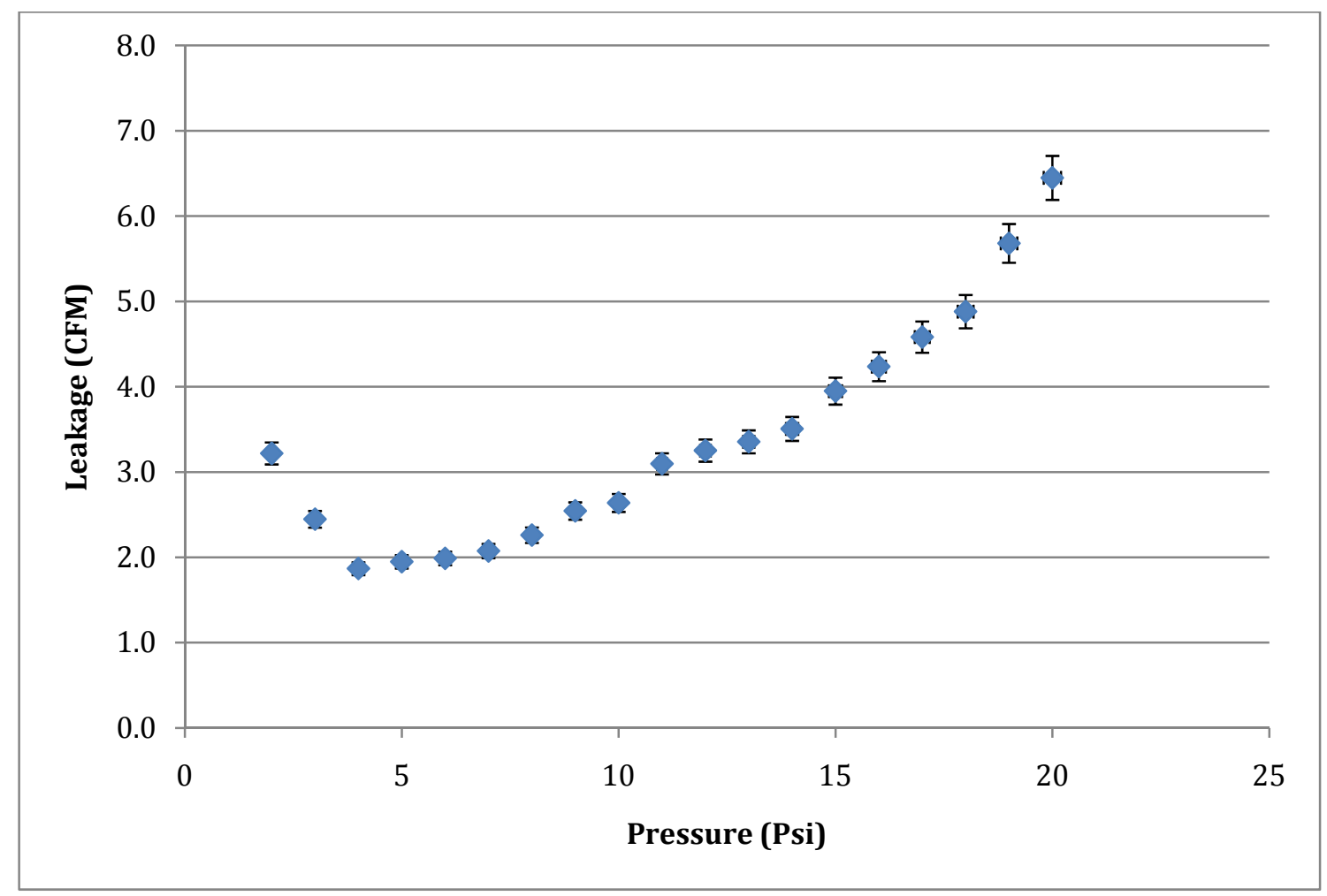

Figure 38: Leakage at Varying Pressures

\subsection{Fatigue and Wear Analysis}

As with any mechanical system, the longevity of the components must be taken into account. Of the custom-designed components of the sliding gate valve design, only the sliding gate itself is subjected to a cyclic load, and therefore fatigue. The solenoid also has a limited lifetime, and will be explored as well. In order to quantify this, a finite element analysis (FEA) study was done with the part in Pro/E Mechanica. With a loading of $3.45 \mathrm{lbf}$ at the pin, the highest stress observed was $634 \mathrm{psi}$ (compression), and with $1.15 \mathrm{lbf}$ on the 
pin in the opposite direction 214 psi (tension) was observed. Figure 39 shows the von Mises stress distribution, with an arrow pointing at the location of maximum stress.

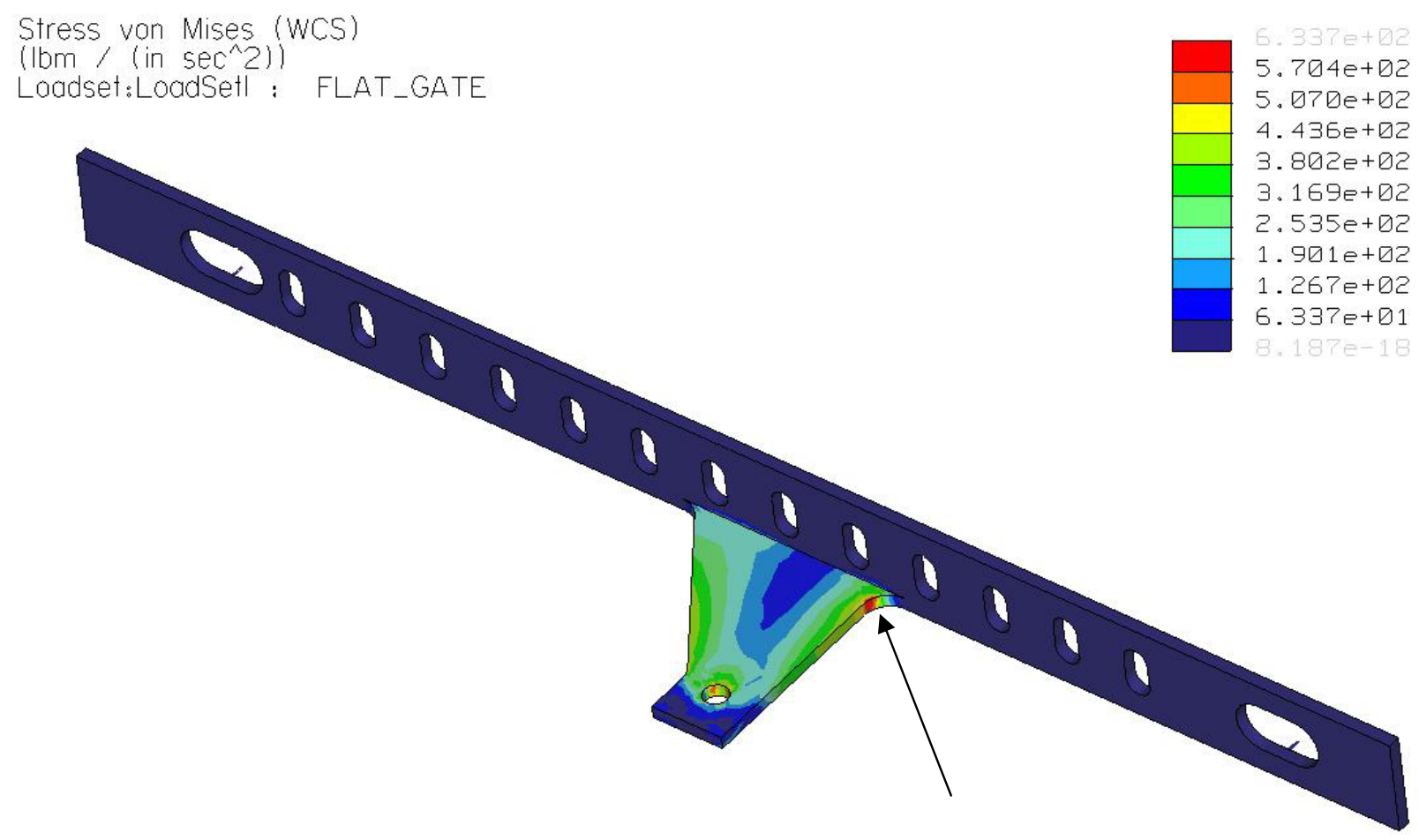

Figure 39: Von Mises Stress Distribution

According to Collins, the equivalent mean stress was calculated to be $424 \mathrm{psi}$, which can then be used for the fatigue analysis. A modified S-N curve was plotted based on 99\% reliability, which yielded Figure 40 . The black line represents S-N curve, with the red line representing the equivalent mean stress on the part. The intersection of these lines represents the cycles until failure for this loading. 


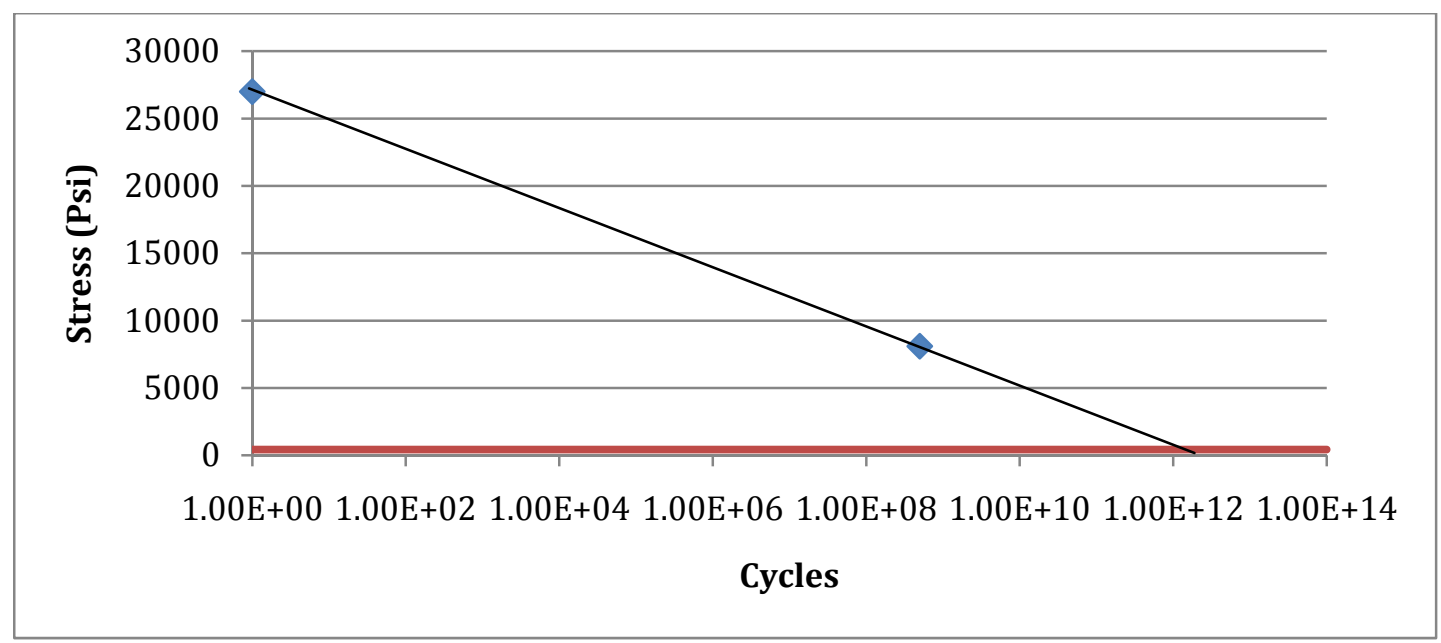

Figure 40: S-N Diagram Aluminum

Based on the lifetime (on the order on 1012), this part's life can be assumed to be infinite. The exact calculation for a 100\% operational cycle at 100 cycles per minute (upper limit for rotational speed) yields 19000 years of life; is it the author's belief that the S-N analysis according to Collins was not meant for such low equivalent mean stresses, and by any account, the fatigue on the sliding gate component is not a limiting factor for this design.

The specified solenoid has an expected life of more than 25 million cycles as long as the manufacturer's recommended duty cycle guidelines are followed. This allows the use of very high voltages, but only for non-continuous use; it is envisioned that the control scheme will ensure that this parameter is met. Table 6 shows the estimated lifetime of the solenoid for varying wind turbine rotation speeds and CC duty cycles, which refers to the percentage of time that $\mathrm{CC}$ is on and the valves are actuating once per revolution.

Table 6: Estimated Solenoid Lifetime

\begin{tabular}{|l|l|l|}
\hline \multicolumn{1}{|c|}{ RPM } & Duty Cycle & Life (yrs) \\
\hline 25 & 0.3 & 6.34 \\
\hline 25 & 0.5 & 3.81 \\
\hline 50 & 0.3 & 3.17 \\
\hline 50 & 0.5 & 1.90 \\
\hline 75 & 0.3 & 2.11 \\
\hline 75 & 0.5 & 1.27 \\
\hline 100 & 0.3 & 1.59 \\
\hline 100 & 0.5 & 0.95 \\
\hline
\end{tabular}




\section{Conclusions and Recommendations}

The sliding gate valve design represents a CC valve system for use in a VAWT. This design met all of the specifications with the exception of leakage. The response times are directly proportional to the power supplied to the solenoid, and for use on a wind turbine a compromise should be sought in an effort to increase total efficiency. The dynamics of the system were accurately modeled in Simulink, and based on the Simulink model, varying power inputs and pressures can be explored without the need to test each one.

The leakage through the closed valve is of concern and should be further investigated. The PTFE on aluminum interface of the gates was assumed to create an airtight seal, but irregularities in the surfaces prevented this from occurring. One possible solution would be to fabricate a labyrinth seal at the interface to prevent air from entering over the top and under the bottom of the gate; this would likely increase the friction force due to the increase in area at the seal. Another solution is to make the total slot area smaller; the total area of the slots were designed to be as large as possible and easy to machine, but perhaps at the expense of increased leakage.

The flow characteristics of the valve could also be further explored, e.g. maximum flow rate, valve flow coefficient and velocity profile at the blowing slot. For this thesis it was sufficient to make the valve as transparent as possible (while open), meaning that the flow is dictated by the inlet pressure, the blowing slot height and other factors rather than any design characteristic of the valve itself. 


\section{References}

Amelio, A. F., \& Fischer, W. C. (1990). Patent No. 4966526. US.

Angle II, G. M. (2008). Aerodynamic Benefits of Near-Surface-Actuated Circulation Control Blowing Slots for Rotorcraft Use. Dissertation, West Virginia University, Mechanical and Aerospace Engineering, Morgantown.

Cagle, C. M., \& Jones, G. S. (2002). A Wind Tunnel Model to Expolre Unsteady Circulation Control for General Aviation Applications. 22nd AIAA Aerodynamic Measurement Technolgy and Ground Testing Conference. St Louis, MO: AIAA.

Cheeseman, I. C., George, J. E., \& Lawrence, C. R. (1970). Patent No. 3524711. US.

Collins, J. A. (2003). Mechanical Design of machine Elements and Machines. Ney York: John Wiley \& Sons.

Dancila, D. S., \& Armanios, E. A. (1998). Patent No. 5791601. US.

Danielson, H. (1976). Patent No. 3990811. US.

Davidson, I. M., \& Islip, L. (1964). Patent No. 3139936. US.

Eilerson, W. H. (1975). Patent No. 3918833. US.

Englar, R. J. (2006). Overview of Circulation Control Pneumatic Aerodynamics: Blown Force and Moment Augmentation and Modification as Applied Primarily to Fixed-Wing Aircraft. In R. D. Joslin, \& G. S. Jones, Applications of Circulation Control Technologies. Reston, VA: American Institute of Aeronautics and Astronautics.

Flint, J. A., \& George, J. E. (1968). Patent No. 3348618. US.

Hall, S. R., \& Spangler Jr., R. L. (1993). Patent No. 5224826. US.

Harness, G. (1970). An Experimental Investigation of a Circulation Controlled Cambered Elliptical Airfoil. Thesis, West Virginia University, Mechanical and Aerospace Engineering, Morgantow.

Holt, D. (1972). A Ciculation Controlled Airfoil with Pulsed Flow. Thesis, West Virginia University, Mechanical and Aerospace Engineering, Morgantown.

Humpherson, D. V. (1996). Patent No. 5529458. US.

Imber, R., Rogers, E., \& Abramson, J. Exploratory Investigations of Circulation Control Technology: Overview for Period 1987-2003 at NSWCCD. In R. D. Joslin, \& G. S. Jones, Applications of Circulation Control Technologies. Reston, VA: American Institute of Aeronautics and Astronautics. 
Jeffrey, P. A., \& Lawrence, T. H. (1985). Patent No. 4507050. US.

Loth, J. L. (2006). Advantages of Combining BLC Suction with Circulation Control High-Lift Generation. In R. D. Joslin, \& G. S. Jones, Applications of Circulation Control Technologies. Reston, VA: American Institute of Aeronautics and Astronautics.

Mayfield, J. (1980, March 31). Navy Sponsors Coanda Rotor Program. Aviation Week and Space Technology , pp. 69-74.

Myer, D. (1972). An Experimental Investigation of a Circulation Controlled Cambered Elliptical Airfoil with a Rounded Trailing Edge. Thesis, West Virginia University, Mechanical and Aerospace Engineering, Morgantown.

Newman, B. (1961). Deflexion of Plane Jets by Adjacent Boundaries - Coanda Effect. Boundary Layer And Flow Control , 232.

Paraschivoiu, I., Trifu, O., \& Saeed, F. (2009). H-Darrieus Wind Turbine with Blade Pitch Control. International Journal of Rotating Machinery .

Schmidt, J. (1978). Patent No. 4131390. US.

Shikha, Bhatt, T., \& Kothari, D. (2003). The Evolution of Wind Power Technology - a Review. The Institute of Engineers (India) .

Smith, J. E., Loth, J. L., Craven, R. P., \& Bond, R. (2002). Patent No. 6425553. US.

Spargo, J. (1976). Patent No. 3964838. US.

Stalker, E. A. (1937). Patent No. 2084464. US.

Stalker, E. A. (1949). Patent No. 2457936. US.

Stalker, E. A. (1950). Patent No. 2493041. US.

Wilkerson, J., Barnes, D., \& Bill, R. (1979, May). The Circulation Control Rotor Flight Demonstrator Test Program.

Williams, R., Leitner, R., \& Rogers, E. (1976). X-Wing: A New Concept in Rotary VTOL. AHA Symposium on Rotor Technology.

Wright, T. (2007, May). That Extra Little Lift. Air \& Space Magazine .

Yuan, S. W., \& Von Karman, T. (1960). Patent No. 2925129. US. 


\section{$\mathrm{STA}^{\circledR}$ Pull Tubular Solenoids - 1" Dia. x 2"}

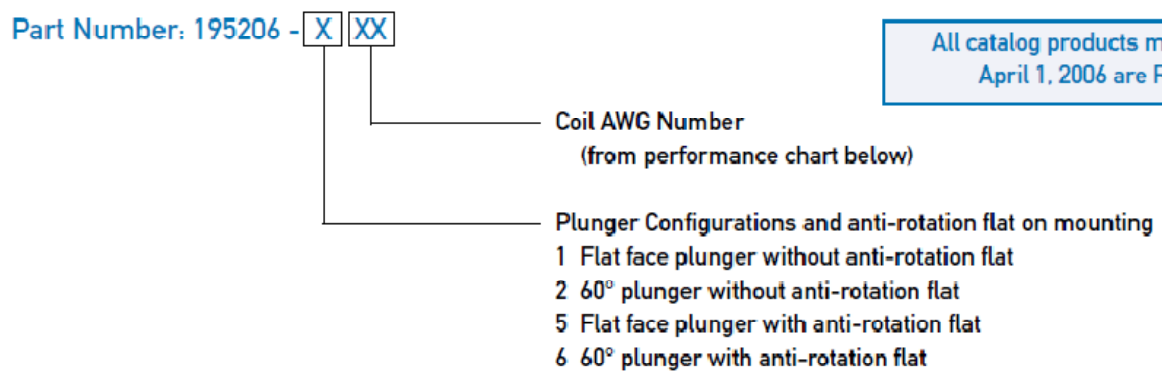

\begin{tabular}{|c|c|c|c|c|c|c|}
\hline \multicolumn{7}{|c|}{ Performance } \\
\hline \multicolumn{3}{|c|}{ Maximum Duty Cycle } & $100 \%$ & $50 \%$ & $25 \%$ & $10 \%$ \\
\hline \multicolumn{3}{|c|}{$\begin{array}{l}\text { Maximum ON Time (sec) } \\
\text { when pulsed continuously }\end{array}$} & $\infty$ & 360 & 32 & 8 \\
\hline \multicolumn{3}{|c|}{$\begin{array}{l}\text { Maximum ON Time (sec) } \\
\text { for single pulse }\end{array}$} & $\infty$ & 470 & 120 & 32 \\
\hline \multicolumn{3}{|c|}{ Watts $\left(020^{\circ} \mathrm{C}\right)$} & 10 & 20 & 40 & 100 \\
\hline \multicolumn{3}{|c|}{ Ampere Turns $\left(@ 20^{\circ} \mathrm{C}\right)$} & 1166 & 1649 & 2332 & 3688 \\
\hline \multicolumn{3}{|c|}{ Coil Data } & & & & \\
\hline $\begin{array}{l}\text { awg } \\
(0 \times X)^{3}\end{array}$ & $\begin{array}{c}\text { Resistance } \\
\left(@ 20^{\circ} \mathrm{C}\right)\end{array}$ & $\begin{array}{c}\# \\
\text { Turns }^{4} \\
\end{array}$ & $\begin{array}{l}\text { VDC } \\
\text { (Nom) }\end{array}$ & $\begin{array}{l}\text { VDC } \\
\text { (Nom) }\end{array}$ & $\begin{array}{c}\text { VDC } \\
\text { (Nom) }\end{array}$ & $\begin{array}{l}\text { VDC } \\
\text { (Nom) }\end{array}$ \\
\hline $\begin{array}{l}23 \\
24 \\
25 \\
26 \\
27 \\
28 \\
29 \\
30 \\
31 \\
32 \\
33\end{array}$ & $\begin{array}{r}1.96 \\
2.69 \\
4.89 \\
8.44 \\
11.50 \\
19.20 \\
31.20 \\
49.60 \\
77.40 \\
119.00 \\
202.00\end{array}$ & $\begin{array}{r}536 \\
600 \\
840 \\
1128 \\
1260 \\
1645 \\
2104 \\
2646 \\
3280 \\
4026 \\
5317\end{array}$ & $\begin{array}{r}4.4 \\
5.2 \\
7.0 \\
9.2 \\
10.7 \\
13.8 \\
17.7 \\
22.0 \\
28.0 \\
35.0 \\
45.0\end{array}$ & $\begin{array}{r}6.3 \\
7.3 \\
9.9 \\
13.0 \\
15.2 \\
19.6 \\
25.0 \\
31.0 \\
39.0 \\
49.0 \\
64.0\end{array}$ & $\begin{array}{r}8.9 \\
10.4 \\
14.0 \\
18.4 \\
21.0 \\
28.0 \\
35.0 \\
45.0 \\
56.0 \\
69.0 \\
90.0\end{array}$ & $\begin{array}{r}14.0 \\
16.4 \\
22.0 \\
29.0 \\
34.0 \\
44.0 \\
56.0 \\
70.0 \\
88.0 \\
109.0 \\
142.0\end{array}$ \\
\hline
\end{tabular}

1 Continuously pulsed at stated watts and duty cycle

2 Single pulse at stated watts (with coil at ambient room temperature $20^{\circ} \mathrm{C}$

3 Other coil awg sizes available - please consult factory

4 Reference number of turns

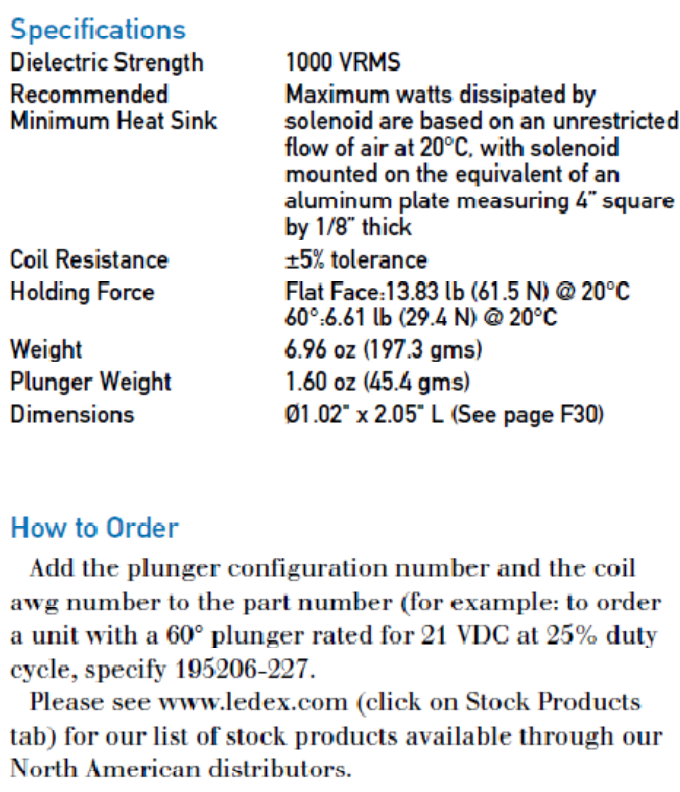

All specifications subject to change without notice. 


\section{STA $^{\circledR}$ Pull Tubular Solenoids - 1" Dia. x 2"}

Pull Tubular Solenoid - 1" dia. x 2" - Flat Face Plunger

Typical Force @ $20^{\circ} \mathrm{C}$

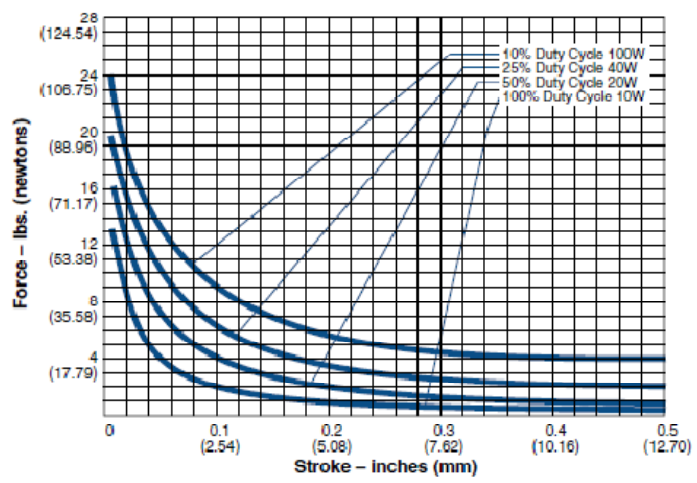

Pull Tubular Solenoid - 1" dia. x 2" - 60 Plunger

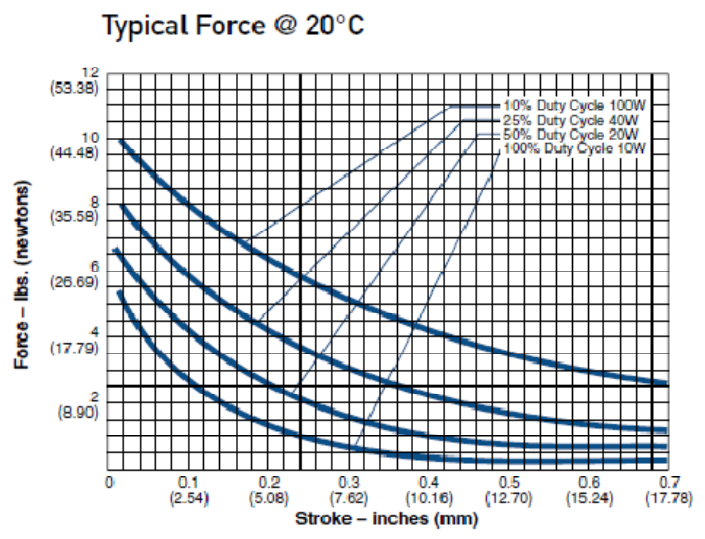

\section{Typical Speed @ No Load. $20^{\circ} \mathrm{C}$}

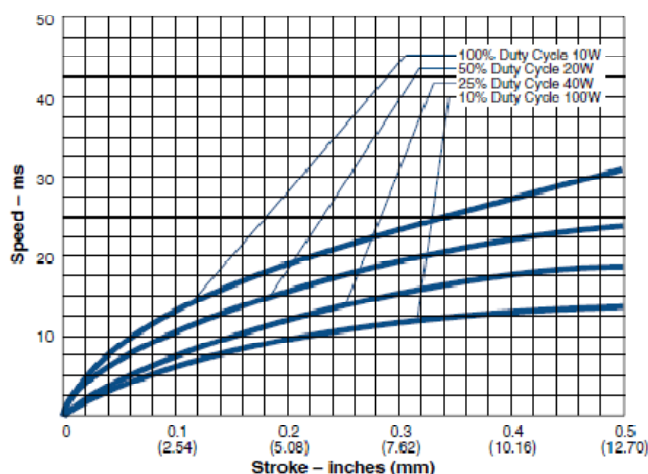

Stroke- inches $(\mathrm{mm})$
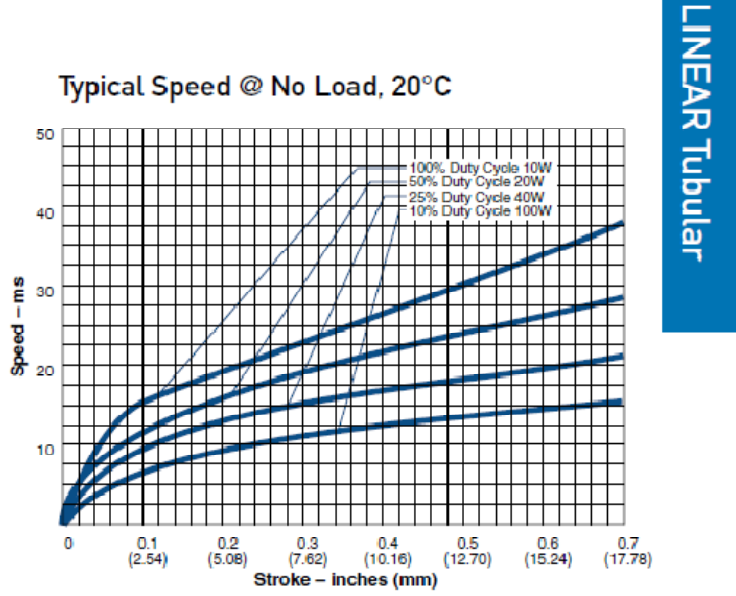

All specifications subject to change without notice. 


\section{Ledex $^{\circledR}$ Tubular Solenoids Dimensions}

Inçeses (mm)

$\mathrm{STA}^{\circledR}$ Series Pull - 1" Dia. x 2"

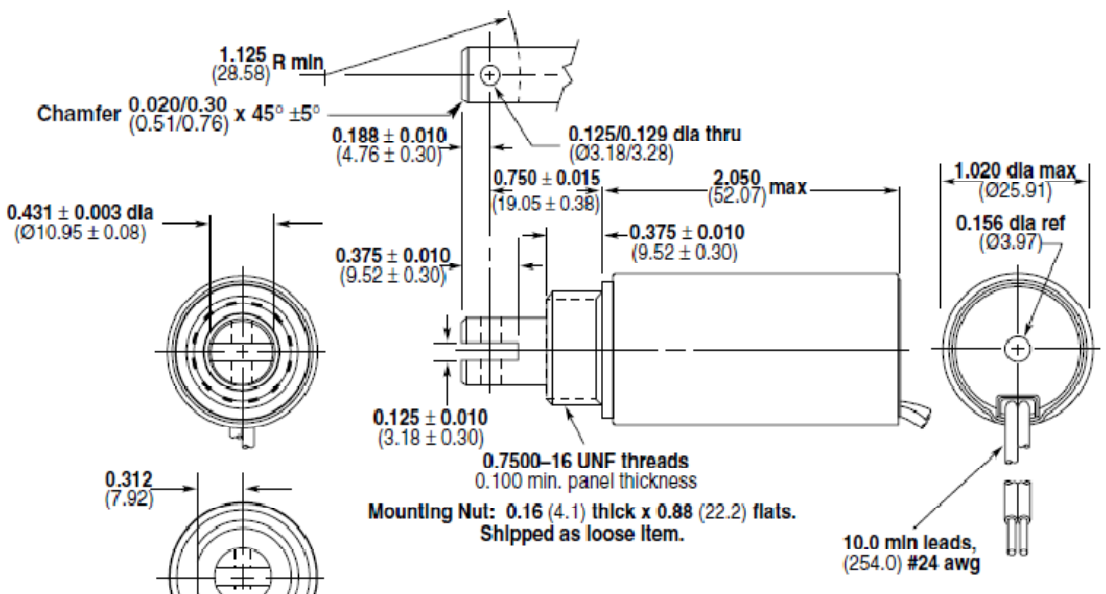

$\mathrm{STA}^{\circledR}$ Series Push - 1" Dia. x 2"

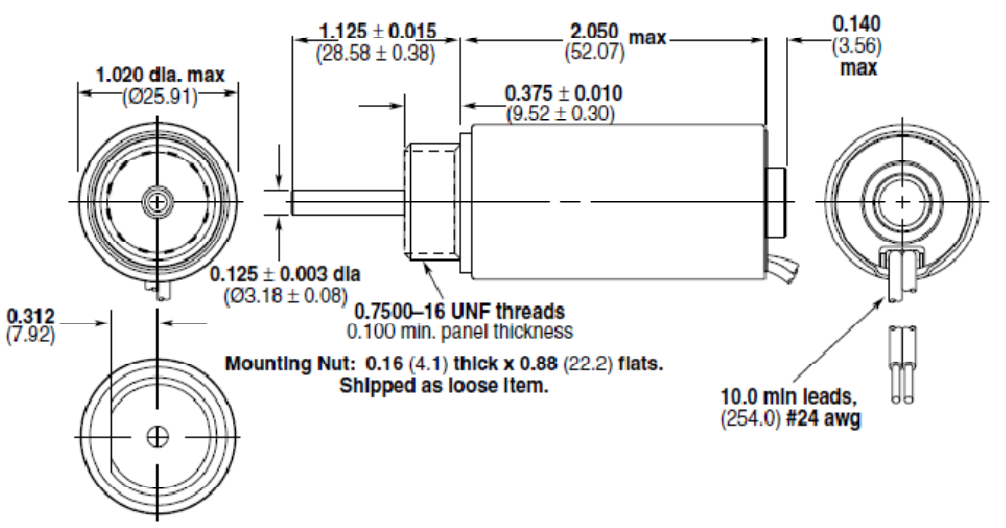

All solenoids are illustrated in energized state

Ledex ${ }^{\circledR}$ Solenoids
All specifications subject to change without notice.

F30

www.ledex.com

1.937 .454 .2345 


\section{Appendix B: Component List for Testing Apparatus and Equipment}

\begin{tabular}{|c|c|c|c|c|c|c|}
\hline Part & Description & Vendor & Vendor Part \# & Manufacturer & Man. Part \# & Quantity \\
\hline \multicolumn{7}{|c|}{ Testing Apparatus Parts } \\
\hline Plenum Covers & 3/32" Aluminum & CIRA Shop & & & & 2 \\
\hline Plenum Divider & 3/32" Aluminum & CIRA Shop & & & & 1 \\
\hline Rib Sections & 1/2" Aluminum & CIRA Shop & & & & 2 \\
\hline Solenoid Mount & 3/32" Aluminum & CIRA Shop & & & & 1 \\
\hline Top and Bottom & 1/2" Thick Plexiglas & CIRA Shop & & & & 2 \\
\hline Fixed Gate & 1/4" Aluminum & $\begin{array}{l}\text { McMaster- } \\
\text { Carr }\end{array}$ & $9055 \mathrm{~K} 361$ & & & 1 \\
\hline PTFE Coating & 0.015" PFTE Film & $\begin{array}{l}\text { McMaster- } \\
\text { Carr }\end{array}$ & $8711 \mathrm{~K} 72$ & & & 1 \\
\hline Sealant & Silicone Rubber & $\begin{array}{l}\text { McMaster- } \\
\text { Carr }\end{array}$ & $93755 \mathrm{~K} 31$ & & & 1 \\
\hline Sliding Gate & $1 / 16^{\prime \prime}$ x 1" x 1" Angle & $\begin{array}{l}\text { McMaster- } \\
\text { Carr }\end{array}$ & $88805 \mathrm{~K} 47$ & & & 1 \\
\hline Springs & \begin{tabular}{|l} 
Stainless Steel \\
Extension
\end{tabular} & $\begin{array}{l}\text { McMaster- } \\
\text { Carr }\end{array}$ & $94135 \mathrm{~K} 2$ & & & 1 \\
\hline Trailing Edge & $1 / 2 "$ Aluminum rod & $\begin{array}{l}\text { McMaster- } \\
\text { Carr }\end{array}$ & $9062 \mathrm{~K} 311$ & & & 1 \\
\hline Solenoid & 1" by 2 " Solenoid & Newark & 20M1819 & Ledex & $195206-124$ & 1 \\
\hline \multicolumn{7}{|c|}{ Electrical Testing Parts } \\
\hline Connectors & Quick Connect Pairs & CIRA Shop & & & & 8 \\
\hline Multimeter & Digital & CIRA Shop & & Meterman & $37 X R$ & 1 \\
\hline On/Off Switch & Trigger Switch & CIRA Shop & & & & 1 \\
\hline Oscilloscope & 4 Channel Digital & CIRA Shop & & Tektronix & TDS-460A & 1 \\
\hline Position Sensors & Roller Switch & CIRA Shop & & & & 2 \\
\hline Power Supply & $28 \mathrm{VDC}, 35 \mathrm{Amp}$ & CIRA Shop & & NewMar & & 1 \\
\hline Shunt Resistor & $0.15667 \mathrm{Ohm}$ & CIRA Shop & & & & 1 \\
\hline Wiring & 20 Gauge Copper & CIRA Shop & & & & 10 \\
\hline Resistor & $20 \mathrm{Ohm}, 25 \mathrm{~W}$ & Digi-Key & RHRC-20-ND & Vishay/Dale & $\begin{array}{l}\text { RH02520R00 } \\
\text { FE02 }\end{array}$ & 1 \\
\hline Rheostat & Adjustable Resistor & Digi-Key & RJS35RE-ND & Ohmite & RJS35RE & 1 \\
\hline \multicolumn{7}{|c|}{ Air Flow Testing Parts } \\
\hline Fittings & Various 1/4" NPT & CIRA Shop & & & & 4 \\
\hline Flow Meter & Inline Flow Meter & CIRA Shop & & & & 1 \\
\hline Gauges & $\begin{array}{l}\text { Glycerin Filled 0-30 } \\
\text { psig }\end{array}$ & CIRA Shop & & & & 2 \\
\hline Regulator & Inline Adjustable & CIRA Shop & & HEDLAND & $\begin{array}{l}\text { H271A-010- } \\
\text { EG }\end{array}$ & 1 \\
\hline Valve & Manual On/Off Valve & CIRA Shop & & & & 1 \\
\hline
\end{tabular}


Appendix C: Data from Testing

\begin{tabular}{|c|c|c|c|c|c|c|}
\hline Pressure (psig) & $\mathrm{V}$ (sol+CSR) & $\mathrm{V}(\mathrm{CSR})$ & $\mathrm{V}$ (solenoid) & I (solenoid) & Power (W) & $\Delta$ t open \\
\hline \multirow[t]{16}{*}{0} & 5.48 & 294 & 5.186 & 1.8766 & 9.7318 & 115.6 \\
\hline & 5.56 & 298 & 5.262 & 1.9021 & 10.0088 & 79.2 \\
\hline & 5.64 & 310 & 5.33 & 1.9787 & 10.5464 & 52 \\
\hline & 6.04 & 330 & 5.71 & 2.1063 & 12.0272 & 35.2 \\
\hline & 6.36 & 346 & 6.014 & 2.2085 & 13.2817 & 28.8 \\
\hline & 7 & 378 & 6.622 & 2.4127 & 15.9770 & 23.6 \\
\hline & 7.48 & 406 & 7.074 & 2.5914 & 18.3318 & 22 \\
\hline & 7.96 & 434 & 7.526 & 2.7702 & 20.8482 & 20 \\
\hline & 8.68 & 470 & 8.21 & 2.9999 & 24.6295 & 18 \\
\hline & 9.72 & 522 & 9.198 & 3.3318 & 30.6463 & 16 \\
\hline & 10.6 & 566 & 10.034 & 3.6127 & 36.2497 & 15.2 \\
\hline & 11.64 & 622 & 11.018 & 3.9701 & 43.7429 & 14.8 \\
\hline & 13 & 690 & 12.31 & 4.4042 & 54.2152 & 13.6 \\
\hline & 15 & 794 & 14.206 & 5.0680 & 71.9957 & 12.8 \\
\hline & 17.7 & 912 & 16.788 & 5.8212 & 97.7255 & 12 \\
\hline & 20.3 & 1032 & 19.268 & 6.5871 & 126.9201 & 11.6 \\
\hline \multirow[t]{15}{*}{5} & 7.16 & 360 & 6.8 & 2.2978 & 15.6252 & 102 \\
\hline & 7.32 & 384 & 6.936 & 2.4510 & 17.0002 & 51.2 \\
\hline & 7.56 & 400 & 7.16 & 2.5531 & 18.2805 & 40.8 \\
\hline & 7.96 & 416 & 7.544 & 2.6553 & 20.0313 & 34.8 \\
\hline & 8.44 & 440 & 8 & 2.8085 & 22.4676 & 29.6 \\
\hline & 8.92 & 464 & 8.456 & 2.9616 & 25.0436 & 26 \\
\hline & 9.56 & 496 & 9.064 & 3.1659 & 28.6956 & 22.4 \\
\hline & 10.28 & 528 & 9.752 & 3.3701 & 32.8656 & 20.8 \\
\hline & 11.16 & 576 & 10.584 & 3.6765 & 38.9123 & 18.8 \\
\hline & 11.72 & 608 & 11.112 & 3.8808 & 43.1231 & 17.6 \\
\hline & 12.28 & 640 & 11.64 & 4.0850 & 47.5496 & 17.2 \\
\hline & 13.88 & 720 & 13.16 & 4.5956 & 60.4787 & 15.6 \\
\hline & 14.92 & 776 & 14.144 & 4.9531 & 70.0564 & 15.2 \\
\hline & 17.5 & 912 & 16.588 & 5.8212 & 96.5613 & 13.6 \\
\hline & 20.1 & 1048 & 19.052 & 6.6892 & 127.4430 & 12.8 \\
\hline \multirow[t]{13}{*}{6} & 7.16 & 364 & 6.796 & 2.3234 & 15.7895 & 154 \\
\hline & 7.32 & 388 & 6.932 & 2.4765 & 17.1674 & 57.6 \\
\hline & 7.64 & 408 & 7.232 & 2.6042 & 18.8336 & 42.4 \\
\hline & 8.04 & 428 & 7.612 & 2.7319 & 20.7949 & 34.8 \\
\hline & 8.28 & 444 & 7.836 & 2.8340 & 22.2071 & 31.2 \\
\hline & 9.32 & 500 & 8.82 & 3.1914 & 28.1483 & 23.6 \\
\hline & 10.12 & 536 & 9.584 & 3.4212 & 32.7888 & 21.6 \\
\hline & 11 & 588 & 10.412 & 3.7531 & 39.0774 & 19.6 \\
\hline & 12.92 & 684 & 12.236 & 4.3659 & 53.4207 & 17.2 \\
\hline & 13.8 & 732 & 13.068 & 4.6722 & 61.0568 & 16.4 \\
\hline & 14.7 & 776 & 13.924 & 4.9531 & 68.9668 & 15.6 \\
\hline & 17.5 & 920 & 16.58 & 5.8722 & 97.3613 & 14 \\
\hline & 20.1 & 1048 & 19.052 & 6.6892 & 127.4430 & 13.2 \\
\hline \multirow[t]{11}{*}{7} & 7.16 & 380 & 6.78 & 2.4255 & 16.4448 & 98.8 \\
\hline & 7.4 & 400 & 7 & 2.5531 & 17.8720 & 66.4 \\
\hline & 7.72 & 416 & 7.304 & 2.6553 & 19.3940 & 48 \\
\hline & 8.04 & 428 & 7.612 & 2.7319 & 20.7949 & 42.8 \\
\hline & 8.44 & 452 & 7.988 & 2.8850 & 23.0457 & 34 \\
\hline & 9.4 & 500 & 8.9 & 3.1914 & 28.4037 & 26 \\
\hline & 10.12 & 532 & 9.588 & 3.3957 & 32.5577 & 23.2 \\
\hline & 11.56 & 620 & 10.94 & 3.9574 & 43.2935 & 19.2 \\
\hline & 13.56 & 712 & 12.848 & 4.5446 & 58.3888 & 17.2 \\
\hline & 16.12 & 844 & 15.276 & 5.3871 & 82.2936 & 14.4 \\
\hline & 20.1 & 1048 & 19.052 & 6.6892 & 127.4430 & 13.2 \\
\hline \multirow[t]{9}{*}{8} & 7.4 & 388 & 7.012 & 2.4765 & 17.3655 & 122.4 \\
\hline & 7.8 & 400 & 7.4 & 2.5531 & 18.8932 & 74.4 \\
\hline & 7.96 & 428 & 7.532 & 2.7319 & 20.5763 & 50.8 \\
\hline & 8.44 & 448 & 7.992 & 2.8595 & 22.8532 & 39.2 \\
\hline & 8.76 & 460 & 8.3 & 2.9361 & 24.3697 & 35.2 \\
\hline & 9.24 & 496 & 8.744 & 3.1659 & 27.6825 & 29.2 \\
\hline & 10.04 & 5.32 & 10.03468 & 0.0340 & 0.3407 & 24.8 \\
\hline & 11 & 580 & 10.42 & 3.7020 & 38.5753 & 21.6 \\
\hline & 13.08 & 684 & 12.396 & 4.3659 & 54.1193 & 18.4 \\
\hline
\end{tabular}




\begin{tabular}{|c|c|c|c|c|c|c|}
\hline & 14.92 & 788 & 14.132 & 5.0297 & 71.0794 & 16.4 \\
\hline & 17.5 & 904 & 16.596 & 5.7701 & 95.7604 & 14.8 \\
\hline & 20.1 & 1040 & 19.06 & 6.6382 & 126.5233 & 13.6 \\
\hline \multirow[t]{11}{*}{9} & 7.8 & 400 & 7.4 & 2.5531 & 18.8932 & 132.4 \\
\hline & 7.88 & 412 & 7.468 & 2.6297 & 19.6388 & 88.4 \\
\hline & 8.28 & 432 & 7.848 & 2.7574 & 21.6400 & 56.8 \\
\hline & 8.84 & 464 & 8.376 & 2.9616 & 24.8067 & 41.6 \\
\hline & 9.32 & 488 & 8.832 & 3.1148 & 27.5102 & 33.6 \\
\hline & 9.72 & 512 & 9.208 & 3.2680 & 30.0919 & 29.2 \\
\hline & 10.2 & 532 & 9.668 & 3.3957 & 32.8294 & 26.8 \\
\hline & 11.64 & 608 & 11.032 & 3.8808 & 42.8126 & 20.8 \\
\hline & 13.08 & 686 & 12.394 & 4.3786 & 54.2687 & 18.4 \\
\hline & 16.1 & 848 & 15.252 & 5.4127 & 82.5537 & 15.6 \\
\hline & 20.1 & 1048 & 19.052 & 6.6892 & 127.4430 & 14 \\
\hline \multirow[t]{12}{*}{10} & 7.8 & 404 & 7.396 & 2.5787 & 19.0718 & 130.4 \\
\hline & 8.2 & 424 & 7.776 & 2.7063 & 21.0444 & 81.6 \\
\hline & 8.68 & 452 & 8.228 & 2.8850 & 23.7382 & 52 \\
\hline & 9.16 & 480 & 8.68 & 3.0638 & 26.5935 & 36.8 \\
\hline & 9.48 & 500 & 8.98 & 3.1914 & 28.6590 & 30.8 \\
\hline & 10.2 & 540 & 9.66 & 3.4467 & 33.2955 & 27.6 \\
\hline & 10.68 & 560 & 10.12 & 3.5744 & 36.1728 & 25.6 \\
\hline & 11.72 & 616 & 11.104 & 3.9318 & 43.6591 & 22.4 \\
\hline & 12.36 & 648 & 11.712 & 4.1361 & 48.4418 & 20.4 \\
\hline & 13.96 & 728 & 13.232 & 4.6467 & 61.4853 & 18.4 \\
\hline & 16.1 & 832 & 15.268 & 5.3105 & 81.0811 & 16.4 \\
\hline & 20.1 & 1032 & 19.068 & 6.5871 & 125.6027 & 14.4 \\
\hline \multirow[t]{11}{*}{11} & 8.04 & 408 & 7.632 & 2.6042 & 19.8753 & 140 \\
\hline & 8.44 & 436 & 8.004 & 2.7829 & 22.2745 & 74.8 \\
\hline & 8.68 & 452 & 8.228 & 2.8850 & 23.7382 & 60 \\
\hline & 9.24 & 476 & 8.764 & 3.0382 & 26.6271 & 43.2 \\
\hline & 9.8 & 512 & 9.288 & 3.2680 & 30.3533 & 33.2 \\
\hline & 10.68 & 552 & 10.128 & 3.5233 & 35.6843 & 27.6 \\
\hline & 11.72 & 604 & 11.116 & 3.8552 & 42.8548 & 23.2 \\
\hline & 12.36 & 640 & 11.72 & 4.0850 & 47.8764 & 22 \\
\hline & 14.04 & 716 & 13.324 & 4.5701 & 60.8922 & 19.2 \\
\hline & 17.3 & 888 & 16.412 & 5.6680 & 93.0226 & 16.4 \\
\hline & 20.1 & 1008 & 19.092 & 6.4339 & 122.8361 & 14.8 \\
\hline \multirow[t]{12}{*}{12} & 8.6 & 428 & 8.172 & 2.7319 & 22.3247 & 117.2 \\
\hline & 8.76 & 444 & 8.316 & 2.8340 & 23.5674 & 86.4 \\
\hline & 9 & 460 & 8.54 & 2.9361 & 25.0744 & 68.4 \\
\hline & 9.16 & 472 & 8.688 & 3.0127 & 26.1744 & 54 \\
\hline & 9.56 & 488 & 9.072 & 3.1148 & 28.2577 & 43.6 \\
\hline & 10.28 & 528 & 9.752 & 3.3701 & 32.8656 & 34 \\
\hline & 11.16 & 576 & 10.584 & 3.6765 & 38.9123 & 27.2 \\
\hline & 12.36 & 640 & 11.72 & 4.0850 & 47.8764 & 22.4 \\
\hline & 13.96 & 720 & 13.24 & 4.5956 & 60.8464 & 19.6 \\
\hline & 14.9 & 768 & 14.132 & 4.9020 & 69.2754 & 18.4 \\
\hline & 17.5 & 896 & 16.604 & 5.7190 & 94.9587 & 17.6 \\
\hline & 20.1 & 1024 & 19.076 & 6.5360 & 124.6813 & 14.8 \\
\hline \multirow[t]{10}{*}{13} & 8.52 & 436 & 8.084 & 2.7829 & 22.4971 & 128.8 \\
\hline & 9 & 464 & 8.536 & 2.9616 & 25.2806 & 77.2 \\
\hline & 9.56 & 492 & 9.068 & 3.1404 & 28.4768 & 52 \\
\hline & 10.28 & 532 & 9.748 & 3.3957 & 33.1010 & 37.2 \\
\hline & 11.16 & 580 & 10.58 & 3.7020 & 39.1677 & 29.6 \\
\hline & 12.36 & 644 & 11.716 & 4.1106 & 48.1592 & 24 \\
\hline & 13.16 & 680 & 12.48 & 4.3403 & 54.1674 & 21.6 \\
\hline & 15 & 772 & 14.228 & 4.9276 & 70.1092 & 18.8 \\
\hline & 17.5 & 896 & 16.604 & 5.7190 & 94.9587 & 14.8 \\
\hline & 20.3 & 1024 & 19.276 & 6.5360 & 125.9885 & 16.8 \\
\hline \multirow[t]{9}{*}{14} & 8.84 & 444 & 8.396 & 2.8340 & 23.7941 & 131.2 \\
\hline & 9 & 464 & 8.536 & 2.9616 & 25.2806 & 94.4 \\
\hline & 9.64 & 492 & 9.148 & 3.1404 & 28.7280 & 59.2 \\
\hline & 10.28 & 532 & 9.748 & 3.3957 & 33.1010 & 41.2 \\
\hline & 11.16 & 580 & 10.58 & 3.7020 & 39.1677 & 31.6 \\
\hline & 12.36 & 640 & 11.72 & 4.0850 & 47.8764 & 25.2 \\
\hline & 13.16 & 680 & 12.48 & 4.3403 & 54.1674 & 22.8 \\
\hline & 14.04 & 724 & 13.316 & 4.6212 & 61.5356 & 20.8 \\
\hline & 16.12 & 840 & 15.28 & 5.3616 & 81.9251 & 18.4 \\
\hline
\end{tabular}




\begin{tabular}{|c|c|c|c|c|c|c|}
\hline & $\begin{array}{l}18.5 \\
20.1\end{array}$ & $\begin{array}{l}904 \\
1024\end{array}$ & $\begin{array}{l}17.596 \\
19.076\end{array}$ & $\begin{array}{l}5.7701 \\
6.5360\end{array}$ & $\begin{array}{l}101.5305 \\
124.6813\end{array}$ & $\begin{array}{l}17.2 \\
16\end{array}$ \\
\hline \multirow[t]{10}{*}{15} & 9.32 & 468 & 8.852 & 2.9872 & 26.4424 & 126.4 \\
\hline & 9.56 & 492 & 9.068 & 3.1404 & 28.4768 & 88 \\
\hline & 9.8 & 508 & 9.292 & 3.2425 & 30.1292 & 71.2 \\
\hline & 10.28 & 528 & 9.752 & 3.3701 & 32.8656 & 57.2 \\
\hline & 10.68 & 552 & 10.128 & 3.5233 & 35.6843 & 46.8 \\
\hline & 11.16 & 576 & 10.584 & 3.6765 & 38.9123 & 38.4 \\
\hline & 12.36 & 640 & 11.72 & 4.0850 & 47.8764 & 28 \\
\hline & 13.96 & 724 & 13.236 & 4.6212 & 61.1659 & 22.8 \\
\hline & 17.5 & 912 & 16.588 & 5.8212 & 96.5613 & 17.6 \\
\hline & 20.1 & 1032 & 19.068 & 6.5871 & 125.6027 & 16.4 \\
\hline \multirow[t]{10}{*}{16} & 9.56 & 492 & 9.068 & 3.1404 & 28.4768 & 100.4 \\
\hline & 9.8 & 516 & 9.284 & 3.2935 & 30.5773 & 75.6 \\
\hline & 10.36 & 532 & 9.828 & 3.3957 & 33.3727 & 62.4 \\
\hline & 10.68 & 552 & 10.128 & 3.5233 & 35.6843 & 52.4 \\
\hline & 11.16 & 576 & 10.584 & 3.6765 & 38.9123 & 41.6 \\
\hline & 12.44 & 636 & 11.804 & 4.0595 & 47.9182 & 30.8 \\
\hline & 14.04 & 716 & 13.324 & 4.5701 & 60.8922 & 23.6 \\
\hline & 15 & 768 & 14.232 & 4.9020 & 69.7656 & 21.6 \\
\hline & 17.5 & 904 & 16.596 & 5.7701 & 95.7604 & 18.4 \\
\hline & 20.1 & 1032 & 19.068 & 6.5871 & 125.6027 & 16.4 \\
\hline \multirow[t]{10}{*}{17} & 9.64 & 492 & 9.148 & 3.1404 & 28.7280 & 134.8 \\
\hline & 10.04 & 512 & 9.528 & 3.2680 & 31.1377 & 90.4 \\
\hline & 10.36 & 532 & 9.828 & 3.3957 & 33.3727 & 70 \\
\hline & 10.84 & 556 & 10.284 & 3.5489 & 36.4965 & 54.8 \\
\hline & 11.88 & 608 & 11.272 & 3.8808 & 43.7440 & 37.6 \\
\hline & 12.52 & 636 & 11.884 & 4.0595 & 48.2430 & 32.8 \\
\hline & 13.24 & 680 & 12.56 & 4.3403 & 54.5146 & 28 \\
\hline & 15.08 & 780 & 14.3 & 4.9786 & 71.1942 & 22.4 \\
\hline & 17.5 & 904 & 16.596 & 5.7701 & 95.7604 & 19.2 \\
\hline & 20.1 & 1032 & 19.068 & 6.5871 & 125.6027 & 16.8 \\
\hline \multirow[t]{10}{*}{18} & 9.64 & 500 & 9.14 & 3.1914 & 29.1696 & 131.2 \\
\hline & 9.88 & 516 & 9.364 & 3.2935 & 30.8408 & 96.4 \\
\hline & 10.28 & 536 & 9.744 & 3.4212 & 33.3362 & 76.8 \\
\hline & 10.84 & 552 & 10.288 & 3.5233 & 36.2480 & 62 \\
\hline & 11.8 & 604 & 11.196 & 3.8552 & 43.1632 & 40.8 \\
\hline & 12.44 & 636 & 11.804 & 4.0595 & 47.9182 & 34.4 \\
\hline & 13.24 & 680 & 12.56 & 4.3403 & 54.5146 & 29.2 \\
\hline & 14.9 & 760 & 14.14 & 4.8510 & 68.5926 & 23.2 \\
\hline & 17.7 & 904 & 16.796 & 5.7701 & 96.9144 & 18.4 \\
\hline & 20.1 & 1016 & 19.084 & 6.4850 & 123.7591 & 17.2 \\
\hline \multirow[t]{9}{*}{19} & 10.04 & 504 & 9.536 & 3.2170 & 30.6769 & 144.4 \\
\hline & 10.36 & 528 & 9.832 & 3.3701 & 33.1352 & 93.6 \\
\hline & 10.76 & 552 & 10.208 & 3.5233 & 35.9661 & 72.4 \\
\hline & 11.8 & 604 & 11.196 & 3.8552 & 43.1632 & 45.2 \\
\hline & 12.44 & 636 & 11.804 & 4.0595 & 47.9182 & 38 \\
\hline & 13.24 & 676 & 12.564 & 4.3148 & 54.2112 & 32 \\
\hline & 15.08 & 772 & 14.308 & 4.9276 & 70.5035 & 23.6 \\
\hline & 16.3 & 824 & 15.476 & 5.2595 & 81.3954 & 21.6 \\
\hline & 20.1 & 1016 & 19.084 & 6.4850 & 123.7591 & 18 \\
\hline \multirow[t]{10}{*}{20} & 10.2 & 504 & 9.696 & 3.2170 & 31.1916 & 162 \\
\hline & 10.92 & 544 & 10.376 & 3.4723 & 36.0282 & 82.4 \\
\hline & 11.32 & 576 & 10.744 & 3.6765 & 39.5005 & 62.4 \\
\hline & 11.96 & 600 & 11.36 & 3.8297 & 43.5055 & 51.2 \\
\hline & 12.6 & 632 & 11.968 & 4.0340 & 48.2784 & 42 \\
\hline & 13.31 & 668 & 12.642 & 4.2637 & 53.9022 & 34.8 \\
\hline & 14.2 & 712 & 13.488 & 4.5446 & 61.2974 & 29.2 \\
\hline & 15.08 & 768 & 14.312 & 4.9020 & 70.1578 & 24.8 \\
\hline & 17.7 & 896 & 16.804 & 5.7190 & 96.1025 & 20.4 \\
\hline & 20.1 & 1016 & 19.084 & 6.4850 & 123.7591 & 18.4 \\
\hline
\end{tabular}

John $\mathrm{H}$.

Digitally signed by John 1.
Hagen 